\title{
A place called home : the role of identification in the post-dissolution phase of a customer relationship with a place brand
}

Citation for published version (APA):

Sillen, K. I. J. (2014). A place called home : the role of identification in the post-dissolution phase of a customer relationship with a place brand. [Doctoral Thesis, Maastricht University]. Universitaire Pers Maastricht. https://doi.org/10.26481/dis.20140227ks

Document status and date:

Published: 01/01/2014

DOI:

10.26481/dis.20140227ks

Document Version:

Publisher's PDF, also known as Version of record

\section{Please check the document version of this publication:}

- A submitted manuscript is the version of the article upon submission and before peer-review. There can be important differences between the submitted version and the official published version of record.

People interested in the research are advised to contact the author for the final version of the publication, or visit the DOI to the publisher's website.

- The final author version and the galley proof are versions of the publication after peer review.

- The final published version features the final layout of the paper including the volume, issue and page numbers.

Link to publication

\footnotetext{
General rights rights.

- You may freely distribute the URL identifying the publication in the public portal. please follow below link for the End User Agreement:

www.umlib.nl/taverne-license

Take down policy

If you believe that this document breaches copyright please contact us at:

repository@maastrichtuniversity.nl

providing details and we will investigate your claim.
}

Copyright and moral rights for the publications made accessible in the public portal are retained by the authors and/or other copyright owners and it is a condition of accessing publications that users recognise and abide by the legal requirements associated with these

- Users may download and print one copy of any publication from the public portal for the purpose of private study or research.

- You may not further distribute the material or use it for any profit-making activity or commercial gain

If the publication is distributed under the terms of Article $25 \mathrm{fa}$ of the Dutch Copyright Act, indicated by the "Taverne" license above, 


\title{
A Place Called Home
}

\section{The role of identification in the post-dissolution phase of a customer relationship with a place brand.}

\author{
Katja Sillen
}


C Copyright Katja Sillen, Maastricht 2014

All rights reserved. No part of this publication may be reprinted or utilized in any form or by any electronic, mechanical or other means, no known, or hereafter invented, including photocopying and recording, or in any information storage or retrieval system, without written permission of the copyright owner.

ISBN 9789461593085

Universitaire Pers Maastricht 


\section{A place called home}

\section{The role of identification in the post-dissolution phase of a customer relationship with a place brand.}

\section{PROEFSCHRIFT}

Ter verkrijging van de graad van doctor aan de Universiteit Maastricht op gezag van de Rector Magnificus, Prof. Dr. L.L.G. Soete volgens het besluit van het College van Decanen in het openbaar te verdedigen op donderdag 27 februari 2014 om 12.00 uur.

Door Katja Sillen

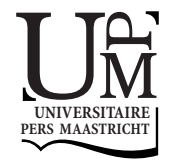




\section{Promotores}

Prof. Dr. Gaby Odekerken-Schröder

Prof. Dr. Martin Wetzels

\section{Beoordelingscommissie}

Prof. Dr. Jos Lemmink, voorzitter

Prof. Dr. Gert-Jan Hospers

Prof. Dr. Mien Segers 
Don't Cry Because It's Over, Smile Because It Happened - Dr. Seuss 

Acknowledgements 
Being a PhD candidate has taught me many lessons. I have internalized the concepts of identification and place branding, and acquired statistical research skills and writing skills. The most valuable lessons, however, are more intangible. I look back on my PhD period as one that formed me. I developed intense bonds with colleagues, learned to network and to work with various goals of different parties in mind. None of these lessons and none of the valuable experiences during this period could have come to me without the support of many.

My whole career as a PhD candidate would not have started without Gaby. When I expressed my careful interest about starting a PhD position, you were immediately enthusiastic and you put faith in me for accomplishing this task. With lots of encouraging words, but also every once in a while the necessary kick in the behind, you pushed me and stimulated me to keep on going beyond what I had done so far. You had to work through many 'textbook' versions of my papers and always provided valuable comments and improvements after sending me an email that you were "looking forward to reading it." Next to this, I am very grateful for the opportunities that you created for me in terms of data collection and networking as well as for the personal life lessons you taught me. Thank you for everything you did, I will never forget it.

My next thank you note goes to Martin, who, as my second promotor and statistical oracle, helped me out in many occasions. I always looked forward to your efficient emails (OK. M.) that let me know that I was still on the right track. As you like efficiency, I will make my thanks efficient too: Thank you for all the feedback and advice. I could not have completed my dissertation without this.

I would also like to express my gratitude to the member of my committee, Jos Lemmink, Mien Segers and Gert-Jan Hospers, and to the other Corona members, for evaluating my work and giving me valuable feedback.

Next, I would like to thank all of the people and organizations that facilitated my research. First of all, Stichting Regiobranding Zuid-Limburg, for sponsoring my PhD track. Wim Ortjens, Gerry Smeets, Jim Rutten, Nicoline Wisse-Smit, Anique Strijthaegen and others, you were my home on Wednesdays, a welcome break in the week and always fun to work with. I was very glad to be part of your team. Thank you for your faith in me and for giving me the opportunity to contribute to the beautiful region of Zuid-Limburg with my research. A special thank you also goes out to RMI, Roger Schils and Raymond Kockelkoren, who so kindly sponsored my data collection on numerous occasions. Furthermore, I would like to thank Gemeente Heerlen, Frans Schurer, Gladys Cools-Tummers and Frans van Heur, as well as Gemeente Maastricht, Hans Dassen and Camiel de Bruijn, for their cooperation in two of my research projects. You provided me with access to residents and ex-residents. Without you, I could not have finished my PhD. So, thank you very much for this. Thanks to NSI for the grant that sponsored my last year of 
research. Thank you to all respondents, students and (ex)residents of the cities of Heerlen and Maastricht for filling out my questionnaires and thereby providing me with the data that now constitute my dissertation. I would also like to thank Ruud Wetzels, Emily de Laat, Laura Heuser, Shima Bagheri, Sueli Brodin and Pieter Verhallen for their assistance in my research. You made equal partners in discussion. René Verkaart of Stoere Binken Design and Hanneke Slangen-Bosch, thank you for your help with the cover and lay-out.

Then, I want to say thank you to my roomies. Iraz, Niek, Anne and Liz, we literally laughed and cried together, we shared so many experiences, frustrations and euphoric moments. Not only work related experiences, but also our private life we shared. You were not only roommates, but became true friends. Stefania, Fransisco, Johannes and Theo, we may not have spent so many years together in one room, but nevertheless, I owe you a big thank you. You provided me with the necessary working spirit in times of need and a nice distraction every now and then. Thank you very much for that.

Then my other lovely other PhD colleagues, Nina, Nadine, Marleen, Jan M., Jan P., Linda, Matthias, Stephan, Hannes, Tom, Jessica, Miriam, Robert and Alex. Thank you for sharing and caring. Pascalle and Eefje, thank you for all assistance in every thinkable field and Marie-José, thank you for the nice talks and the ever clean office, you were all priceless. Of course, I am not going to forget my other department colleagues, the assistant professors and the tutors and especially Lieven and Sabine, with whom it was always nice to work together and where I could always go for a piece of advice. Thank you for that. Also, thank you to all of my students and thesis students for allowing me to teach you. I would also like to thank my colleagues at CBS, who were very welcoming and supported me throughout the finalization of my dissertation.

My working environment has been very supportive, but without the support of people in my private life, I could not have accomplished this. Lily-Anne, Charles, Bart, Dennis, Peggy, Ann-Kristin, Desirée, Martijn, Mieke and Sigrid. I think you know all ins and outs of my PhD process, the good times and the bad. And always, you were present, to listen, give advice and brighten me up when necessary. Also thank you very much Oma and all of my family, relatives and friends as well as my boyfriend's family for always being interested in my progress. I am blessed to have such good friends and family that surround me. I think that you can only be an excellent performer at work if you have a great social life. Judging the people around me in my social life, I have all resources to do great work.

Then my parents, papa en mama. I am so proud of you. Without you, I would not be the person that I am today. Mama, you are my mirror of self-reflection. I always call you when I do not know how to respond to a situation or when something is going wrong. For some weird reason you are almost always right. I treasure this, and I treasure the relationship we have together. And as for you papa, you are more quiet, more in the 
background, but you know exactly the right thing to say at the right moment. I will forever think back fondly of the (conference) trip we made to Florida together, this was unforgettable. We are so alike in personality and I am so proud of that. Thank you both for your everlasting support and love.

Next to thank is my sister Vera. Veerke, I think your existence has forever determined the way I live. You enjoy, love and talk without limits. I love the way you say you are my pit bull sister and I know you will protect me as I will always protect you, too. Thank you for designing the cover of my dissertation. This is the most special gift you could give me, and I am so proud of you. Ik vind je lief zus.

And then Bas. You are closest to me, which all too often implied you had to endure my grumpiness, despair and tears of frustration, but somehow, you always succeed in making me smile again. Thank you for that and for sharing in my happiness, laughter and success. Nobody understands me like you do. Every day when I go home, I look forward to seeing you. Thank you so much for all of your support. Life is so much better when I can spend it with you. I love you.

This acknowledgement is the last part of my dissertation that I wrote. Completing my PhD has been hard work, but it has been so worth it. In my family, when we work hard and in the evening sit down to reflect on the results of a hard day of work, only to begin the next day with fresh energy, we use a special quote. I now reflect on my work, only to begin freshly with a new day in my career. Therefore, I would like to end my acknowledgements with this quote.

"Zo. Dat miech geine mie kump." 



\section{Table of Contents}

$\begin{array}{ll}\text { Acknowledgements } & 7\end{array}$

$\begin{array}{ll}\text { List of figures } & 17\end{array}$

$\begin{array}{ll}\text { List of tables } & 17\end{array}$

Introduction $\quad 19$

1.1 Introduction $\quad 21$

1.2 Practical Considerations $\quad 21$

1.3 Theoretical Considerations $\quad 22$

1.4 Dissertation Structure $\quad 23$

Chapter 2 Home Is Where The Mind Is - Theory On Identification And Place Branding $\quad 27$

2.1 Introduction 29

2.2 The Foundational Theory of Identification 31

2.3 Defining Identification $\quad 32$

2.4 Customer-Brand Identification 33

2.5 The Antecedents and Consequences of Identification 34

2.6 The Origins of Place Branding 35

$\begin{array}{ll}2.7 \text { The Place Brand } & 37\end{array}$

2.8 Stakeholders in Place Branding 38

2.9 Place Identification $\quad 40$

Chapter 3 All's Well That Ends Well Part 1-Customer Brand Relationships in the Post-Dissolution Phase. Study 1 - Products \& Services and their Ex-Customers 41

3.1 Introduction 43

3.2 Identification in the Post-Dissolution Phase $\quad 45$

$\begin{array}{ll}3.3 \text { Coping } & 47\end{array}$

3.4 Attribution $\quad 50$

Study 1 - Products \& Services and their Ex-Customers 54

3.5 Research Method 54

3.5.1 Sample and Procedure 54

3.5.2 Psychometric Properties of the Measurement 55

3.6 Results Study $1 \quad 56$

3.6.1 Overall Model Fit 56

3.6.2 Identification and Return Intention and Word-Of-Mouth 57 
3.6.3 Identification and the Use of Coping Strategies

3.6.4 The Use of Active Coping Strategies and Return Intention and Word-OfMouth

3.6.5 The Use of Expressive Support Seeking Strategies and Return Intention and Word-Of-Mouth $\quad 58$

3.6.6 The Moderating Role of Attribution 58

3.6.7 Attribution and the Use of Active Coping Strategies 59

3.6.8 Attribution and the Use of Expressive Support Seeking Strategies 60

3.6.9 Mediation Tests 63

3.7 Discussion Study $1 \quad 63$

3.8 Future Research and Conclusion 65

Chapter 4 All's Well That Ends Well Part 2- Customer Brand Relationships In The Post-Dissolution Phase. Study 2 - Places and their Ex-Residents 67

$\begin{array}{ll}4.1 \text { Introduction } & 69\end{array}$

4.2 The Post-Dissolution Phase 70

4.3 Identification in the Post-Dissolution Phase $\quad 71$

4.4 Coping $\quad 72$

4.5 Attribution $\quad 73$

Study 2 - Places and their Ex-Residents $\quad 76$

4.6 Research Method 76

4.6.1 Sample and Procedure 76

4.6.2 Psychometric Properties of the Measurement 76

$\begin{array}{ll}4.7 \text { Results Study } & 77\end{array}$

4.7.1 Overall Model Fit 78

4.7.2 Identification and Return Intention and Word-Of-Mouth 78

4.7.3 Identification and the Use of Coping Strategies 78

4.7.4 The Use of Active Coping Strategies and Return Intention and Word-OfMouth 78

4.7.5 The Use of Expressive Support Seeking Strategies and Return Intention and Word-Of-Mouth $\quad 79$

4.7.6 The Moderating Role of Attribution 79

4.7.7 Attribution and The Use of Active Coping Strategies 79

4.7.8 Attribution and the Use of Expressive Support Seeking Strategies 80

4.7.9 Mediation Test 82

4.8 Discussion Study $2 \quad 83$

4.9 Future Research and Conclusion $\quad 85$ 
Chapter 5 Talking Places - The Development Of Word-Of-Mouth As A Tool For Place Branding. Study 3 - Balancing Place Identities $\quad 87$

5.1 Introduction $\quad 89$

5.2 Place Branding $\quad 92$

5.3 Permeability and Identity Management 93

5.4 Identity Management and Identification 96

5.5 Identification and Behavioral Outcomes 99

5.6 Group Status and Ties to New Place of Residence 101

$\begin{array}{ll}\text { Study 3: Balancing Place Identities } & 104\end{array}$

$\begin{array}{ll}5.7 \text { Research Method } & 104\end{array}$

5.7.1 Sample and Procedure 104

5.7.2 Psychometric Properties of the Measurement 105

$\begin{array}{ll}5.8 \text { Results } & 107\end{array}$

$\begin{array}{lll}\text { 5.8.1 Overall Model Fit } & 107\end{array}$

5.8.2 Permeability and Identity Management 108

5.8.3 Identity Management and Identification 108

5.8.4 Identification and Behavior 109

5.8.5 Group Status and Place Connection 110

5.9 Discussion Study $3 \quad 113$

5.10 Future Research and Conclusion $\quad 116$

$\begin{array}{ll}\text { Chapter } 6 \text { Discussion \& Conclusion } & 119\end{array}$

6.1 Introduction $\quad 121$

6.2 Synopsis 122

6.2.1 Study 1: Products \& Services and their Ex-Customers 122

6.2.2 Study 2: Places and their Ex-Residents 123

6.2.3 Study 3: Balancing Place Identities 125

6.3 Discussion of Implications 127

6.3.1 The Post-Dissolution Phase 128

6.3.2 Extending Marketing Concepts to the Place Branding Context. 128

6.3.3 Balancing Different Place Related Identities 130

6.4 Future Research Intentions 131

6.5 Final Comments 132

$\begin{array}{ll}\text { References } & 133\end{array}$

$\begin{array}{lr}\text { Appendix A } & 149\end{array}$

$\begin{array}{ll}\text { Appendix B } & 151\end{array}$ 


\section{List of figures}

Figure 1.1 Overall conceptual framework $\quad 25$

Figure 2.1 Identity and related concepts. 33

Figure 3.1 Conceptual framework study 1

$\begin{array}{ll}\text { Figure } 3.2 \text { Results overview study } 1 & 61\end{array}$

Figure 4.1 Conceptual framework study $2 \quad 75$

Figure 4.2 Results overview study $2 \quad 81$

Figure 5.1 Conceptual framework study $3 \quad 103$

$\begin{array}{ll}\text { Figure } 5.2 \text { Results overview study } 3 & 111\end{array}$

\section{List of tables}

Table 3.1 Discriminant validity and descriptive statistics study 1

Table 3.2 Results overview study 1 direct effects 61

Table 3.3 Results overview study 1 moderating effects 62

Table 4.1 Discriminant validity and descriptive statistics study $2 \quad 77$

Table 4.2 Results overview study 2

Table 5.1 Discriminant validity and descriptive statistics study $3 \quad 106$

Table 5.2 Results overview study $3 \quad 112$ 

Introduction 


\subsection{Introduction}

'Home, let me come home, home is whenever l' $m$ with you'. This sentence, taken from a song by Edward Sharpe and the Magnetic Zeros, indicates the intangibility and variability of the concept 'home'. Humans can refer to multiple places as 'home'. These multiple homes are created throughout our lives. It can be the place where one grew up, the place one studied in or the place that is one's current residence. In any way, a place called home represents a 'sense of place' that has meaning to a person and is part of this person's identity. The purpose of this dissertation is not to define the concept of home. Rather, this dissertation assesses if a person's place related identity changes after moving away from a place and which consequences this moves has for place related behavior.

While living in a place, one makes friends, perhaps even establishes a family, and memories are created that are forever connected to that particular place. Through this, a place becomes engraved into one's soul. Living in any place will form a person and creates a new piece of his or her identity. Still, places may not be home forever. People move, following someone they love, going to college, looking for a change of scenery, or simply desiring economic opportunities elsewhere. However, even when no longer living there, one can never completely forget about a place. When people are asked about any place they once called home, they may relive part of the memories that were created there and share their experiences with the people around them. By doing so, these ex-residents turn into place brand ambassadors who influence the place brand image of their conversation partners. This makes residents and ex-residents valuable partners in place branding.

\subsection{Practical Considerations}

The research that was conducted for the purpose of this dissertation strongly originated from practice. While part-time working in a place branding organization, challenges and opportunities that place branding managers are facing in real life were observed. These practical problems were the foundation of the research that is incorporated in this dissertation. The academic outcomes were returned to practice in the form of management reports for the Maastricht Region Branding Foundation, Gemeente Heerlen and Gemeente Maastricht. The practical relevance of this research was supported by the attention of local media to the outcomes of my projects. Below, some of the practical considerations of this dissertation are shared.

Although people continuously bond with the place they live in (Cuba \& Hummon, 1993), they have increasingly more options to choose from when deciding where to re- 
create, work or live (Hospers, 2006). Therefore, places nowadays must compete with each other in order to be in the consideration set of prospective visitors (Kemp, Williams \& Bordelon, 2012b), residents and investors (Dinnie, 2004). Places have a large variety of features related to their heritage: culture, art and natural resources (Kemp, Childers \& Williams, 2012a). Selecting a place, especially for living and working, is often based on the congruence of the place's features and the personal values of an individual (Choo, Park \& Petrick, 2011). As there is a high correlation between a place's reputation and a person's willingness to come to that particular place (Reputation Institute, 2012), place brand managers are looking to brand a place such that many people can perceive a certain level of self-congruence which enables them to come to the place and bond with it.

In practice, people indicate that when moving to another place of residence, the move is mostly for work-related or social reasons, such as closeness of friends and family. Work or family, however, is not the only reason to move; quality of life and location are also often mentioned as reasons influencing a decision to move (Sillen, 2013). This implies that, for a place brand manager, it would be of vital importance to attract jobproducing entrepreneurs and businesses, and to show the attractiveness and quality of life of the place.

However, a place brand manager does not have full control of the brand. Although he or she can make the brand attractive, only real experience with the place can make a person feel at home and makes the place a part of a person's identity. Only when a person can integrate in the local community in terms of relationships with family and friends (Cuba \& Hummon, 1993), a person can truly identify with a place and call it home.

\subsection{Theoretical Considerations}

This dissertation strives to integrate the practical issues experienced by place brand managers with academic concepts and research issues, thereby contributing to the literature in place branding, relationship marketing and social identity. First, it contributes to place branding theory, which is developing, but is currently considered to be in its infancy (Konecnik Ruzzier \& De Cheratony, 2013). Specifically, the research in this dissertation ties in to the recent call for better integration of the concept of identification into place branding literature (Kavaratzis \& Hatch, 2013). Residents are considered to be one of the most important stakeholder groups in place branding (Kemp et al., 2012a), as they communicate about places to express their social identity (Kaplan, Yurt, Guneri \& Kurtulus, 2010) and thereby function as ambassadors for the place brand (Choo et al., 2011). However, in the existing literature, it is not precisely known how the concept of 
identification ties in to this brand communication. This area is further explored in the research of this dissertation.

The second theoretical research avenue relates back to residents as place brand experts. Living or having lived in a place makes residents and ex-residents an expert in the eyes of people who have no first-hand experience with the place (Konecnik Ruzzier \& De Cheratony, 2013). This expert role can make ex-residents a valuable asset for a place brand as they travel to other places and develop relationships with the people there. Although the importance of residents as a stakeholder group has been recognized in research (e.g. Van Ham, 2008), no attention has been paid to the role of exresidents.

These issues are discussed in the current dissertation and tie into existing research on relationship marketing. People who move dissolve the official relationship with the place brand, yet still maintain memories and cognitive ties related to the old place brand. These people are said to be in the post-dissolution phase of the customer-brand relationship (Odekerken-Schröder, Hennig-Thurau \& Knaevelsrud, 2010). Research on the post-dissolution phase of customer-brand relationships is rather limited to date. Additionally, the transferability of concepts that originate in product and services marketing to a place branding context is questionable (Anholt, 2008). Consequently, this dissertation presents a framework for the post-dissolution phase in a product and services context centering on the concept of identification and then transfers and extends this framework into the place branding context, to address the main research question:

What role does identification with a place brand play in the post-dissolution phase of a customer-brand relationship, and what (positive) consequences does identification with a place brand have in the post-dissolution phase of the customer-brand relationship?

\subsection{Dissertation Structure}

This dissertation consists of four chapters that address the main research question. In Chapter 2, an overview is provided of the main theories and concepts used in this dissertation that form the foundation for the three empirical research projects conducted for this dissertation. The empirical research projects address the post-dissolution phase in a product and service context as well as the post-dissolution phase in a place branding context.

In the first empirical study, which is described in Chapter 3, the main focus is on the development of a framework for the post-dissolution phase of a customer-brand relationship with a product or services brand. Based on relationship marketing theory 
and social identity theory, a framework is developed, which centers on the concept of customer brand identification. Specifically, the role of identification in the post-dissolution phase of the customer brand relationship with a product and services brand is described in relation to the concepts of coping, return intention and word-of-mouth. The first study is conducted among university students of a medium-sized university who were asked to describe real relationships with a brand they had in the past, but have now ended.

The second study, described in Chapter 4, extends the post-dissolution framework as developed in Chapter 3 into the place branding context, therewith coming to the core topic of this dissertation. Study 2 focuses on the behavior of ex-residents who have moved away from a place and are asked to describe their current cognitions and behaviors with regard to their old place of residence. The results of this study show that coping does contribute to the post-dissolution phase in a product and services context, but is not as representative in a place branding context. The link between identification with the brand and the outcome variables of behavioral intention and word-of-mouth, however, is consistent and strong across contexts. The sample of this second study consisted of people who migrated from a specific medium-sized European city in the last year. The respondents in this sample were asked to describe their cognitive processes surrounding the move by responding to a survey.

Identification has proved to be an important factor in the post-dissolution phase of a customer-relationship with a place brand, but the underlying mechanism appears to be different from the post-dissolution phase in a product and services context. Therefore, the third empirical study, which is described in Chapter 5, digs deeper into the concept of customer relationships with place brands. The focus on the post-dissolution phase is broadened, and not only is the post-dissolution relationship with a previous place brand addressed, but the new place brand is also entered into the equation. Furthermore, the framework is restructured to accommodate for the concept of identity management strategies, which are regarded as a way in which a new balance can be found between the old and the new place identity after a move. Results indicate that individuals can identify with two places at the same time and function as ambassadors for both of these places. However, these multiple identification sources slightly compromise each other in terms of behavioral outcomes. The identity management strategies that are used indeed contribute to the creation of a new balance in identities. The study in Chapter 5 was conducted by means of a survey among residents who had recently moved to a specific medium-sized European city. 
Below in figure 1.1, the overall conceptual framework that is considered in the current dissertation is presented. The framework below contains the most important concepts, some moderating variables will be added in the empirical studies that are not included in the framework below.

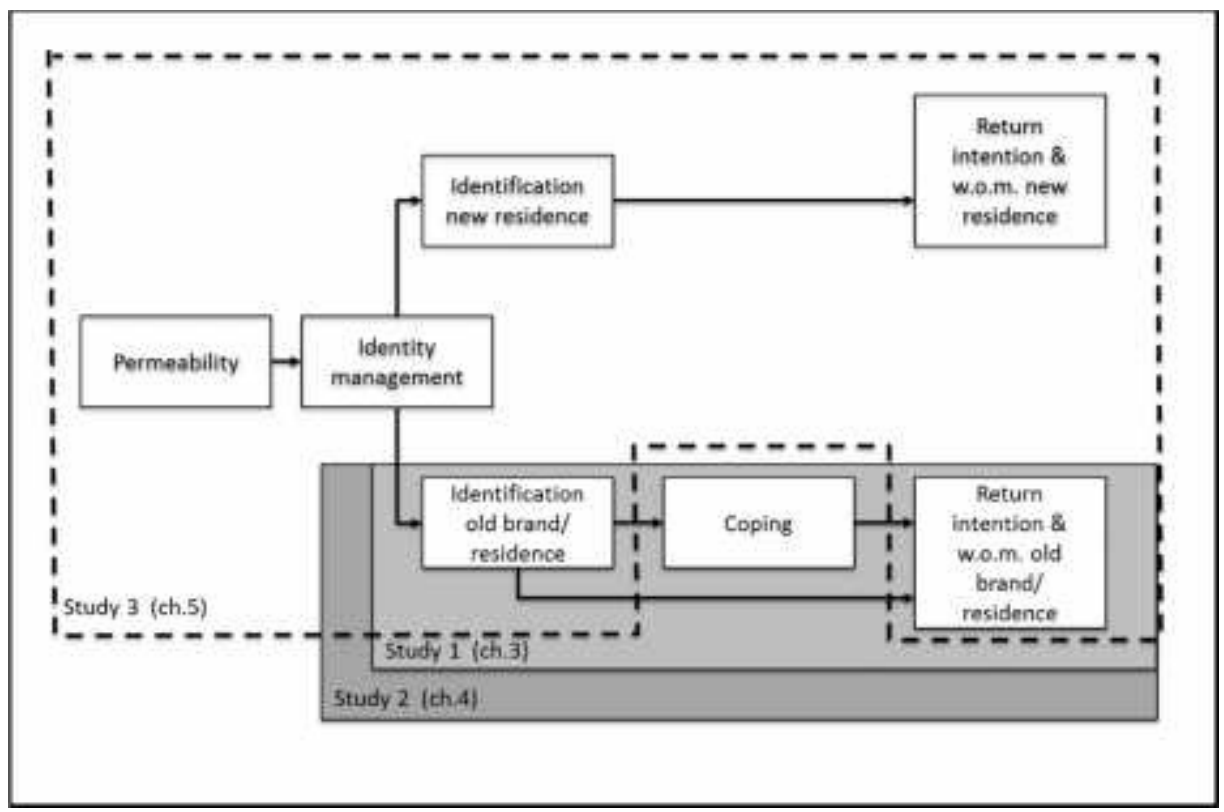

Figure 1.1 Overall conceptual framework 

Chapter 2

Home Is Where The Mind Is - Theory On Identification And Place Branding 


\subsection{Introduction}

A brand can encourage you to 'think different' (Apple), it can tell you that 'impossible is nothing' (Adidas) and to 'have it your way' (Burger King). 'It can make you feel like the man you are' (Buick), it can help you to 'find yourself here' (State of California) and 'honor thy self' (Johnny Walker) simply 'because you're worth it' (L'Oreal). Through brands, we can achieve 'successful living' (Diesel) and get to see the 'bright site of life' (Maastricht Region Branding Foundation). While most people would agree that although we might be 'lovin' it' (McDonald's), consuming one brand does not define who we are. Nevertheless, brands are important elements in the process of identity creation and help the individual to create a certain sense of uniqueness (Tuškej, Golob \& Podnar, 2011).

People do not exist in a vacuum, but instead constantly interact with their environment in order to create an identity (Hogg, 2003). Being a family member, a coworker, a follower of a certain religion, a customer of a certain brand or an inhabitant of a certain place defines the self and provides an individual, as well as the people around him, with a perceptual lens (Hogg, Terry \& White, 1995) that helps to make sense of the environment. This lens supports individuals in categorizing their environment and create order by giving themselves and others a place within this environment (Bhattacharya, Rao \& Glynn, 1995). As people anthropomorphize brands and treat them as partners in a relationship (Fournier, 1998), they have a desire to incorporate brands as part of their identity (Park, Maclnnes, Priester, Eisengerich \& lacobucci, 2010). This incorporation of a brand into the self-concept is referred to as identification (Bhattacharya et al., 1995).

In social sciences, a distinction is made between the development of an individual's personal identity and social identity (Hogg, 2003) through identification. Individuals use brands in a personal as well as in a social sense in the identity creation process. In personal identification, the individual develops a bond with the brand while in social identification, the brand is used as a means to communicate about the self-identity (Tuškej et al., 2011). The current dissertation refers to the brand as a means for social identification and therefore deals specifically with the identity communication and the resulting identification. When identifying with a brand in such a way, individuals categorize themselves as members of a group in order to describe their identity (Bhattacharya \& Sen, 2003).

Individuals can identify with multiple groups at the same time (Webber, 2010), but they do not identify with all groups in the same way. When individuals look at a social group, they create their own reality by installing cognitive and evaluative filters (Bhattacharya \& Sen, 2003) that result in a perceptual 'truth'. This 'truth' can differ at certain moments in time. A person's identity is highly dynamic and responsive to a 
change in context, since the context that an individual is currently in makes a certain part of the identity salient (Hogg et al., 1995). A change in context, therefore, brings a flow of cognitions and emotions (Amiot, Terry, Jimmieson \& Callan, 2006) and might alter a person's social identity. In the current dissertation, the focus is on such a contextual change and the consequences of such a change for a person's social identity. Specifically, the main focus is on migration decisions and the contextual changes that result from this migration. Drawing on the theories of customer relationships and the relationship life cycle (Dwyer, Schurr \& Oh, 1987), this dissertation looks at the post-dissolution phase of a customer relationship. In his original work, Dwyer and his colleagues refer to five customer relationship phases of awareness, exploration, commitment and dissolution, but they also refer to a "grave dressing phase" that entails the psychological recovery from a relationship dissolution. Since customers use brands to develop their selfconcept, dissolving a relationship with a brand can be seen as a trauma as the dissolution can undermine a person's self-esteem (Johnson, Matear \& Thomson, 2011). Individuals who identify with a brand go through a psychological process after the relationship has been dissolved in order to protect their identity and make sense of what happened (Halinen \& Tàhtinen, 2002). During this period, customers can still experience cognitions, emotions, behaviors and even a certain level of identification with the brand, which can classify this period as a post-relationship or post-dissolution phase (Odekerken-Schröder et al., 2010). The studies that are conducted in the current dissertation deal with this concept of a post-dissolution phase and show the dynamic movements in identity after a contextual change as well as the consequences these dynamics have for both the social identity of the individual, and for certain brand-related outcomes.

In this chapter, we zoom in to the concept of identification, as this concept forms the foundation on which this dissertation is built. Next to this, a certain case of identification, namely, identification with a place brand, is excavated. As with other brands, individuals can also identify with place brands (Cuba and Hummon, 1993; Warnaby \& Medway, 2013), but since the characteristics of a place brand are different from the characteristics of a product or services brand (Kavaratzis \& Hatch, 2013) and research on place identification is still fairly limited (Kavaratzis \& Hatch, 2013), this topic deserves some further attention. First, the underlying theory of identification is discussed, followed by customer-brand identification, its antecedents and consequences. This chapter then continues onto the topic of place branding and describes the underlying theory of place branding, the place as a brand, the role of stakeholders in place branding and concludes with place identification. 


\subsection{The Foundational Theory of Identification}

Social identity theory (Tajfel \& Turner, 1979) and social categorization theory (Turner, 1985) are seen as the cornerstones of marketing research on the concept of identification (Currás-Pérez, Bigne-Alcaniz \& Alvarado-Herrera, 2009). Social identity theory poses that an individual creates a social identity, which is based on the social groups and categories one belongs to (Hogg et al., 1995), with the purpose of enhancing self-esteem (Homburg, Wieseke \& Hoyer, 2009) and defining the self (Hogg et al., 1995). Social categorization theory, on the other hand, describes the basic category creation process that is necessary for people to simplify the world and divide it into the social categories they need for the creation of their social identity (Homburg et al., 2009). By categorizing, people create order and give themselves, as well as others, a position within the complicated environment that they live in (Bhattacharya et al., 1995) and thereby create the fundamental information that is needed for the composition of a social identity. Categorization theory is not directly included in the empirical research of this dissertation, but acts as a foundation for identification and therefore it is discussed in a little more depth.

During categorization, people classify others either into an in-group or an outgroup (Hogg et al., 1995) by looking at perceived similarities between themselves and the people around them. During this process, an individual is occupied with attempting to resolve a certain tension between the need to be different from others (the outgroup) and the need to be equal to others (the in-group). This is referred to as optimal distinctiveness (Bhattacharya and Sen, 2003; Elsbach \& Bhattacharya, 2001). The categorization process and the resulting level of optimal distinctiveness defines a person (Hogg et al., 1995) and creates feelings of belongingness to specific groups and categories. The belongingness to social groups as a means to form the social identity in terms of identification is so immensely important for the establishment of who we are, that it is even considered to be a critical factor of human survival (Kawakami, Phills, Greenwald, Simard, Pontiero, Brnjas, Khan, Mills \& Dovidio, 2012).

The identity of the self has been described by both identity theory as well as social identity theory. Both theories describe the multiple identities that a person has, but identity theory focuses on the role related identities a person has (i.e. being a father, a colleague, an athlete), whereas social identity focuses on relations between the self and groups (i.e. being Dutch, a sports club fan, a Harley Davidson biker) (Hogg et al., 1995). So, while identity theory focuses on the individual representation of the self in a certain situation, social identity theory has a more collective orientation, describing the relationships that the individual has with the group as a whole. Social identity theory, therefore, implies that the individual behaves positively towards this group in its entirety, and not necessarily to individual members (Gomèz, Brooks, Buhrmester, Vazquez, Jetten \& 
Swann, 2011). As identification is a cognitive construct (Bhattacharya \& Elsbach, 2002), in the current dissertation, there is a focus on cognitive processes surrounding certain transgressions in relationships. Social identity theory is more suitable than identity theory to describe these cognitive processes that surround a person's identity (Hogg et al., 1995).

\subsection{Defining Identification}

Through the categorization process, people develop a social identity that consists of cognitive linkages between a person's own identity and the identity of a group or organization (Elsbach \& Bhattacharya, 2001). These cognitive links manifest into a perceived cognitive state of oneness between the group identity and the person's identity, which is referred to as identification (Kuenzel \& Halliday, 2010; Currás-Pérez et al., 2009). Identification as such is the cognitive component of a person's social identity, and is complemented by both affective commitment as the affective component and self-esteem as the evaluative component (Bergami \& Bagozzi, 2000; Currás-Pérez et al., 2009). In the current research, focus is only on identification as the cognitive component of one's social identity and, therefore, these concepts are used interchangeably.

Identification with a social group or category can be based on perceived membership as well as on actual membership of a social group (Owens, Robinson \& Smith-Lovin, 2010). People can identify with a group even if they are not a formal member of this group. They do not need to interact with the group or experience strong personal ties to specific people in the group for identification to occur (Bhattacharya \& Sen, 2003). Not all members of a group need to identify with this group. Additionally, not all people who identify with a group are considered as members (Bhattacharya \& Elsbach, 2002).

Thus, in the current dissertation, identification is defined as: a perceived cognitive state of oneness that describes the positive similarities between one's own identity and the identity of other social entities and which results in an individual defining him or herself in terms of this other entity as part of their social identity. 
In figure 2.1 below, we show how a person's identity is constituted and how identification is part of a person's identity. The part that is printed in bold is the focus of this dissertation.

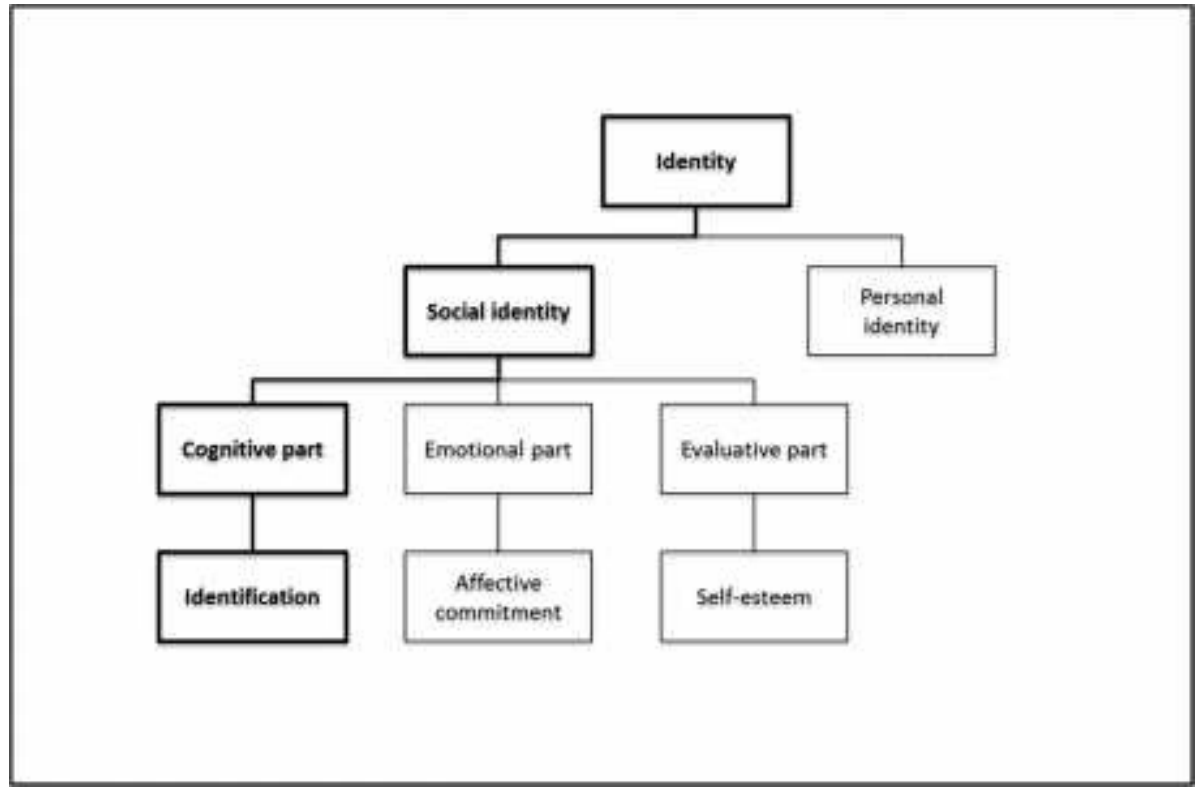

Figure 2.1 Identity and related concepts. ${ }^{1}$

\subsection{Customer-Brand Identification}

Looking at the customer-brand relationship from the above described perspective of social identity theory and social categorization theory, new insight is given into the development of this relationship (He, Li \& Harris, 2012). Individuals define themselves partly by the roles they play within organizations as well as the roles they play as customers (Currás-Pérez et al., 2009). Brands can be perceived as social entities in the creation of a social identity, as they function as a pseudo-person and facilitate the identification of an individual with a brand (Tuškej et al., 2011). When an individual identifies with a brand, this individual defines him or herself in terms of the brand (Bhattacharya et al., 1995) and may see a brand as an extension of the self (Kuenzel \& Halliday, 2010). Brands are important entities in the creation of a self-identity as they help an individual show uniqueness (Tuškej et al., 2011) and provide a kind of intangible value to an individual (Bhattacharya \& Sen, 2003).

1 The part that is printed in bold is the focus of this dissertation. Based on: Hogg et al., 1995; Bergami \& Bagozzi, 2000; Currás-Pérez et al., 2009; Kuenzel \& Halliday, 2010 
Relationships that are based on customer-brand identification are the kind of deep relationships that companies should strive for (Bhattacharya \& Sen, 2003). Customers who identify with a brand develop stronger customer relationships (Ahearne, Bhattacharya \& Gruen, 2005) with the brand, which turns identification into a customer retention strategy (Bhattacharya et al., 1995). As retaining existing customers become increasingly more important in the marketplace, because of increased competition in the global market (Florek, Insch \& Gnoth, 2006; Roos \& Gustafsson, 2007), the role of identification in a customer-brand relationship is becoming equally more critical. When a company has a good reputation, recovery in times of crisis is easier (Keh \& Xie, 2009). It is, therefore, important for a company to have a strong customer orientation as this is a prerequisite for companies to develop a level of identification between their customers and the brand (Bhattacharya et al., 1995).

\subsection{The Antecedents and Consequences of Identification}

In establishing a social identity, individuals put effort into creating a stable and consistent sense of the self over time as well as across situations (Bhattacharya \& Sen, 2003). Stability of the self-concept helps a person to be recognizable to others across different situations and enables the establishment of stable relationships (Owens et al., 2010). In order to maintain this stability, an individual avoids acting in a way that opposes their self-view (Ward \& Broniarczyk, 2011). In deciding which brand to identify with, a brand is deemed to be a more attractive identification target when the brand identity is coherent (Currás-Pérez et al., 2009) and the customer has positive experiences with the brand (Bhattacharya \& Elsbach, 2002).

Without any direct or indirect experience with a brand, a person starts off by having a neutral stand towards an organization that can either move in a positive or negative direction (Bhattacharya \& Elsbach, 2002). A positive experience is the fundament of identification with the brand. Nevertheless, no matter how positive the experience, an individual only identifies with a brand when it is associated with values that overlap the values that the customer holds for him or herself. This principle is referred to as selfcongruity (Tuškej et al., 2011). Only when an individual perceives a brand to be congruent with the self-related identity, can the brand serve as a means to satisfy self-definitional needs (Keh \& Xie, 2009; Currás-Pérez et al., 2009), which is the purpose of identification. Next to self-congruity, a brand is also deemed as more suitable for identification when it is positively distinctive from other identities and high in perceived status (Bhattacharya \& Sen, 2003). Frequency of contact increases the level of identification, but identification also induces more contact (Bhattacharya et al., 1995). 
Individuals who experience customer-brand identification share their identity and values with the company and are, therefore, a loyal and trusting customer group (Keh \& Xie, 2009), behaving in a positive way towards a brand. Identification with a brand leads to both in-role as well as extra-role behaviors (Ahearne et al., 2005). The positive behavior towards the brand reinforces the positive feelings of identification and raises the group status of the customer's in-group. So, through this behavior, customers keep fulfilling the self-definitional needs that are related to the brand (Homburg et al., 2009).

Brand identification thus leads to positive behavior towards the brand (Kuenzel \& Halliday, 2010). There are different positive consequences of identification described in literature. Identification induces positive word-of-mouth (Brown, Barry, Dacin \& Gunst, 2005; Tuškej et al., 2011; Bhattacharya \& Sen, 2003), loyalty (Keh \& Xie, 2009; He et al., 2012; Bhattacharya et al., 1995), trust (Bhattacharya \& Sen, 2003), commitment (Keh \& Xie, 2009) and repurchase intention (Tuškej et al., 2011; Keh \& Xie, 2009). Identification also functions as a buffer against negative brand experiences (Johnson et al., 2011) and limits defection (Bhattacharya et al., 1995). Customers who identify with the brand consequently can be seen as ambassadors and champions of the brand (Ahearne et al., 2005; Bhattacharya \& Sen, 2003). A customer-brand relationship based on identification is thus an attractive relationship for both the customer as well as the organization behind the brand. This already holds for product brands, but the role of identification in a relationship is even larger when concerning intangible brands. The more intangible a brand is, the more a customer is embedded in the creation of the brand identity, and the more important is the role of identification (Bhattacharya \& Sen, 2003).

\subsection{The Origins of Place Branding}

As the concept of identification is applicable to a wide variety of contexts (Bhattacharya et al., 1995), the current dissertation investigates the role of identification in place branding. A place brand is highly intangible (Kavaratzis \& Ashworth, 2005) and relies heavily on stakeholders in their branding efforts (Kemp et al., 2012b). Next to this, the development of place branding theory is only in its infancy (Konecnik Ruzzier \& De Cheratony, 2013). Place branding efforts have long existed (Dinnie, 2009; Anholt, 2010), as places, both consciously as well as unconsciously, tried to differentiate from one another on the basis of economic, social, political, and cultural aspects (Kaplan et al., 2010) as they were competing for trade, population, wealth, prestige or power (Kavaratzis \& Ashworth, 2005). Place branding is increasingly more consciously applied to locations (Dinnie, 2004); the question for a place nowadays is not whether or not to brand, but rather how to brand (Hanna \& Rowley, 2011). This growth in place branding practice is, however, not yet followed by a growth in grounded theory (Kavaratzis \& Ashworth, 
2005). Only in the last two decades have researchers started to see the place as a brand (Konecnik Ruzzier \& De Cheratony, 2013; Zenker \& Braun, 2010). As place branding is a relatively new field of academic literature, it is dealing with a lack of empirical research (Hanna \& Rowley, 2011). There is a growing number of publications that contribute to the theory of place branding (Dinnie, 2009; Lucarelli \& Berg, 2011), but a collective theory is currently still lacking. Consequently, there is still a wide gap between place branding theory and place branding practice (Kavaratzis \& Hatch, 2013).

Place branding as an academic praxis was founded as branding for tourism destinations, but is no longer restricted to such destinations as it is now also applied to places for attracting new residents, businesses and economic opportunities (Hanna \& Rowley, 2011). In practice, because of globalization (Kavaratzis \& Ashworth, 2005), places nowadays must compete with each other in order to be in the consideration set of prospective visitors (Kemp et al., 2012b) as well as residents and investors (Dinnie, 2004). Globalization enables people to live and work where they want, thereby leaving places that do not have growth opportunities (Hanna \& Rowley, 2008). This results in increased competition of places (Medway, Warnaby \& Dharny, 2010; Dinnie, 2004; Riza, Doratli \& Fasli, 2012). In an attempt to brand a place like a company or a product (Van Ham, 2008), places are being run in a way that resembles a business (Kavaratzis, 2004).

A destination brand (branding a place for tourism purposes) can be better aligned with product and services branding, whereas a location brand (branding a place to attract business and residents) is more related to corporate branding praxis (Dinnie, 2004; Skinner, 2008; Hanna \& Rowley, 2008). Place branding is not directly a form of corporate branding, but similarities between the two branding forms are recognized (Hankinson, 2007; Kavaratzis \& Hatch, 2013). Place brands hold resemblance to corporate brands as they are multidisciplinary, intangible and complex. Both place brands and corporate brands have multiple identities and target multiple groups of stakeholders (Kavaratzis \& Ashworth, 2005; Dinnie, 2008; Hospers, 2011; Kaplan et al. 2008; Kavaratzis, 2009; Kavaratzis, 2004; Konecnik Ruzzier \& De Cheratony, 2013). Especially this last distinction is important, as the presence of multiple stakeholders is one of the main features that distinguishes the place branding process from other types of branding (Dinnie, Melawar, Seidenfuss \& Musa, 2009; Hanna \& Rowley, 2011). A place encompasses a large group of organizations, businesses, services, and other entities that all carry their own brand. A place brand is, therefore, always co-created through a large variety of stakeholders (Hankinson, 2007; Dinnie \& Fola, 2009) that deal with the brand each day and are part of the brand (Kavaratzis \& Hatch, 2013). The involvement of all of these stakeholder groups in the brand-creation process (Dinnie \& Fola, 2009) makes it impossible to follow a conventional targeting approach to attract 'customers' (Kavaratzis \& Hatch, 2013). 


\subsection{The Place Brand}

Within place branding literature, the focus is on three main themes: (1) how to produce a place brand, (2) how to use and consume a place brand, and (3) showing the effects of place branding (Lucarelli \& Berg, 2011; Kavaratzis \& Hatch, 2013). The place brand is thus the central notion in all of these literature streams. Still, there is little consensus about which kind of marketing or branding can be applied to place branding, and, additionally, there is confusion about the terminology related to place branding (Skinner, 2008). Places often try to capture the place image in a catchy slogan, but a place is much more than that (Kavaratzis \& Ashworth, 2005). Places have brand related characteristics of brand identity, brand differentiation and brand personality, which implies that place brands can be managed to create brand equity, brand value and brand awareness (Kavaratzis \& Ashworth, 2005). Still, place branding is more about creating and planning developmental policies instead of the creation of a business strategy as is done with the branding of products and services (Hanna \& Rowley, 2008). Due to this intuitive confusion, it is wise to look at the constitution of the place brand and how place branding differs from products and services branding.

As there is a large diversity of actions and objects that contribute, both intentionally as well as unintentionally, to the creation of a place brand (Kavaratzis \& Hatch, 2013), a place brand can be considered an intellectual property (Van Ham, 2008), and as something formed in people's minds (Kavaratzis \& Hatch, 2013). A place brand is never derived from one single primary attribute (Merrilees, Miller \& Herington, 2009), but rather consists of a multitude of images that are not always in line with each other (Hospers, 2011), and sometimes conflicting, both across and within individuals (Kavaratzis \& Hatch, 2013). Next to this, places are legally defined. This definition is not always consistent with the psychological definition of a place (Warnaby \& Medway, 2013), which complicates the place branding process even further (Hankinson, 2007). Another consequence of this legal definition is that the place branding process is often intertwined with politics (Hankinson, 2007), which partly inhibits places to act in a marketoriented way (Skinner, 2008), and limits the possibility to create brand loyalty (Kemp et al., 2012a). The environment, heritage and infrastructure determine an important part of a place identity and are often beyond the control of a place brand manager (Skinner, 2008).

There is a difference between claiming that the place is a brand and assuming that a place can be branded. In line with previous literature (e.g. Anholt, 2005; Anholt, 2008; Dinnie, 2008; Skinner, 2008), this dissertation follows the notion that the place is a brand, but that branding places like a conventional product or service, is questionable at best. Place branding can be regarded as a form of place management, since much of the place branding efforts are made in changing the perception of a place in the eyes of 
diverse stakeholder groups (Kavaratzis \& Ashworth, 2005). Too many marketers assume that places are just an extension of products, and that traditional product marketing techniques can therefore be applied to the place branding field (Kavaratzis \& Ashworth, 2005). Unlike a brand new product or service, however, a place brand does not start with a clean slate (Skinner, 2008; Hankinson, 2004), but always has to deal with a preexisting reputation of a place. Determining the place brand is not a matter of distilling the essence of a place; neither is it as simple as changing a logo, color or slogan (Kavaratzis \& Hatch, 2013). Since places have multiple brand identities, they cannot be branded as clearly as products and services (Skinner, 2008). Consequently, richness and complexity should characterize the description of any place brand (Anholt, 2009), which limits the applicability of traditional marketing and branding techniques (Skinner, 2008) and results in a lack of control over the branded entity (Kavaratzis \& Hatch, 2013). This lack of control in the place branding process is related to the "product", the "consumer experience" and the "branding organization" (Hankinson, 2004).

\subsection{Stakeholders in Place Branding}

Stakeholder management is an important component of the place branding process (Kemp et al., 2012b). In conducting place branding, a distinction has to be made between an out-group (people who have not been in contact with the brand in terms of working and/or living) and an in-group (people who are or have been in contact with the brand in terms of working and/or living), which have different perceptions, social cognitions and mental representations of a place (Kotler \& Gertner, 2002). The perception of a place brand differs among the various stakeholder groups (Hospers, 2011), since these groups have a different kind and level of knowledge about the place brand (Zenker \& Braun, 2010). The out-group has a rather simple and uniform image of the brand, referred to as the external place brand image, while the in-group has a more complex and differentiated place brand image, called the internal place brand image (Zenker \& Braun, 2010; Vanolo, 2008; Kavaratzis, 2004). Simultaneous to the difference in image, a place brand is consumed by multiple target groups for varying purposes (Hankinson, 2007; Hanna \& Rowley, 2008). Communicating the same brand message to both the out-group as well as the in-group does not account for the different perceptions of the place brand among these two groups and is not in line with the customer-based view. Unfortunately, this is not yet extensively recognized within place branding practice (Zenker \& Braun, 2010).

For an out-group, the media is one of the main information sources concerning the place brand (Caldwell \& Freire, 2004), especially in the negative sense (Kotler \& Gertner, 
2002). Furthermore, place images are used as mental shortcuts. This means that, especially if people are in a low-involvement situation related to the place, they only rely on these existing images and ignore any information that does not fit the image that they already have in mind. This makes it hard to alter an existing image of a place brand (Kotler \& Gertner, 2002). Therefore, the effects of place branding campaigns seem to disappear rather fast (Van Ham, 2008). It has been recognized, however, that in-groups or internal stakeholders can play an important role in the branding of the place among the out-group (Konecnik Ruzzier \& De Cheratony, 2013). Next to the reliance on media, the perception of a place brand among the out-group relies on their experiences with the attitudes, values and behaviors of the residents in the place (Kaplan et al., 2008). These experiences are referred to as indirect place experiences (Kavaratzis \& Ashworth, 2005).

Internal stakeholders are one of the key target groups in the place branding process (Van Ham, 2008) as they make and live for the place brand (Konecnik Ruzzier \& De Cheratony, 2013). There are four main internal stakeholder groups in place branding: visitors, residents, workers as well as businesses and industry (Zenker \& Braun, 2010). In the current dissertation, focus is placed on (ex-)residents as a key stakeholder group. Just as happy employees have been found to create happy customers (Berry \& Parasuraman, 1991), happy residents can create happy visitors and happy new residents (Choo et al., 2011). Residents and peers who talk about a place, have a greater impact on the place brand as they are perceived to be more reliable in their information provision than media (Balakrishnan, 2009), which is another main source of information for the outgroup. Due to the important role of residents in the place branding process, it is important to engage in internal branding towards the residents (Choo et al., 2011; Kemp et al., 2012a). By starting with a focus on these internal stakeholders, place brand managers can ensure that their efforts are aligned with the wants and needs of the local community (Kemp et al., 2012b) and thereby also positively impact the out-group.

Communication about a place brand can be divided into primary communication (informational communication about actions and events related to the place), secondary communication (advertising and marketing communication related to a place), and tertiary communication (word-of-mouth by media and stakeholders). Primary and secondary communication positively influence tertiary communication (Kavaratzis, 2004; Hanna \& Rowley, 2011; Zhang \& Zao, 2009). However, place brand managers have no control over environmental factors that might have a negative influence on the brand, especially when these factors are reported by media (Kotler \& Gertner, 2002). This paper poses, however, that residents are, in general, more positive about a place brand than the media and can, to some extent, counter negative media influence. 


\subsection{Place Identification}

Living in a place entails that this place is home. A person has social ties that link to the place, as well as memories and significant life events that are related to the place (Cuba \& Hummon, 1993). Therefore, many of the aspects of a person's social identity are intimately related to the notion of a place (Dixon \& Durrheim, 2000). Places with characteristics of congruency between the self and the place brand help individuals develop a pride of place (Hanna \& Rowley, 2008) and facilitate the use of the place brand as a representation of a person's self-image (Kemp et al., 2012a; Kaplan et al., 2008).

There are three main ways in which an individual can incorporate a place as part of their self-concept. First, physical insideness describes the knowledge that a person has about the practical characteristics of a place. Second, social insideness refers to the social connections a person has in a place, in terms of community, friends and family. Third, autobiographical insideness refers to the memories that are connected to a place. This last kind of insideness is the main source of place identification (Dixon \& Durrheim, 2000). As customers can identify with a product brand when relating to the memories they have of that brand, customers can also develop brand-self connections with place brands (Kemp et al., 2012a) and like products and services brands, places are satisfying self-actualization needs (Caldwell \& Freire, 2004).

People develop a strong attachment to the place they live in, in the form of a cognitive structure (Cicognani, Menezes \& Nata, 2011), which is referred to as place identification. By conducting internal branding, a place branding manager can deepen the link between an individual and the place brand (Choo et al., 2011). When individuals identify with a place in such a way, they can become ambassadors for the place by promoting the place brand through word-of-mouth. This promotion is especially effective towards external stakeholders, such as visitors and future residents (Kemp et al., 2012b; Choo et al., 2011). As residents are not paid to talk positively about or behave positively towards

a place, they are seen as a trustworthy source of information for other people and can enrich the experience that other people have with the place (Choo et al., 2011). 
Chapter 3

\section{All's Well That Ends Well Part 1- Customer Brand Relationships in the Post-Dissolution Phase.}

Study 1 - Products \& Services and their Ex-Customers 


\subsection{Introduction}

Firms have long known that it is worthy to strive for customer retention and develop a relationship with customers who are committed to the brand, rather than focusing solely on the acquisition of new clients (Nitzan \& Libai, 2011; Morgan \& Hunt, 1994; Verhoef \& Lemon, 2012). Customers who commit themselves to a relationship with a brand and see the brand as part of their identity are more loyal, more likely to purchase the brand, and more positive about the brand (Jones, Dacin \& Taylor, 2011). When retention is not possible and the relationship is dissolved, customer win-back is the next best alternative (Homburg, Hoyer \& Stock, 2007). When a customer is impressed with the win-back efforts of a company, the chance for return of the customer is between $82 \%$ and $95 \%$ (Department of Consumer Affairs, 2011) with a return on investment of up to $214 \%$, whereas the return on investment of a newly acquired customer is a mere 23\% (Thomas, Blattberg \& Fox, 2004). Furthermore, an adequate customer win-back strategy has shown positive implications for both return intention as well as positive word-of-mouth (Retail Consumer Report, 2011). It remains challenging for firms, however, to decide on the right win-back strategy as they cannot predict the way that customers behave, especially when they are not in direct contact with the firm.

Existing research has demonstrated that it is mostly the customer who decides to dissolve a relationship with a brand (Michalski, 2004; Maute, 2011). It can be difficult for a firm to notice that a relationship dissolution occurred, because customers often neglect to voice the exit (Stauss \& Friege, 1999; Donoghue \& De Klerk, 2006). This probes firms to view relationship dissolution from a customer perspective as the end of behavioral exchange (Bogomolova, 2010), which is the case when customers no longer purchase, or specifically state to dissolve the relationship (Stauss \& Friege, 1999). After their exit, customers enter a phase in which they stay away from the brand, because their needs changed or they are disappointed (Stauss \& Friege, 1999). During this period, customers consider the consequences of the relationship dissolution for their identity (Halinen \& Tahtinen, 2002), and think about whether or not they want to return to the brand (Coulter \& Ligas, 2000). This phase after relationship dissolution, during which customers' behaviors are unaccounted for, is referred to as the post-dissolution phase (Odekerken-Schröder et al., 2010). The post-dissolution phase marks a period of absence of a customer from a certain brand (Stauss \& Friege, 1999). This period could possibly, but not necessarily, be followed by relationship revival (Odekerken-Schröder et al., 2010).

The bond of identification and commitment between a customer and a brand, created throughout the relationship, continues beyond the end of exchange activities between a firm and a customer (Johnson et al., 2011). Even though the behavioral relationship has been dissolved, customers still feel a connection to the brand (Odekerken- 
Schröder et al., 2010), especially when it concerns a relationship with a brand that they were identifying with. In this case, customers experience separation distress, which indicates that they mourn the dissolution (Park et al., 2010), and have to cope with the harm of this relationship dissolution to their self-concept (Johnson et al., 2011). Although it is recognized that the post-dissolution phase is part of a customer-relationship lifecycle, little is known about how customers cope with the separation distress they experience during the post-dissolution phase and which consequences this coping has on their intention to revive the relationship in the future or to positively talk about the brand.

Grasping these identity related processes at the customer side in the post-dissolution phase can help managers to better predict customer responses and consequently select a more appropriate win-back strategy. Understanding customer processes in the post-dissolution phase helps managers to answer a number of questions. Are efforts to make a customer committed and loyal during the relationship wasted after the relationship has been dissolved? How do customers' cognitive processes contribute to positive brand behaviors after dissolution? Can these cognitive processes be predicted by factors that are easily observable by the brand?

The purpose of this chapter is to determine the factors in the post-dissolution phase that customers use to decide whether to stay away from a brand or to revive the relationship in the future. We develop a model for positive behavior towards a brand after relationship dissolution on the basis of customer-brand identification, coping theory and attribution theory. We then use real customer experiences with products and services, to determine which processes customers go through in the post-dissolution phase, how this induces behavior towards their old brand and how this process is influenced by attribution of the relationship dissolution.

This chapter first aims to contribute to existent research on the post-dissolution phase of customer relationships (e.g. Odekerken-Schröder et al., 2010; Johnson et al., 2011) by extending literature on customer-brand identification. It has been shown that customer-brand identification, which is the inclusion of a brand as part of a person's identity (Bhattacharya et al., 1995), has a positive impact on both behavioral as well as attitudinal variables related to relationship quality during the relationship (Bhattacharya \& Sen, 2003). In this article, this knowledge is extended by showing that identification, built up during a relationship, maintains positive implications for the brand even after dissolution. The investment in identification between a customer and a brand is thus both beneficial during the course of the relationship as well as after the dissolution and proves to be an even worthier asset for relationship management than initially anticipated. 
Second, this research makes the coping processes during the post-dissolution phase more insightful for both theory and practice. Customers have, based on their attributed locus of causality of a relationship dissolution as well as the context of the dissolution, a different focus in coping with this dissolution (Bogomolova, 2010). They can assume an active coping style in which they deal with relationship dissolution in a problem-focused way, or make use of expressive support seeking in which customers mostly rely on their surroundings in order to cope with the dissolution of a customer-brand relationship (Duhachek, 2005). This chapter shows that the use of each coping method, in turn, has a varying impact on positive behaviors towards the old brand after dissolution. Companies can thus, based on the context of the dissolution and attribution information of their customer, predict how their customers will respond in the post-dissolution phase. Gathering this simple information can aid firms in assessing which win-back strategies would be most suitable for these customers.

The study that is described in this chapter asks consumers for their previous experiences with product and service brands and shows that customer-brand identification after dissolution is positively related to behavior towards the old brand, irrespective of attribution. The use of coping strategies partially mediates the relationship between identification after dissolution and behavioral responses towards the brand. Next to this, the role played by the different coping strategy and the strength of the various relationships is partly dependent on attribution, which makes attribution a predicting mechanism when assessing coping responses.

The studies show three major findings: (1) investing in identification with a brand is not only a worthy asset during the relationship, but also shows to be advantageous after the dissolution of the relationship, (2) coping processes play a mediating role in the post-dissolution phase of a customer brand relationship with a product or services brand, and, (3) attribution serves as a predictive mechanism in the post-dissolution phase. We proceed now with an extensive literature review and conceptualization of the model. The methodology of the study and the results are then discussed, followed by a discussion of the results and implications of the current research for both theory and practice.

\subsection{Identification in the Post-Dissolution Phase}

When a customer truly identifies with a brand, this brand identity is an intrinsic part of the individual's personal identity and is likely to endure, even if there is opposing information available (Lam, Ahearne, Hu, \& Schillewaert, 2010). It has been found that even after relationship dissolution, many customers speak about their own identity as related 
to the old brand (Odekerken-Schröder et al., 2010). If customers dissolve the relationship with a brand they identified with, they experience some psychic loss (Mael \& Ashforth, 1992), and are not able to let the brand go immediately. Customers still see themselves as if the brand belongs to them and is part of their identity, even though they are no longer a formal customer of this brand (Hogg et al., 1995; Odekerken-Schröder et al., 2010).

Throughout this dissertation, identification is defined in a customer context as the cognitive inclusion of a brand in a person's concept of the social self (Bhattacharya et al., 1995; Bhattacharya \& Sen, 2003), which is referred to as customer-brand identification (Tuškej et al., 2011; He et al., 2012). Customer-brand identification is linked to, but different from, brand attitude, since attitude clearly reflects a brand judgment that is distinctive from the brand's linkage to the self. This implies that whereas attitude indicates a valence (i.e. negative versus positive) (Park et al., 2010) identification is measured in strength (i.e. does not exist versus exists strongly) (Mael \& Ashforth, 1992). The strength of identification in the post-dissolution phase is dependent on factors related to the relationship that have been dissolved, such as autobiographical brand memories (Park et al., 2010). Since the customer is mostly void of brand influences after relationship dissolution, the identification with a brand after dissolution is rather static. Consequently, identification in the post-dissolution phase is defined as a "state" (StokburgerSauer Ratneshwar \& Sen, 2012; Tuškej et al., 2011) rather than a process.

Moving back to the formation of this identity, it should be noted that humans are notably conscious of themselves. They reflect on their behavior frequently in order to create a social identity, which serves as a link between themselves and the world around them (Leary \& Tangney, 2003). An individual's past and the experiences he or she had, constitute a major basis of this identity (Markus \& Wurf, 1987). In existent research, it has been shown that individuals can identify with religious groups, hobbies and jobs, but also with brands, places and companies (Bhattacharya et al., 1995; Lam et al., 2010; Stokburger-Sauer et al., 2012). The bond that is formed when an individual is attached to a brand this way, is not easily broken (Park et al., 2010).

The consequences of customer-brand identification that have been defined in extant research have a positive effect on the relationship between the brand and the customer. It is generally recognized that customer-brand identification positively impacts brand relationship outcomes during the relationship, like loyalty (He et al., 2012), extrarole behaviors, resilience to negative information (Ahearne et al., 2005; Bhattacharya \& Sen, 2003; Stokburger-Sauer et al., 2012), purchase intention (Keh \& Xie, 2009), and positive word-of-mouth (Brown et al., 2005; Tuškej et al., 2011). Especially these last two variables, purchase intention and word-of-mouth, are of interest for the current research concerning the post-dissolution phase. Purchase intention is referred to as return intention in the context of this research as it reflects the intention to return to a 
product or service brand (Keh \& Xie, 2009). Positive word-of-mouth, on the other hand, is an indicator of continued ambassadorship for the brand (De Bruyn \& Lilien, 2008).

The link between identification and the desirable outcomes of relationships can be described as positive and linear (Mael \& Ashforth, 1992), and also holds longitudinally (Lam et al., 2010). The more that customers identify with a brand, the stronger the positive consequences of this identification and the longer their duration. This longitudinal robustness of identification has also been shown by Mael and Ashforth (1992), who pose that "identification may be rather robust, withstanding erosion through time and exposure to other... contexts" (p. 116), and by Bhattacharya and Sen (2003), who pose that even if the customers are not a formal member of the organization they can identify with it. It has been found that previously built experience with the brand can decrease the effect of negative experiences related to the brand (Johnson et al., 2011). So, when a customer has had a negative dissolution experience based on brand failure, previous identification with the brand serves as a buffer against this negative information (Bhattacharya \& Sen, 2003). Furthermore, customers who relate their identity to the old brand in the post-dissolution phase also show return intention and attachment related to the former brand (Odekerken-Schröder et al., 2010). This leads to the assumption that customer-brand identification is not only existent in the post-dissolution phase, but also has positive implications for the individual's behavior towards the focal brand even after the dissolution of the relationship. Therefore:

H1a\&b: Given that a customer identified with a brand during the relationship, the level of customer-brand identification after the relationship dissolution has a positive impact on (a) return intention and (b) positive word-of-mouth related to the old brand.

Customer-brand-identification is cognitive in nature (Bhattacharya et al., 1995; Bergami \& Bagozzi, 2000), but with both cognitive and emotional consequences (StokburgerSauer et al., 2012). However, emotions are only experienced temporarily; they fade over time and are impossible for customers to remember correctly in retrospect (Walker, Skowronski \& Thompson, 2003). This is why, in the current research, the focus is on the cognitive responses of customers in the post-dissolution phase, which manifests as coping.

\subsection{Coping}

Existent research on the aftermath of relationship dissolution includes multiple referrals to coping as a cognitive response (e.g. Bogomolova, 2010). When customers dissolve their relationship with a brand, they analyze the information that they receive based on 
this dissolution, by, for example, asking themselves whether they took the right decision. The purpose of this process is to protect their identity (Halinen \& Tahtinen, 2002), and to decide on a future course of action (Sweeny, 2008). Customers use various coping methods simultaneously (Tsarenko \& Strizhakova, 2012) to readjust themselves to their environment (Thoits, 1986). After relationship dissolution, the consumption environment of a customer changes, which, given that the customer was involved in the relationship, induces a need for coping with this change. After dissolving a long-term relationship, customers may feel the need to reassess their personal identity as they can no longer refer to their former brand as their own, and question themselves if they have to construct a new, independent identity (Tajfel \& Turner, 1986) for which they then use coping as a mechanism.

The different coping responses in the post-dissolution phase are based on research by Duhachek (2005), who distinguishes between active coping, expressive support seeking and avoidance coping. Active coping is more an inward directed method of coping, aimed at problem solving, where the subject assesses for himself what is going on and deals with it himself based on a high level of self-efficacy (Tsarenko \& Strizhakova, 2012). Expressive support seeking is a more outward directed method where other people are actively involved in the coping process (Jun \& Yeo, 2012) to help the customer to express feelings and communicate about the dissolution (Tsarenko \& Strizhakova, 2012) in order to solve issues revolving around the dissolution of the relationship. In avoidance coping, a customer responds in a passive way (Tsarenko \& Strizhakova, 2012) and takes his mind off the problem by directing his attention to other things, thereby not dealing with an incident directly (Duhachek, 2005). This implies that, while a customer will probably not buy the product anymore, he or she will still refer to him or herself as a customer of the brand. Avoidance coping is thus considered to not be applicable in the post-dissolution phase.

Next to a direct relationship between identification with the old brand after dissolution and positive behaviors related to the old brand, it is expected that identification after dissolution gives rise to both active coping as well as expressive support seeking as coping responses, in order to put the dissolution of the relationship in perspective and decide on future behavior (Bogomolova, 2010). Therefore, we hypothesize:

H2a\&b: The level of customer-brand identification after dissolution positively impacts the use of (a) active coping strategies and (b) expressive support seeking strategies in the post-dissolution phase of customer-brand relationships.

People use multiple coping strategies simultaneously (Carver, Scheier \& Weintraub, 1989), but the use of these coping strategies does not necessarily lead to the same out- 
comes. This comes from an intrinsic need for consistency that all people have (Winkielman, Huber, Kavanagh, \& Schwarz, 2012). According to consistency theory (Heider, 1958; Aronson, 1969), people will do their utmost to keep consistent what they think, say and do, to protect their self-concept. During cognitive processing, they try to think in a fluent and consistent way, and create a coherent structure of beliefs since this feels much better than comparing two pieces of information that are inconsistent (Winkielman et al., 2012).

Customers are more likely to search for active coping options when they perceive that they themselves can do something about the situation (Amiot et al., 2006; Sweeny, 2008). With the use of active coping, the customer rationalizes the choice of leaving and attempts to establish consistency of cognition and behavior. Since the active coping mechanisms are infused with the positive associations stemming from identification with the old brand after dissolution, positive behavior towards the old brand after dissolution would be considered as consistent with the cognitive state of the customer. This consistency makes the customer feel good about him or herself (Winkielman et al. 2012). Therefore, the use of active coping decreases negative feelings towards the brand (Strizhakova, Tsarenko \& Ruth, 2012) and leads to behavioral intentions (Patrick, Lancellotti \& Demello, 2009) such as return intention and word-of-mouth.

H3a\&b: The use of active coping strategies in the post-dissolution phase of customerbrand relationships positively impacts behavior towards the old brand in the form of (a) return intention and (b) positive word-of-mouth.

Expressive support seeking can, on the other hand, be used as an outlet for one's feelings and frustrations as well as for reassurance in uncertain situations (Carver et al., 1989). This implies that when using expressive support seeking, people talk about the dissolution with friends and relatives and look for support for their decision to leave. Positive behavior towards the old brand after dissolution would thus be inconsistent with their prior behavior of talking to friends or looking for support related to the dissolution of the relationship. Positive behavior towards the old brand would cause the loss of face and damage to the self-image (Winkielman et al., 2012). The fear of loss of face is so detrimental (Sweeny, 2008) that it is unlikely that the customer acts in a positive way towards the brand after the use of expressive support seeking, even though identification lays at the foundation of the use of coping. Therefore, we expect that the use of expressive support seeking strategies has a negative effect on both return intention as well as positive word-of-mouth related to the old brand after dissolution. 
H4a\&b: The use of expressive support seeking strategies in the post-dissolution phase of customer-brand relationships negatively impacts behavior towards the old brand in the form of (a) return intention and (b) positive word-of-mouth.

So far, the attribution of the dissolution has not been taken into account. It is vital, however, to include the question of who is to blame for the dissolution of a relationship as attribution has a differential impact on coping responses (Sweeny, 2008; Yi \& Baumgartner, 2004) and therefore impacts the strength of the different relationships between identification after dissolution, coping, and the behavioral responses in the post-dissolution phase of customer-brand relationships.

\subsection{Attribution}

When relationship dissolution occurs, customers use various criteria to assess what happened and form an appraisal of this (Lazarus, 1993). An important part of this appraisal is attribution where customers gather information about the cause of the event and decide whether the event happened because of their own behavior (internal attribution) or because of an external agent (external attribution) (Sweeny, 2008). The determination of attribution can be indicated as falling under a self-other responsibility continuum (Oliver, 1993), which is referred to as the locus of causality (Eberly, Holley, Johnson \& Mitchell, 2011). Traditionally, according to attribution theory (Heider, 1958), customers decide between internal and external explanations (Eberly et al., 2011) of an event. The attribution of blame influences the coping efforts (Watson \& Spence, 2007; Sweeny, 2008) of the customer and impacts how they respond to the brand in the post-dissolution phase (Bogomolova, 2010). When customers know who to blame, they have a target for their coping actions (Donoghue \& De Klerk, 2012).

Internal attribution will direct the customers' attention to themselves, since they made the decision to leave. Thinking highly of the brand and then dissolving the relationship is information that is not consistent and is thus threatening the self-concept of the customer (Winkielman et al., 2012). When internally attributing the dissolution, the brand did nothing wrong, so the positive beliefs about the brand have not been harmed (Odekerken-Schröder et al., 2010). It is, therefore, also expected that identification with the brand after dissolution positively influences the use of active coping as the customer is using this strategy when aligning the decision to leave with positive feelings that he or she still has towards the brand. Furthermore, as people use active coping mainly to address and resolve situations (Strizhakova et al., 2012), the individual will make an effort to think rationally and find a satisfactory outcome (Tsarenko \& Strizhakova, 2012). Since 
the brand effectively did nothing wrong and the customer thought this through rationally, self-perception theory suggests one is generally in a more positive state with respect to the brand (Garnefeld, Helm \& Eggert, 2011) when internally rather than externally attributing the dissolution. This positive state, in turn, positively impacts behavior towards the brand (Garnefeld et al., 2011). We, therefore, hypothesize:

H5a: Attribution moderates the relationship between the level of customer-brand identification after dissolution and the use of active coping strategies in the post-dissolution phase of customer relationships such that the relationship is strongest in the case of internal attribution.

H5b\&c: Attribution moderates the relationships between the use of active coping strategies in the post-dissolution phase of customer-brand relationships and (b) return intention and (c) positive word-of-mouth such that the relationships are strongest in the case of internal attribution.

External attribution, on the other hand, gives rise to a more outward focus, since the target is the brand. In the case of external attribution, the brand is clearly to blame, and dissolving the relationship is a choice that is completely consistent with these negative associations. To prolong the blame (Tsarenko \& Strizhakova, 2012) and relieve the emotions that are attached to external attribution (Yi \& Baumgartner, 2004), customers talk about the brand to others in order to renew their self-concept and to restore their damaged identity (Johnson et al., 2011; Jun \& Yeo, 2012). Talking to others is, in the case of external attribution, more effective than active coping strategies (Tsarenko \& Strizhakova, 2012) inducing individuals who externally attribute the dissolution to rather focus on expressive support seeking strategies when compared to internal attribution.

The identification with the old brand after relationship dissolution that the customer experiences and which infuses the expressive support seeking strategy is, however, contradicting the negative associations the customer has because of external attribution (Ben-Zur, 2009). For the explanation, it is important to turn back to consistency theory. Consistency theory looks at the self-concept and whether the actions taken are in line with this self-concept (Harmon-Jones, Amodio, \& Harmon-Jones, 2009). The consistency that customers try to achieve is always a consistency with their salient attitude (Greenwald, 1975). When customers experience external attribution, their positive associations and identification with the brand are no longer salient. What is salient at the moment is that they are angry or disappointed with the brand. Greenwald (1975) poses that customers in this case use self-perception theory, meaning that they infer their attitudes from their current behavior. They cannot rely on identification to determine how 
to cope with relationship dissolution, because of a disruptive change in their environment, and they, therefore, have to rely on their current behavior of leaving and being angry. Hence, it is expected that external attribution negatively moderates the relationship between identification after dissolution and the expressive support seeking strategies that the customer uses and thus weakens the relationship. Furthermore, expressive support seeking strategies are used in case of external attribution to relieve the stress (Tsarenko \& Strizhakova, 2012) that was related to the dissolution. The expressive support seeking strategies that are used are infused with negative associations stemming from their current attitude towards the brand and their (negative) communication about the dissolution with other people (Jun \& Yeo, 2012), and are used to prolong their blame of the brand (Tsarenko \& Strizhakova, 2012). Consequently, external attribution is expected to strengthen the negative relationship between expressive support seeking and the behavioral outcomes.

H6a: Attribution moderates the relationship between the level of customer-brand identification after dissolution and the use of expressive support seeking strategies in the post-dissolution phase of customer relationships such that the relationship is strongest in the case of internal attribution.

H6b\&c: Attribution moderates the relationships between the use of expressive support seeking strategies in the post-dissolution phase of customer-brand relationships and (b) return intention and (c) positive word-of-mouth such that the link is weakest in the case of internal attribution. 
Together, the hypotheses that are developed above compose a conceptual framework for the post-dissolution phase of a customer brand relationship. This framework is visualized in figure 3.1. The moderating influences concern the influence of internal attribution. $A+$ indicates the relationship is expected to be strongest when attribution is internal, a - indicates the relationship is expected to be weakest when attribution is internal.

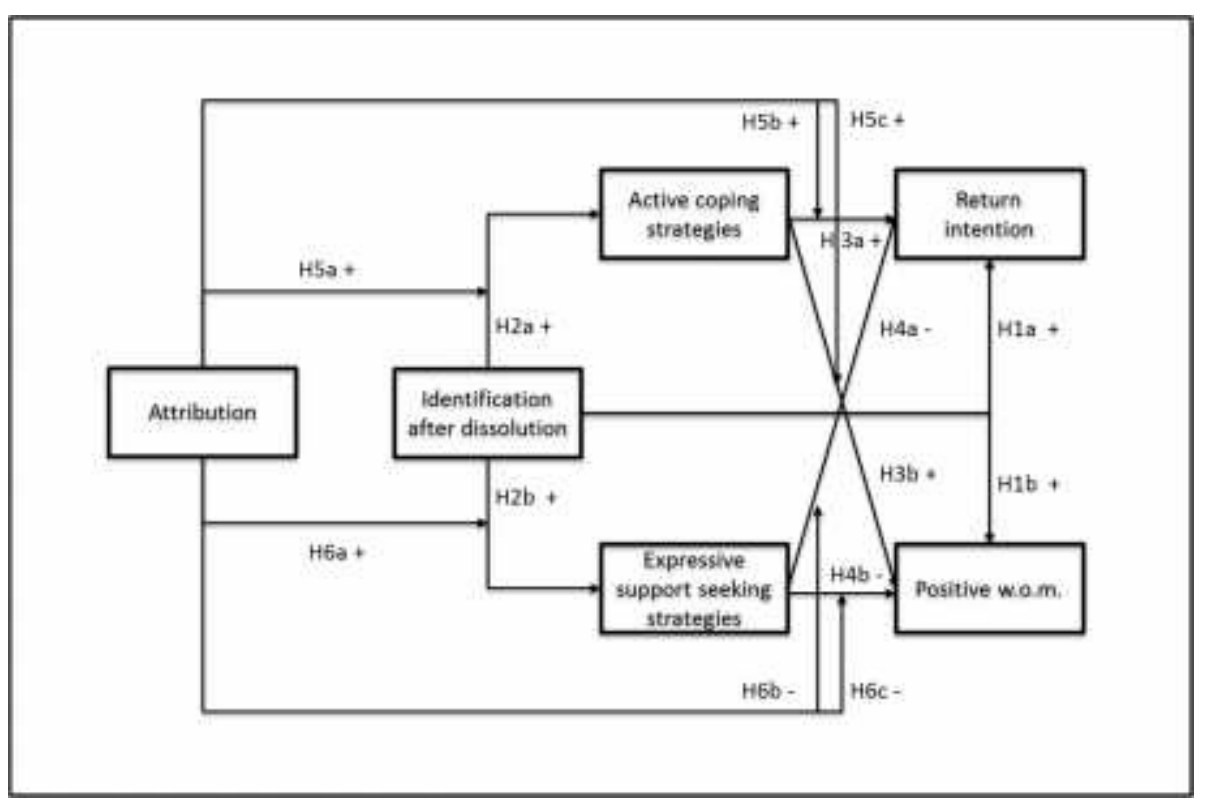

Figure 3.1 Conceptual framework study $1^{2}$

2 The moderating influences concern the influence of internal attribution. A + indicates the relationship is expected to be strongest when attribution is internal, a - indicates the relationship is expected to be weakest when attribution is internal. 


\section{Study 1 - Products \& Services and their Ex-Customers}

\subsection{Research Method}

\subsubsection{Sample and Procedure}

The data for this study has been collected at a medium-sized Dutch university. Participating students consisted of undergraduates and graduates. These 226 students signed up to participate in an hour long research session as part of a course requirement. Sessions took place in a research facility of the university to provoke the full attention of the students to the study. Upon entering the research facility, students were seated in separate cubicles and provided with a pen and paper. The respondents had to write about a real customer-brand relationship that they once had, but which had dissolved.

Participants were asked to report on a brand that said something about themselves during the time of the relationship. They were left completely free in the selection of the brand, ensuring that they picked a brand that was salient to them (Romaniuk \& Sharp, 2004). Writing a story about the brand ensured reviving their memories related to the brand and forced the respondents to summarize their experiences related to the brand in a meaningful story (Fredrickson, 2004). The research was divided into three parts. The first two parts were conducted offline and the third part was conducted online. In the first part of the assignment, respondents reported on what the brand meant to them during the relationship, while the second part focused on how the relationship was dissolved. The two parts were performed on different sheets of paper and separated by a filler task. In the second part, the respondents were asked to categorize the relationship dissolution based on locus of causality (i.e. classify attribution as external, internal or mixed), thereby determining their attribution. The third part consisted of a series of online questions on the respondents' experiences in the post-dissolution phase, thereby obtaining data for the most important constructs in the developed framework.

Of the 226 participating students, only one student did not answer all of the questions and was consequently removed from the final sample. Therefore, the total sample consisted of 225 respondents. Respondents were equally distributed across gender (49.8\% male) with an average age of 21 . Nationality was mainly German (53.8\%) and Dutch (21.3\%). The majority of respondents wrote about their customer-brand relationship with a clothing, shoes or jewelry brand (42.2\%). The dataset further included stories about mobile phones and computers (18.2\%), mobile phone and internet providers (12.4\%), cosmetics (4.9\%), other technological products or services $(4.0 \%)$, food $(4.0 \%)$, 
toys (3.6\%), gyms (1.8\%) and other products and services (8.9\%). In total, 94 respondents categorized that they experienced external attribution during the relationship dissolution, 76 respondents categorized the locus of causality of the dissolution as internal attribution and 55 respondents indicated their attribution was a mix of both internal and external attribution. Respondents were asked to self-assess their capability to complete the story writing assignment on a seven point scale. When asked how easy the assignment was (with a high score indicating the assignment was easy) and how successful respondents were in recalling the relationship (with a high score indicating the respondent was successful in recalling the relationship), respondents found the task to be easy $(M=5.11, S D=1.58, p<0.01)$ and stated they were successful in recalling the relationship $(M=5.02, S D=1.55, p<0.01)$, which conveyed that the instructions were clear.

\subsubsection{Psychometric Properties of the Measurement}

All scales for this study are presented and referenced in Appendix A of this dissertation. The scales employed to measure customer-brand identification before and after dissolution, active coping, expressive support seeking, return intention, and positive wordof-mouth, are reflective, which implies that the scale items correlate with each other. All measures, except for customer-brand identification before dissolution, are based on existing scales. Customer-brand identification before dissolution has been established by coding the first part of the writing tasks by three expert coders, who independently assessed the level of identification with a brand before relationship dissolution on a seven point scale. The average of the three coders' estimates constitutes the level of identification before dissolution (coefficient $\alpha=0.82$ ). The attribution variable is categorical and, therefore, suitable to split the dataset for the purpose of multigroup comparison (Hair, Sarstedt, Ringle, \& Mena, 2012), which is used in analyzing the moderating effect of attribution in hypothesis 5 and 6 . For the moderation analyses, a t-test approach was used, as suggested by Chin (2002).

Smart PLS 2.0 M3 was used to obtain partial least squares estimates for both the exogenous as well as the endogenous variables in the measurement model. Smart PLS is deemed to be suitable for the study, since it places only minimum requirements on normality (Antioco, Moenaert, Feinberg \& Wetzels, 2008), and can produce reliable results even with small sample sizes (Davis \& Golicic, 2010). The various psychometric properties of the measurement scales were assessed by reporting the convergent validity, reliability, and discriminant validity. Convergent validity is evaluated by examining the standardized loadings of the items on the latent variables (Chin, 1998) with a cut-off value of at least 0.5, but ideally 0.7 (Hair, Black, Babin, Anderson \& Tathem, 2006). Several items that did not make this 0.7 cut-off value were consequently removed in order 
to improve the psychometric properties of the scales. When assessing reliability, average variance extracted (AVE) was used with a cut-off value of 0.5 (Fornell \& Larcker, 1981). The AVE ranged between 0.58 and 0.91 . No items had to be removed, and the items obtained after assessing convergent validity were maintained. Composite reliability, an assessment of reliability with a cut-off value of 0.7 (Nunnally \& Bernstein, 1994), varied between 0.89 and 0.97 for our constructs in the current research. This implies that all of the constructs made the cut and were deemed reliable. Discriminant validity addresses to which extent the items load on constructs to which they do not essentially belong (Barclay, Higgins \& Thompson, 1995), which means the square root of the AVE should be larger than all other correlations in the model (Barclay et al., 1995; Chin, 1998). As is shown in Table 1, the constructs in the model show discriminant validity since all square roots were larger than the interconstruct correlations.

Table 3.1 Discriminant validity and descriptive statistics study 1

\begin{tabular}{|l|l|l|l|l|l|l|l|l|}
\hline & Mean & SD & $\mathbf{1}$ & $\mathbf{2}$ & $\mathbf{3}$ & $\mathbf{4}$ & $\mathbf{5}$ & $\mathbf{6}$ \\
\hline $\mathbf{1}$ Active Coping & 4.00 & 1.47 & $\mathbf{0 . 7 8}$ & & & & & \\
\hline $\mathbf{2}$ Expressive support seeking & 3.30 & 1.43 & 0.47 & $\mathbf{0 . 7 6}$ & & & & \\
\hline $\mathbf{3}$ Identification before & 4.64 & 1.35 & -0.19 & -0.10 & $\mathbf{0 . 8 6}$ & & & \\
\hline $\mathbf{4}$ Return intention & 3.31 & 1.79 & 0.05 & -0.29 & 0.08 & $\mathbf{0 . 9 0}$ & & \\
\hline $\mathbf{5}$ Identification after & 2.01 & 1.22 & 0.19 & 0.17 & 0.18 & 0.31 & $\mathbf{0 . 8 2}$ & \\
\hline $\mathbf{6}$ Positive W.O.M & 3.78 & 1.92 & 0.02 & -0.25 & 0.24 & 0.77 & 0.48 & $\mathbf{0 . 9 5}$ \\
\hline
\end{tabular}

\subsection{Results Study $\mathbf{1}^{3}$}

Bootstrapping with 1000 resamples was used to obtain standard errors for parameters in the model. In the analyses, identification before dissolution was controlled for in order to keep the focus on the post-dissolution phase constant. The descriptive statistics of the analyses are presented in Table 2.1.

\subsubsection{Overall Model Fit}

In starting the analysis of the structural model, the $\mathrm{R}^{2}$ is observed which has an average value of 0.15 for the endogenous constructs. Since it is generally insufficient to base conclusions concerning model fit solely on one measure (Fan, Thompson \& Wang, 1999),

\footnotetext{
${ }^{3}$ We report the beta-values and standard errors of the analyses. Significance of the one-sided hypotheses is indicated as follows. For marginally significant results $0.1>p>0.05=+$, for significant results $0.05>p>0.001=*$ and for highly significant results $\mathrm{p}<0.001=* *$.
} 
the Goodness Of Fit (GOF) measure for the total model is calculated using the total sample. Based on the article by Tenenhaus, Vinzi, Chatelin, and Lauro (2005), the GOF of a model is small when it reaches a value of 0.1 , medium when reaching a value of 0.25 and large when it reaches a value of 0.36 . The current model has a GOF index of 0.33 , which acknowledges a medium to strong fit of the model. Furthermore, a blindfolding procedure was conducted in SmartPLS to assess the predictive value of our model. When the results for the construct cross validated redundancy are above zero for all constructs (Tenenhaus et al., 2005), the model has predictive value. As the values range between 0.02 and 0.31 , we can conclude that the model has predictive value and, consequently, proceed with the analyses without removal of constructs.

When testing the moderating effect of attribution, the total sample of the three groups was split according to their self-selected attribution category. The group who indicated to have experienced mixed attribution is not included in this analysis, resulting in a two-group comparison. Based on Barclay et al. (1995), it was determined that the smallest sample of analysis (76 respondents for internal attribution) is adequate, since the largest number of paths leading to a variable is 4 , which is less than one tenth of the number of respondents. Furthermore, a power test with G*POWER 3.1.5 (Faul, Erdfelder, Lang \& Buchner, 2009) was conducted to determine the sample size that is needed for the analysis. With an average effect size of 0.15 , an alpha level of 0.05 and 4 predictor variables (including the control variable), a minimum sample size of 74 was obtained, which is less than our smallest sample size of 76. Therefore, the multigroup moderation analysis is powerful enough to be executed.

Below, the results of the first study are presented. The direct effects are analyzed by looking at the complete sample of 225 respondents. Only in the hypotheses that concern moderation, the sample is split up into two attribution groups of internal and external attribution. The middle group, who experienced mixed attribution, is left out for the purpose of multigroup analysis.

\subsubsection{Identification and Return Intention and Word-Of-Mouth}

In hypothesis 1, it was stated that identification after relationship dissolution positively influences both (a) return intention as well as (b) positive word-of-mouth. If customers experience a higher level of identification with the old brand after dissolution they indeed have a higher tendency to return to the brand $\left(\beta=0.31^{* *}, \mathrm{SE}=0.06\right)$ as well as a higher tendency to talk positively about the brand $\left(\beta=0.45^{* *}, \mathrm{SE}=0.05\right)$. These results support both hypothesis $1 \mathrm{a}$ as well as hypothesis $1 \mathrm{~b}$. The positive impact of identification on the respective brand related outcomes demonstrates the robustness of the identification-behavior link in customer-brand relationships, even after dissolution of the relationship. 


\subsubsection{Identification and the Use of Coping Strategies}

Hypothesis 2 was devoted to the effect of identification with the old brand after dissolution on the two coping responses. It was predicted that people who identified with the old brand after dissolution have a higher need for coping in general and thus the level of customer-brand identification after relationship dissolution would be positively related to both active coping ( $\mathrm{H} 2 \mathrm{a}$ ) as well as expressive support seeking $(\mathrm{H} 2 \mathrm{~b})$. The analysis of our data shows that the stronger people's identification with their old brand after dissolution of the relationship, the more they make use of both active coping ( $\beta=0.23^{* *}$, $\mathrm{SE}=0.06)$ as well as expressive support seeking $(\beta=0.19 * *, S E=0.07)$ thereby finding support for $\mathrm{H} 2 \mathrm{a}$ as well as $\mathrm{H} 2 \mathrm{~b}$.

\subsubsection{The Use of Active Coping Strategies and Return Intention and Word-Of-Mouth}

In hypothesis 3, a positive effect of the use of active coping strategies on ( $\mathrm{H} 3 \mathrm{a}$ ) return intention and $(\mathrm{H} 3 \mathrm{~b})$ positive word-of-mouth is predicted. The results of the PLS estimation show support for both $\mathrm{H} 3 \mathrm{a}$ as well as $\mathrm{H} 3 \mathrm{~b}$, since it was found that when people make more use of active coping strategies, it has a positive, significant impact on their intention to return to the old brand $(\beta=0.19 *, S E=0.08)$ and talk positively about the old brand $(\beta=0.14 *, S E=0.07)$.

\subsubsection{The Use of Expressive Support Seeking Strategies and Return Intention and Word-Of-Mouth}

A negative effect was predicted of expressive support seeking strategies on $(\mathrm{H} 4 \mathrm{a})$ return intention and ( $\mathrm{H} 4 \mathrm{~b})$ positive word-of-mouth towards the old brand in hypothesis 4 . The more customers make use of expressive support seeking strategies in the post-dissolution phase, the less they are inclined to return to the old brand $\left(\beta=-0.43^{* *}, \mathrm{SE}=0.07\right)$, which supports hypothesis $4 a$. Next to this, support was found for hypothesis $4 b$, since the use of expressive support seeking strategies in the post-dissolution phase indicates a decrease in the positive word-of-mouth behavior towards the old brand $\left(\beta=-0.38^{* *}\right.$, $\mathrm{SE}=0.06)$.

\subsubsection{The Moderating Role of Attribution}

Hypothesis 5 and hypothesis 6 concern the moderating influence of attribution on the relationship between identification and the coping responses, the relationship between the coping responses and return intention and the relationship between the coping responses and word-of-mouth. In order to investigate the moderating effect of attribution, 
the sample was split into three groups according to the self-selected attribution category of the respondents. In order to compare the two extreme attribution categories, the middle group of mixed attribution was left out and the complete analyses was run again for each of the two remaining groups. Next, t-tests were conducted with the path coefficients of both internal as well as external attribution as suggested by Chin (2002), to see whether the path coefficients for the two attribution categories are significantly different from each other. If we find a significant difference, the relationship between the two variables is indeed moderated by attribution.

\subsubsection{Attribution and the Use of Active Coping Strategies}

Hypothesis 5a predicts the moderating effect of attribution on the relationship between identification with the old brand after dissolution and the use of active coping strategies such that the positive relationship is strongest in the case of internal attribution. The results show that the relationship between identification with the old brand after dissolution and active coping is indeed stronger for internal attribution ( $\beta_{\text {int }}=0.40 * *$, $\left.S E_{i n t}=0.09\right)$ than for external attribution $\left(\beta_{\text {ext }}=0.21+, \mathrm{SE}_{\mathrm{ext}}=0.14\right)$, but that the difference between the two coefficients is not significant ( $t=1.09$ ). Thus, attribution does not significantly moderate the relationship between identification with the old brand after dissolution and active coping, and hypothesis 5 a cannot be supported. Active coping is thus infused with identification with the old brand after dissolution, regardless of how the dissolution is attributed.

In hypothesis $5 b$, the moderating impact of attribution on the relationship between active coping and return intention was assessed. Again, it was hypothesized that the positive relationship is strongest when the subject internally attributed the relationship dissolution. Although the relationship between active coping and return intention shows a positive significant result in case of internal attribution $\left(\beta_{\text {int }}=0.29 *\right.$, SEint $\left.=0.14\right)$, compared to a non-significant result when externally attributing the dissolution ( $\beta_{\text {ext }}=$ $\left.0.09, \mathrm{SE}_{\mathrm{ext}}=0.18\right)$, the difference between the coefficients is not significant $(\mathrm{t}=0.89)$, resulting in a lack of support for hypothesis $5 b$.

In hypothesis $5 \mathrm{c}$, the moderating influence of attribution on the relationship between active coping and positive word-of-mouth was assessed, such that the positive relation that was predicted is strongest in the case of internal attribution. Marginal support for hypothesis $5 c$ was found as the relationship is significantly stronger in the case of internal attribution $\left(\beta_{\mathrm{int}}=0.33^{* *}, \mathrm{~S} \mathrm{E}_{\mathrm{int}}=0.12\right.$ ) when compared to external attribution $\left(\beta_{\text {ext }}=0.02, \mathrm{SE}_{\mathrm{ext}}=0.18\right)$ on a ten percent level $(\mathrm{t}=1.37+)$. This indicates that people who internally attribute the dissolution base their positive word-of-mouth behavior more on their active coping efforts than people who externally attribute the dissolution. 


\subsubsection{Attribution and the Use of Expressive Support Seeking Strategies}

In hypothesis 6a, it was depicted that attribution had a moderating influence on the relationship between identification with the old brand after dissolution and the use of expressive support seeking strategies such that the predicted positive relationship would be weakest in case of external attribution. Support was found for hypothesis 6a as the relationship between identification with the old brand after dissolution and expressive support seeking is significantly less strong $\left(t=2.56^{*}\right)$ in the case of external attribution $\left(\beta_{\mathrm{ext}}=0.10, \mathrm{SE}_{\mathrm{ext}}=0.11\right)$ when compared to internal attribution $\left(\beta_{\mathrm{int}}=0.47^{* *}\right.$, $\mathrm{SE}_{\text {int }}=0.09$ ). . The results for this hypothesis signals that whereas the use of expressive support seeking is infused with identification with the old brand in the case of internal attribution, this is not the case for external attribution. When externally attributing the relationship dissolution, the use of expressive support seeking strategies is not based on identification with the old brand.

Hypothesis $6 b$ assesses the moderating impact of attribution on the relationship between expressive support seeking and return intention such that the negative relationship is strongest in the case of external attribution. Although the negative relationship is indeed strongest in the case of external attribution $\left(\beta_{\mathrm{ext}}=-0.47^{* *}, \mathrm{SE}_{\mathrm{ext}}=0.09\right.$ ) when compared to internal attribution $\left(\beta_{\mathrm{int}}=-0.30 *, \mathrm{SE}_{\mathrm{int}}=0.13\right.$ ), hypothesis $6 \mathrm{~b}$ is not supported as attribution does not significantly moderate the relationship between the use of expressive support seeking strategies and return intention ( $t=1.11)$. When determining their future purchase intentions, people base themselves on expressive support seeking strategies irrespective of attribution.

Hypothesis $6 c$ finally predicts a moderating influence of attribution on the relationship between the use of expressive support seeking strategies and positive word-ofmouth such that the predicted negative relationship is strongest in the case of external attribution. Hypothesis $6 c$ is supported as the relationship between expressive support seeking and positive word-of-mouth is significantly more negative $\left(t=1.92^{*}\right)$ in the case of external attribution $\left(\beta_{\mathrm{ext}}=-0.44^{* *}, \mathrm{SE}_{\mathrm{ext}}=0.09\right.$ ) when compared to internal attribution $\left(\beta_{\text {int }}=-0.14, \mathrm{SE}_{\mathrm{int}}=0.14\right)$. A more negative coefficient was found for external attribution than for internal attribution when expressive support seeking is related to positive wordof-mouth, which indicates that people who experience external attribution tend to base their word-of-mouth behavior more on expressive support seeking than people with internal attribution do.

In figure 3.2, table 3.2 and table 3.3 on the next pages, the results of the study are summarized. Bold lines in the figure indicate support for the hypothesis, thin lines indicate marginal support and interrupted lines indicate no support for the hypothesis. 


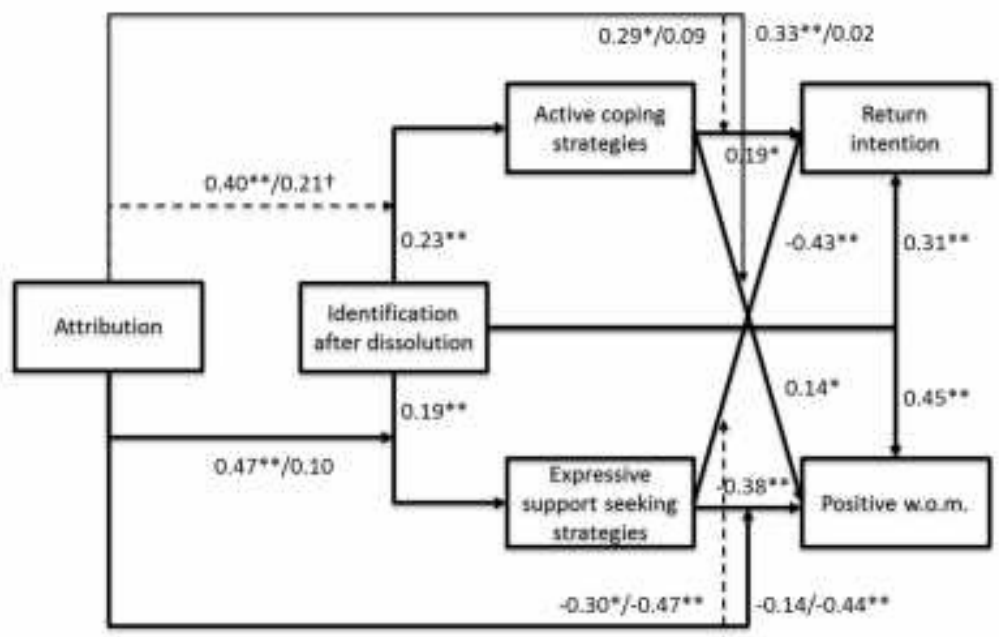

Figure 3.2 Results overview study $1^{4}$

Table $3.2^{5}$ Results overview study 1 direct effects

\begin{tabular}{|l|l|l|l|l|}
\hline Hypotheses & Coefficient & SE & Finding \\
\hline H1a & Identification after $\rightarrow$ Return Intention & $0.31^{* *}$ & 0.06 & Supported \\
\hline $\mathbf{H 1 b}$ & Identification after $\rightarrow$ Positive w.o.m. & $0.45^{* *}$ & 0.05 & Supported \\
\hline $\mathbf{H 2 a}$ & Identification after $\rightarrow$ Active coping strategies & $0.23^{* *}$ & 0.06 & Supported \\
\hline $\mathbf{H 2 b}$ & $\begin{array}{l}\text { Identification after } \rightarrow \text { Expressive support } \\
\text { seeking }\end{array}$ & $0.19^{* *}$ & 0.07 & Supported \\
\hline $\mathbf{H 3 a}$ & Active coping strategies $\rightarrow$ Return Intention & $0.19^{*}$ & 0.08 & Supported \\
\hline $\mathbf{H 3 b}$ & Active coping strategies $\rightarrow$ Positive w.o.m. & $0.14^{*}$ & 0.07 & Supported \\
\hline $\mathbf{H 4 a}$ & $\begin{array}{l}\text { Expressive support seeking } \rightarrow \\
\text { Return Intention }\end{array}$ & $-0.43^{* *}$ & 0.07 & Supported \\
\hline $\mathbf{H 4 b}$ & Expressive support seeking $\rightarrow$ Positive w.o.m. & $-0.38^{* *}$ & 0.06 & Supported \\
\hline
\end{tabular}

4 Bold lines indicate support for the hypothesis, thin lines indicate marginal support and interrupted lines indicate no support for the hypothesis. $0.1>p>0.05=+, 0.05>p>0.001=* p<0.001=* *$ $50.1>p>0.05=+, 0.05>p>0.001=* p<0.001=* *$ 
Table $1.3^{6}$ Results overview study 1 moderating effects

\begin{tabular}{|c|c|c|c|c|c|c|c|}
\hline Hуро & heses & 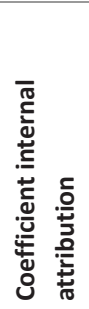 & 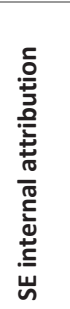 & 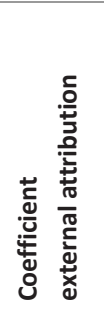 & 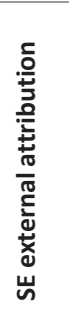 & 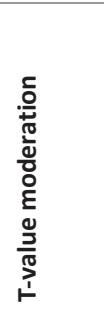 & 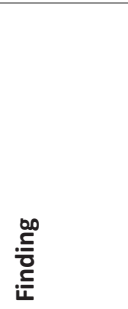 \\
\hline $\mathrm{H} 5 \mathrm{a}$ & $\begin{array}{l}\text { Identification after } * \\
\text { Attribution } \rightarrow \text { Active } \\
\text { coping strategies }\end{array}$ & $0.40 * *$ & 0.09 & $0.21 \dagger$ & 0.14 & $t=1.09$ & $\begin{array}{l}\text { Not } \\
\text { supported }\end{array}$ \\
\hline H5b & $\begin{array}{l}\text { Active coping strategies * } \\
\text { Attribution } \rightarrow \text { Return } \\
\text { intention }\end{array}$ & $0.29 *$ & 0.14 & 0.09 & 0.18 & $\mathrm{t}=0.89$ & $\begin{array}{l}\text { Not } \\
\text { supported }\end{array}$ \\
\hline H5c & $\begin{array}{l}\text { Active coping strategies * } \\
\text { Attribution } \rightarrow \text { Positive } \\
\text { w.o.m. }\end{array}$ & $0.33^{* *}$ & 0.12 & 0.02 & 0.18 & $t=1.37 t$ & $\begin{array}{l}\text { Marginally } \\
\text { Supported }\end{array}$ \\
\hline H6a & $\begin{array}{l}\text { Identification after } * \\
\text { Attribution } \rightarrow \text { Expressive } \\
\text { support seeking }\end{array}$ & $0.47 * *$ & 0.09 & 0.10 & 0.11 & $\mathrm{t}=2.56^{*}$ & Supported \\
\hline H6b & $\begin{array}{l}\text { Expressive support seeking } \\
\text { strategies * Attribution } \rightarrow \\
\text { Return intention }\end{array}$ & $-0.30 *$ & 0.13 & $-0.47 * *$ & 0.09 & $\mathrm{t}=1.11$ & $\begin{array}{l}\text { Not } \\
\text { supported }\end{array}$ \\
\hline H6c & $\begin{array}{l}\text { Expressive support seeking } \\
\text { strategies * Attribution } \rightarrow \\
\text { Positive w.o.m. }\end{array}$ & -0.14 & 0.14 & $-0.44 * *$ & 0.09 & $\mathrm{t}=1.92 *$ & Supported \\
\hline
\end{tabular}

$60.1>p>0.05=+, 0.05>p>0.001=* p<0.001=* *$ 


\subsubsection{Mediation Tests}

Four Sobel (1982) tests were performed in order to verify whether the active coping and expressive support seeking mediated the relationships between identification with the old brand after dissolution and positive behavior towards the old brand in the form of return intention and positive word-of-mouth. It was found that identification after dissolution also directly influences the positive behavioral responses to the old brand, therefore, only partial mediation is assessed. Based on the hypotheses of the research, a positive mediating effect of active coping and a negative mediating effect of expressive support seeking are expected.

Active coping was found to partially and positively mediates the relationship between identification after dissolution and return intention $\left(\beta_{x m}=0.23, \beta_{m y}=0.19\right.$, $\left.z=1.94^{*}\right)$. Next to this, positive partial mediation of active coping in the relationship between identification after dissolution and positive word-of-mouth $\left(\beta_{x m}=0.23, \beta_{m y}=0.14\right.$, $z=1.62+$ ) is found with marginal significance. This means that active coping partially explains the response patterns and the processes customers go through in the post-dissolution phase in terms of deciding how to behave towards the brand in the future, and that this mediating effect is stronger for return intention than for word-of-mouth.

Expressive support seeking was found to partially and negatively mediates the relationship between identification after dissolution and return intention $\left(\beta_{\mathrm{xm}}=0.19, \beta_{\mathrm{my}}=\right.$ $-0.43, z=-2.54 *)$. Expressive support seeking also partially and negatively mediates the relationship between identification after dissolution and positive word-of-mouth $\left(\beta_{x m}=0.19, \beta_{m y}=-0.38, z=-2.49 *\right)$. This means that expressive support seeking, as explained by MacKinnon, Krull and Lockwood (2000), suppresses the positive effect that identification after dissolution has on return intention.

\subsection{Discussion Study 1}

With this study, a framework was established for customer response in the post-dissolution phase of customer-brand relationships. The results show that customers are not 'done' with a brand after the dissolution of a relationship, but instead go through a postdissolution phase in which they use cognitive processing in order to make sense of the situation and determine how to behave towards the brand in the future. The first and possibly most important finding is that even though a customer decided to dissolve the relationship, this customer is not truly lost to the brand. Identification with the brand after dissolution is a strong and positive motivational source, which has an impact on both return intention as well as positive word-of-mouth with respect to the old brand, independent of attribution. Investing in a healthy customer-brand relationship in terms 
of identification during the relationship thus even pays off after this relationship has been dissolved, irrespective of the way it has been dissolved. Most likely, the brand is so strongly tied up in the social environment of the customer during the relationship, that this results in a deep love for the brand (Batra, Ahuvia \& Bagozzi, 2012) of which identification with the brand is one of the major determinants. Since the social environment does not change swiftly after the dissolution of the customer-brand relationship, identification with the brand is still, to some extent, nurtured by this environment, which facilitates the prolonged positive effects of identification after dissolution.

Identification does not only cause customers to behave positively towards the old brand, it also gives rise to coping responses in the form of both active coping as well as expressive support seeking. When a customer identifies with a brand in the post-dissolution phase, he or she has a higher need to cope with the ending. While coping responses are not mutually exclusive (Carver et al., 1989) and customers make use of both active coping as well as expressive support seeking when identifying with an old brand in the post-dissolution phase, these coping styles do have differential effects on the behavioral responses towards the brand. Active coping acts as a facilitator, as the use of this coping strategy positively influences both return intention as well as word-ofmouth. Active coping is infused with positive identification with the old brand and these positive feelings towards the situation have been found to counter negative emotions that could interfere with active coping efforts (Vélez, Wolchik, Tein \& Sandler, 2011) in an interpersonal relationship dissolution context. The effect of the internally directed processes in active coping that were found confirm the results of previous studies in the context of interpersonal relationship dissolution. Active coping has been described as a mechanism that puts thoughts of the dissolved relationship and behavior towards the dissolved relationship in line with each other, which increases predictability and lowers stress (Tein, Sandler \& Zautra, 2000). Thus, active coping causes the customer to reconcile their positive brand-identification with their thoughts of the old brand, which then, in turn, results in a positive outcome in terms of behavioral responses towards the old brand.

Expressive support seeking on the other hand acts as a supressor. When using expressive support seeking, customers deal with the ending in a more externally directed way in which they vent and look for support for their decision to dissolve the relationship. Using expressive support seeking has been related to better adjustment to the new situation after dissolution of a relationship in an interpersonal context (Tein et al., 2000) and, therefore, decreases the intention to return to the situation. Furthermore, the use of expressive support seeking leads to increased rumination, which hinders positive behavior towards a brand (Strizhakova et al., 2012). The use of expressive support seeking then suppresses the positive direct effect of identification with the old brand after dissolution on the behavioral intentions to the brand. 
When looking at the role of attribution in the post dissolution phase, it was found that identification fuels the use of coping strategies more when the customer internally attributes the dissolution of the relationship. With internal attribution, there is more room for positive cognitions related to the brand that come from identification, which is also referred to as the 'love is blind effect' (Grégoire \& Fisher, 2006). When externally attributing the dissolution, the coping process is fuelled by negative cognitions (Bonifield \& Cole, 2007), which are then inconsistent (Winkielman et al., 2012) with the positive identification with the brand that the customer experiences after dissolution. Therefore, we find a less prominent role of identification in relation to the coping styles when customers externally attribute the dissolution of the relationship.

Whereas the experience of internal attribution strengthens the positive relationship between active coping and positive word-of-mouth, external attribution strengthens the negative relationship between expressive support seeking and positive word-ofmouth. Attribution does, however, not influence the outcomes of the coping process when related to return intention. In previous research, it has been found that different emotions are attached to a certain type of attribution (Weiner, 2000). Where internal attribution has been found to lead to feelings of regret, which, in turn, positively influences behavioral intentions, external attribution leads to feelings of anger that negatively impact behavioral intention towards a brand (Bonifield \& Cole, 2007). This explains the moderating impact of attribution on positive word-of-mouth towards the old brand, but does not explain why this moderating impact was not found for return intention. When a person talks positively about the old brand after relationship dissolution, he or she does not actively have to come back to the dissolution decision.

Actually returning to the brand would make the effort that was involved in the dissolution redundant and a sunk-cost, and would cause dissonance in accepting that a mistake was made (Arkes \& Blumer, 1985). This is something that a customer would rather avoid. Thinking back of the dissolution while deciding to return would increase this dissonance, and the customer would want to avoid this by not thinking of the sunkcost while determining the return intention.

\subsection{Future Research and Conclusion}

During the course of this research, several limitations and interesting avenues for further research were discovered. First, to get more insight into the functioning of identification as a concept and as a sprocket in the bigger system of the post-dissolution phase, one might consider the role of brand love after relationship dissolution. Literature on brand love is just starting to reach full conceptualization (Batra et al., 2012) as is literature on the post-dissolution phase. Combining the two streams in the future may lead 
to an even better understanding of customers' processing in the post-dissolution phase with more insights for both theory as well as practice.

Second, based on the results of this study, it is recommended to look at the role of other concepts in the post-dissolution phase of customer brand relationships. For example, the role of attribution stability (Weiner, 2000), was previously mentioned, which could contribute to additional insight into the post-dissolution phase. Furthermore, an interesting avenue for future research would be the interacting influence of brand salience (Romaniuk \& Sharp, 2004) and identity salience and how this salience develops in the post-dissolution phase of customer brand relationships. By the design of this study, the old brand was made salient to the respondent. It could however be envisioned that there are differences in salience of the brand and of the related brand identity depending on the attribution and the time passed since the dissolution.

In conclusion, this chapter provided a comprehensive framework of the post-dissolution phase of customer brand relationships. The results show that positive behavioral intentions toward the old brand in the form of return intention and positive wordof-mouth are dependent on the context, as well as on the identification with the old brand, coping responses and attribution of the dissolution. In the next chapter, the framework that has been developed in the current chapter is transferred into the context of place branding in order to assess the generalizability of the developed framework across contexts. 
Chapter 4

\section{All's Well That Ends Well Part 2- Customer Brand Relationships In The Post-Dissolution Phase.}

Study 2 - Places and their Ex-Residents 


\subsection{Introduction}

In the previous chapter, the post-dissolution phase of a customer-brand relationship was reviewed and a theoretical framework for this phase was set up and tested. In the current chapter, the scope of this research is broadened. The study that is introduced in the current chapter sheds a different light on the theory of the post-dissolution phase of customer-brand relationships by applying the model to the boundary condition of place branding. According to Kaplan et al. (2010), place branding is developing into an area of interest for marketers. This follows the trend that the definition of product marketing is expanding into the field of non-profit marketing, social marketing and image marketing.

As extensively reviewed in Chapter 2, the applicability of current marketing and branding concepts from products or services marketing to place branding is questioned (e.g. Anholt, 2008), but has, to the best of our knowledge, not been explicitly tested. In place branding, there is always a preexisting image of the brand (Skinner, 2008), which is formed by for example history, heritage and culture (Dinnie, 2004; Dinnie, 2008). Furthermore, one is dependent on external factors like politics, geographical conditions, economic conditions and residents' characteristics (Kaplan et al., 2010) which makes customer decision-making related to places a complex process (Balakrishnan, 2009). In the post-dissolution phase of customer-brand relationships, however, ex-customers also have a myriad of experiences and previous knowledge about the brand and, therefore, go through a complicated experiential process as well.

Hence, the purpose of this chapter is to first and foremost address the issue of transferability of products and services marketing concepts to place branding. Consequently, the extent to which the theories and resulting framework as discussed in Chapter 3 can be transferred to the post-dissolution phase of a customer-brand relationship in the place branding context is investigated. A second goal of this research is to obtain deeper insight into the post-dissolution phase of a customer-brand relationship in a place branding context, thereby contributing to literature on both relationship marketing as well as place branding, which has, to date, suffered from a lack of empirical research (Hanna \& Rowly, 2011). Third, in previous research, places, and especially places of residence, have been recognized to play an important role in the identity formation of a person (Dixon \& Durrheim, 2000; Hanna \& Rowley, 2008; Kemp et al., 2012a; Kaplan et al., 2008; Cicognani et al., 2011). With the current research, the importance of identification with an old place of residence is explored.

In order to study the role of identification in the post-dissolution phase of a customer-brand relationship with a place brand, a real life study has been conducted amongst people who moved away from a mid-sized European city in the last year. Sub- 
jects were questioned about their attribution, coping, identification and behavior regarding their old city of residence. The results of study 2 on places and their ex-residents in the current chapter are similar to study 1 on products and services and their ex-customers with respect to the direct relationship between identification with the old brand after dissolution and a respondents' behaviors towards their old city of residence. As in the previous chapter, identification positively influences return intention as well as word-of-mouth towards the previous city of residence. Nevertheless, the place branding context that is studied in this chapter also points to some varying results. In this context, coping does not have the expected effect on the behavioral responses, nor does it mediate the relationship between identification and return intention or word-of-mouth. Moreover, positive word-of-mouth is completely independent of any coping influence and is solely dependent on identification with the old brand. This suggests that coping processes and the resulting positive behaviors towards the old brand in the post-dissolution phase differ strongly based on whether the dissolution took place in a products or services context or in a place branding context. Based on the current research, it is concluded that the post-dissolution phase differs when compared to a products and services context. Consequently, when conducting research on place branding, one needs to thoroughly look at the characteristics of a place as a brand on some levels. For example, identification and word-of-mouth seem to be transferrable while other concepts, such as coping, seem to play a lesser role. These results present a scientific basis for skepticism about transferability of concepts that has been uttered in place branding literature for some time, while the importance of other concepts, like identification, holds across the two contexts.

The study in the current chapter adheres to the theoretical framework that was developed in Chapter 3. To avoid repetition, the previously proposed framework will not extensively be deliberated upon in the current chapter. However, the most important variables leading to the hypotheses are shortly addressed, and placed in parallel to the place branding context in order to justify the extension across contexts.

\subsection{The Post-Dissolution Phase}

The post-dissolution phase was defined in the previous chapter as the period of absence of a customer from a certain brand (Stauss \& Friege, 1999), which is initiated by the end of behavioral exchange (Bogomolova, 2010) viewed from a customer perspective. The start of the post-dissolution is often hard to recognize for managers as customers neglect to voice the ending of their relationship with the (products or services) brand (Stauss \& Friege, 1999). The same definition of the post-dissolution phase is adhered to in this chapter and express the end of behavioral exchange is expressed as the move of 
a resident to another place, thereby ending the direct relationship with the place as a resident and marking the beginning of the post-dissolution phase. This implies that the relationship ending with a place brand, and therefore the beginning of the post-dissolution phase, is easier to observe for a place brand manager as the resident has to subscribe to the local government of the new residence, thereby automatically unsubscribing from their old place of residence and ending their 'brand consumption' as a resident.

\subsection{Identification in the Post-Dissolution Phase}

People are becoming more mobile due to globalization and they leave places with less desirable characteristics to move to places where they can fully develop their individual interests and skills (Hanna \& Rowley, 2008). In this way, people choose to move to a place where there is a match between the personal identity of the resident and the brand identity of the place (Kaplan et al., 2010). Still, like in a products and services context, the old place of residence is not forgotten and the connection with the brand is expected to endure beyond the official dissolution of the relationship (OdekerkenSchröder et al., 2010). While living in the place, a person has experiences and memories that forever tie to this place and create a sense of identification (Stokburger-Sauer et al., 2012) similar to the identification with a products or services brand as described in the previous chapter. Therefore, mimicking the definition of identification in Chapter 2 , identification in this chapter is defined as the cognitive inclusion of a place brand in a person's concept of the self (Bhattacharya et al., 1995; Bhattacharya \& Sen, 2003).

Return intention (i.e. renewing the consumption behavior of the brand as a resident or a customer) as well as positive word-of-mouth have been termed as variables of interest in the previous chapter as these concepts are known to be positive consequences of identification with a brand during the relationship (Keh \& Xie, 2009; Brown et al., 2005; Tuškej et al., 2011). Next to their relevance during the brand relationship, these concepts are also of importance after the relationship has been dissolved (Hospers, 2011), as they depict whether a person will return to the brand and fulfill an ambassador function for the brand. In the context of place branding, this implies both the intention of a person to return as a resident as well as the ambassadorship of this person in his or her new place of residence.

Given the assumed identification with a place brand during the post-dissolution phase and the known existence of return intention and positive word-of-mouth as positive consequences of identification, the following hypothesis was defined: 
H1a\&b: Given that a resident identified with a place brand during the relationship, the level of identification after the relationship dissolution has a positive impact on (a) re-

turn intention and (b) positive word-of-mouth related to the old place brand.

\subsection{Coping}

In the current literature, it is known that after dissolving the relationship with a brand, a person goes through a cognitive process in order to incorporate the new situation into their identity (Halinen \& Tahtinen, 2002) as well as to determine their future behavior towards the brand (Sweeny, 2008). Coping is recognized as one of the cognitive responses during the post-dissolution phase of a customer-brand relationship (Bogomolova, 2010) that assists in adapting the social identity of a person to a state that is independent of the brand (Tajfel \& Turner, 1986). The adjustment process to the new residence after a move is expected to involve multiple elements of coping with moving away from their old place of residence and is, therefore, comparable with the coping process in a products and services context.

In Chapter 3, a review of different coping mechanisms is included based on a conceptualization by Duhachek (2005) with a focus on active coping and expressive support seeking. Whereas active coping is an internal method primarily aimed at problem-solving (Tsarenko \& Strizhakova, 2012), expressive support seeking is externally directed and includes other individuals in the coping process as a means of support (Jun \& Yeo, 2012). Given that a customer identifies with the old place of residence, a higher level of identification is expected, resulting in stronger coping efforts. Therefore, it is hypothesized that:

H2a\&b: The level of customer-brand identification after dissolution positively impacts the use of (a) active coping strategies and (b) expressive support seeking strategies in

the post-dissolution phase of customer-brand relationships with a place brand.

The expectations related to the use of coping strategies in the products and services context are based on consistency theory (Heider, 1958; Aronson, 1969), which implies that people attempt to keep their thoughts and behaviors consistent. In using active coping, the person tries to align the behavior of moving to a new place of residence to his or her internal cognitions about the old place, which are still positive as they are influenced by positive identification. It is expected that this mechanism results in positive behavior towards the old place of residence. Although this person has moved, and essentially left the place brand, he or she still thinks positively about the place and, therefore, behaves in a positive way towards this brand as compensation for leaving, in 
order to align his or her own thoughts with his behavior. Therefore, it is hypothesized that:

H3a\&b: The use of active coping strategies in the post-dissolution phase of customerbrand relationships with a place brand positively impacts behavior towards the old place brand in the form of (a) return intention and (b) positive word-of-mouth.

Whereas active coping is an internal coping method, in using expressive support seeking, people look for support among friends and relatives (Carver et al., 1989) for the problems and concerns that they have around the dissolution of their relationship with the place brand. As these problems and concerns are related to negative cognitions, consistency theory depicts that the resulting behavior towards the old place of residence is also expected to be negative in order to avoid any damage to the self-image (Winkielman et al., 2012) of the resident. This results in the following hypothesis:

H4a\&b: The use of expressive support seeking strategies in the post-dissolution phase of customer-brand relationships with a place brand negatively impacts behavior towards the old place brand in the form of (a) return intention and (b) positive word-ofmouth.

\subsection{Attribution}

The last part of the conceptual framework as defined in Chapter 3 takes the attribution of the dissolution into account as a moderating factor. When there is internal attribution and the resident moves due to reasons beyond the control of the old place brand, the positive cognitions about the old place of residence are not harmed (Odekerken-Schröder et al., 2010) and the resident is expected to make more use of active coping as a consequence of this positive state towards the place brand. This, in turn, leads to more positive behavior towards the place brand (Garnefeld et al., 2011), strengthening the relationships between identification, the use of active coping strategies and the behavioral variables of return intention and word-of-mouth.

H5a: Attribution moderates the relationship between the level of customer-brand identification with a place brand after dissolution and the use of active coping strategies in the post-dissolution phase of customer relationships such that the relationship is strongest in the case of internal attribution. 
H5b\&c: Attribution moderates the relationships between the use of active coping strategies in the post-dissolution phase of customer-brand relationships with a place brand and (b) return intention and (c) positive word-of-mouth such that the relationships are strongest in the case of internal attribution.

In the case of external attribution, the resident moves due to factors that are related to the old place of residence that drove the resident away and results in negative brand associations. The use of expressive support seeking is then a way to cope through blaming the old place of residence (Tsarenko \& Strizhakova, 2012) and relive negative emotions that are attached to the dissolution (Yi \& Baumgartner, 2004). The use of expressive support seeking makes the negative associations to the old place brand salient as the ex-resident talks about the place brand in a negative way. Self-perception theory (Greenwald, 1975) suggests that a person infers behavior from their current attitudes. As the attitude towards the old place brand is more negative in the case of external attribution, a moderating effect is expected of external attribution on the relationship between identification and expressive support seeking as well as on the relationship between expressive support seeking and the behavioral variables of return intention and positive word-of-mouth. It is, therefore, hypothesized that:

H6a: Attribution moderates the relationship between the level of customer-brand identification with a place brand after dissolution and the use of expressive support seeking strategies in the post-dissolution phase of customer relationships such that the relationship is strongest in the case of internal attribution.

H6b\&c: Attribution moderates the relationships between the use of expressive support seeking strategies in the post-dissolution phase of customer-brand relationships with a place brand and (b) return intention and (c) positive word-of-mouth such that the link is weakest in the case of internal attribution.

The hypotheses that are described above are visualized in the conceptual framework as depicted in Figure 4.1. This conceptual framework is identical to the framework as described in Chapter 3. 


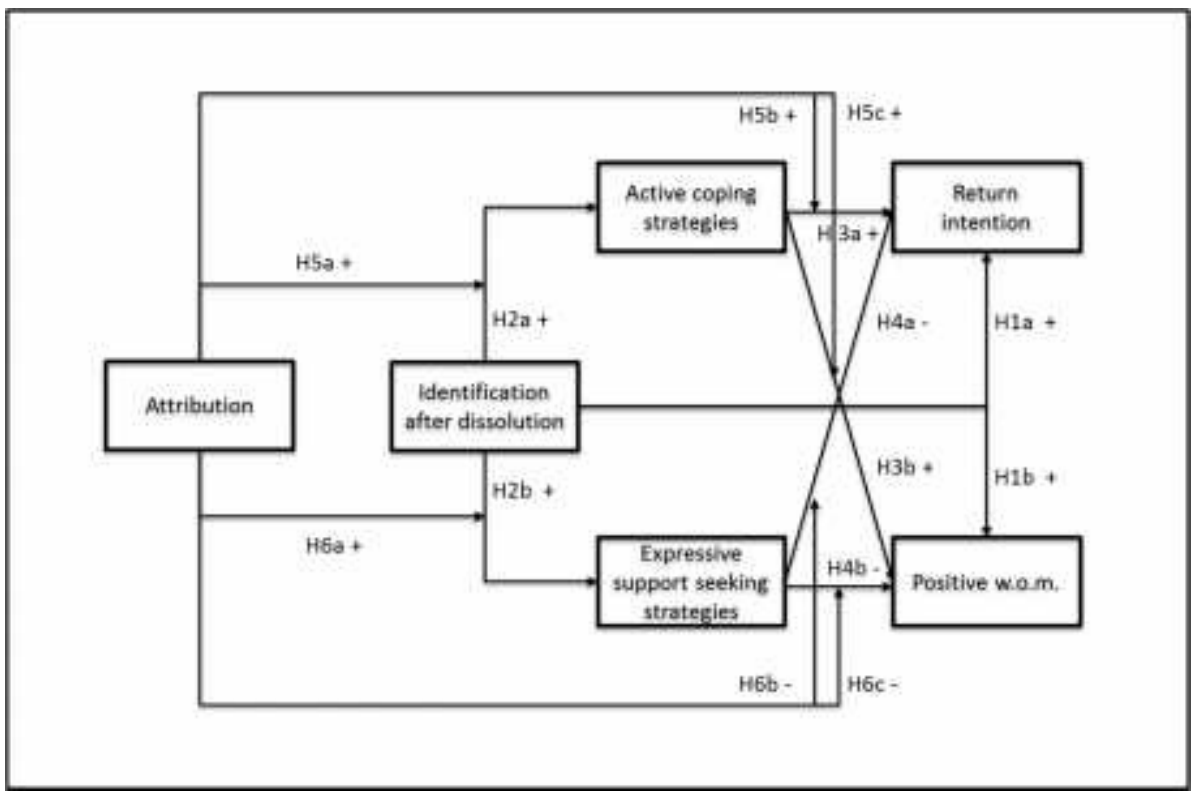

Figure 4.1 Conceptual framework study $2^{7}$

7 The moderating influences concern the influence of internal attribution. A + indicates the relationship is expected to be strongest when attribution is internal, $\mathrm{a}$ - indicates the relationship is expected to be weakest when attribution is internal. 


\section{Study 2 - Places and their Ex-Residents}

\subsection{Research Method}

\subsubsection{Sample and Procedure}

The data for this study was collected in cooperation with a mid-sized European city. One thousand people that moved away from the city in the past year were selected from the city records and received a letter asking them to participate in a research about their moving motives and their current connection to their former habitat. The former residents who received a letter were asked to go to the website of the municipality and participate in an online questionnaire. In the online questionnaire, they answered questions on their former city of residence, their current city of residence, their moving motives as well as the variables that were incorporated into our research framework.

The data collection approach resulted in 151 responses. After deleting the respondents who did not complete the questionnaire, a final sample of 110 responses was left equaling a response rate of $11.0 \%$. Respondents' characteristics showed that $45.5 \%$ of the respondents were male, $57.3 \%$ of the respondents were less than 40 years old, and most of the respondents had some form of secondary education (76.4\%). The larger share of respondents currently lived in a rented (58.2\%) as opposed to a bought (41.8\%) home, most of the respondents lived in a family constellation (78.2\%) as opposed to living alone $(21.8 \%)$ and $67.3 \%$ did not relocate beyond the borders of the province.

\subsubsection{Psychometric Properties of the Measurement}

In the current study, the same scales for the core variables were used as in study one which are presented and referenced in Appendix A of this dissertation. Instead of identification before ending, which was used as a control variable in the first study, the customer's connection to the old region brand was used as a control and proxy for identification before ending. This option was chosen because in a place branding context, it is not clear that ties with a place are completely cut after moving away from the place. The respondent may still have friends or family in the old place of residence, which could bias the results. A customer's current ties to the old region brand were objectively measured. Respondents were given six possible ties to the region (e.g.: I was born in this region, I have friends in this region) and the number of ties respondents had with the region were counted, leading to a scale of one to six where six is the highest level of connection to the old region brand.

In the first study, attribution was assessed with a categorization. However, since this categorization is not straightforward in a place branding context (i.e. the question 
of who is to blame for your move, is impossible to answer), attribution was therefore measured with a one item construct that asked respondents to indicate the extent to which their move had to do with factors related to the old city of residence. This way, the item provides a proxy for attribution with a low score indicating internal attribution and a high score indicating external attribution. The scale of the attribution variable was used to create interaction effects that are used to assess the moderating effects of hypotheses 5 and 6 .

As in our first study, Smart PLS 2.0 M3 was used to obtain the model parameters. The psychometric properties of the measurement scales were reassessed by evaluating validity and reliability for the current sample. To make sure convergent validity of all items is above the cut-off value of 0.7 (Hair et al., 2006), some items were removed from the various constructs. Consequently, the AVE of the constructs varied between 0.61 and 0.93, exceeding the cut-off value of 0.5 (Fornell \& Larcker, 1981). Composite reliability for which we use a cut-off value of 0.7 (Nunnally \& Bernstein, 1994) ranges between 0.87 and 0.98 , so it is concluded that the constructs are reliable. As is shown in Table 4.1, discriminant validity is also established since all square roots of the AVE exceed all other correlations in the model (Barclay et al., 1995; Chin, 1998).

Table 2.1 Discriminant validity and descriptive statistics study 2

\begin{tabular}{|l|l|l|l|l|l|l|l|l|}
\hline & Mean & SD & $\mathbf{1}$ & $\mathbf{2}$ & $\mathbf{3}$ & $\mathbf{4}$ & $\mathbf{5}$ & $\mathbf{6}$ \\
\hline $\mathbf{1}$ Active Coping & 4.87 & 1.43 & $\mathbf{0 . 7 9}$ & & & & & \\
\hline $\mathbf{2}$ Connection & 4.39 & 1.67 & -0.05 & $\mathbf{N . A .}$ & & & & \\
\hline $\mathbf{3}$ Expressive Support Seeking & 3.72 & 1.51 & 0.47 & 0.03 & $\mathbf{0 . 7 8}$ & & & \\
\hline $\mathbf{4}$ Identification after & 3.26 & 1.59 & 0.01 & 0.06 & 0.31 & $\mathbf{0 . 8 4}$ & & \\
\hline $\mathbf{5}$ Return intention & 2.47 & 1.59 & -0.39 & 0.20 & 0.02 & 0.35 & $\mathbf{0 . 8 8}$ & \\
\hline $\mathbf{6}$ Positive W.O.M. & 4.18 & 1.91 & 0.01 & 0.10 & 0.21 & 0.55 & 0.45 & $\mathbf{0 . 9 6}$ \\
\hline
\end{tabular}

\subsection{Results Study ${ }^{8}$}

As in the first study, bootstrapping with 1000 resamples was used to obtain standard errors for parameters in the model. In all analyses, the connection with the region was included as a control variable. The descriptive statistics of the analyses are presented in table 4.1.

8 We report the beta-values and standard errors of the analyses. Significance of the one-sided hypotheses is indicated with an asterisk. For marginally significant results $0.1>p>0.05=t$, for significant results $0.05>p>0.001$ $=*$ and for highly significant results $\mathrm{p}<0.001=* *$. 


\subsubsection{Overall Model Fit}

The $\mathrm{R}^{2}$ of the model has an average value of 0.15 . In addition to this, the GOF was calculated for the model. The GOF statistic is 0.33 , indicating a moderate to strong fit of or model (Tenenhaus et al., 2005). Finally, a blindfolding procedure in SmartPLS was conducted in order to assess the predictive value of our model. The values for the construct cross validated redundancy range between 0.01 and 0.29 . Since these values are larger than zero we can conclude that our model has enough predictive power for conducting the analyses.

\subsubsection{Identification and Return Intention and Word-Of-Mouth}

Hypothesis 1 depicts a positive influence of identification after dissolution on (a) return intention and (b) positive word-of-mouth. Also, when looking at place brands instead of products or services brands, we find support for this hypothesis. The stronger the identification with the old brand after dissolution, the more customers are inclined to return to the city $\left(\beta=0.34^{* *}, \mathrm{SE}=0.09\right)$ and the more they talk positively about the place brand $\left(\beta=0.55^{* *}, S E=0.08\right)$. Therewith, we find support for hypothesis $1 \mathrm{a}$ and hypothesis $1 \mathrm{~b}$. Also, in the context of place branding, identification proves to be a valuable tool for assessing positive behavior towards the old brand in the post-dissolution phase.

\subsubsection{Identification and the Use of Coping Strategies}

In hypothesis $2 a$ and $2 b$ the influence of identification on the use of active coping and expressive support seeking strategies were assessed. No support was found for hypothesis $2 a$ in this study $(\beta=0.01, S E=0.12)$, which implies that the use of active coping strategies is not infused with identification with the old brand after dissolution. We do find support for hypothesis $2 b$, as the more people identify with the old place brand after dissolution, the more they make use of expressive support seeking strategies in the postdissolution phase $(\beta=0.31 * *, S E=0.10)$.

\subsubsection{The Use of Active Coping Strategies and Return Intention and Word-Of-Mouth}

Hypothesis 3 depicts a positive impact of the use of active coping strategies on return intention ( $\mathrm{H} 3 \mathrm{a}$ ) and positive word-of-mouth ( $\mathrm{H} 3 \mathrm{~b})$. We do not find support for hypothesis $\mathrm{H} 3 \mathrm{a}$ as the use of active coping has a significant negative impact on return intention $\left(\beta=-0.44^{* *}, S E=0.11\right)$ instead of the positive effect that was predicted and found in study 1 . Thus, when customers make use of active coping, this negatively influences their intention to return to the old brand. Additionally, no support is found for hypothesis $3 \mathrm{~b}$ 
as the use of active coping strategies does not have a significant impact on how positively customers speak about their old place brand $(\beta=-0.02, \mathrm{SE}=0.11)$.

\subsubsection{The Use of Expressive Support Seeking Strategies and Return Intention and Word- Of-Mouth}

A negative effect of expressive support seeking on both return intention and positive word-of-mouth was depicted in hypotheses $\mathrm{H} 4 \mathrm{a}$ and $\mathrm{H} 4 \mathrm{~b}$, respectively. As a result of the SmartPLS analyses, it was found that the use of expressive support seeking marginally increases the intention to return instead of the predicted negative effect $(\beta=0.13 \dagger$, $\mathrm{SE}=0.09$ ). Word-of-mouth, on the other hand is not influenced by the expressive support seeking strategies $(\beta=0,05, S E=0.13)$. Thereby, hypothesis $4 a$ and $4 b$ are not supported.

\subsubsection{The Moderating Role of Attribution}

The moderating role of attribution in this study was assessed using the approach as suggested by Chin, Marcolin and Newsted (2003). A one-item attribution scale was used. The attribution variable was included in the model as a moderator and the analyses were rerun interpreting the created interaction terms shows whether attribution moderates the relationships in the model.

\subsubsection{Attribution and The Use of Active Coping Strategies}

In hypothesis 5a, it was depicted that the relationship between identification with the old place brand and the use of active coping strategies is moderated by attribution, such that the positive relationship is strongest for internal attribution. Support was found for hypothesis $5 a(\beta=-0.19 *, S E=0.10)$. Since the beta for this moderation is negative, it can be concluded that when customers externally attribute the ending, the influence of identification on active coping decreases when compared to internal attribution, which supports hypothesis $5 a$.

Hypothesis $5 \mathrm{~b}$ predicts the moderating influence of attribution on the relationship between the use of active coping strategies and a customer's intention to return to the old brand, such that the positive relationship is strongest for internal attribution. However, a negative direct relationship was found instead of the hypothesized positive relationship. Translating this to the current hypothesis, the negative relationship is expected to be weakest for internal attribution. When analyzing, the negative relationship between active coping and return intention is indeed found to be weaker for customers who experience internal attribution than for customers who experience external attribution $\left(\beta=0.33^{*}, S E=0.18\right)$. This supports hypothesis $5 b$ given that the direct relationship 
between active coping and intention to return to the old brand was found to be negative instead of positive as was predicted.

Hypothesis $5 c$ assesses whether attribution moderates the influence of the use of active coping strategies on positive word-of-mouth behavior towards the old brand, such that the relationship is strongest for internal attribution. Here, no significant moderation was found $(\beta=-0.12, S E=0.12)$ and thus no support for hypothesis $5 c$.

It can thus be concluded that customers who experience external attribution are less likely to make use of active coping strategies than customers who experience internal attribution. But if they use active coping, they are less likely to return to their old place of residence.

\subsubsection{Attribution and the Use of Expressive Support Seeking Strategies}

Hypothesis 6a, in turn, depicts a moderating influence of attribution on the relationship between identification with the old place brand after dissolution and the use of expressive support strategies such that the positive influence of identification is least strong when customers externally attribute the ending. A strong moderation was indeed found, with a negative beta $\left(\beta=-0.34^{* *}, \mathrm{SE}=0.08\right)$, implying that when customers experience external attribution, the use of expressive support seeking strategies is significantly less based on identification after dissolution than when experiencing internal attribution, which supports hypothesis $6 a$.

In hypothesis $6 \mathrm{~b}$, the predicted moderating effect of attribution on the negative relationship between expressive support seeking and return intention relationship is strongest in the case of external attribution. A moderating effect is found where attribution negatively moderates the relationship between the use of expressive support seeking strategies and return intention $(\beta=-0.27 *, S E=0.16)$. When experiencing external attribution, the relationship between the use of expressive support seeking strategies and return intention is weaker than when experiencing internal attribution instead of the hypothesized positive effect. However, since the direct effect of expressive support seeking on return intention is also reversed, it can still be concluded that there is support for hypothesis $6 b$.

Lastly, hypothesis $6 c$ depicts a moderating influence of attribution on the relationship between the use of expressive support seeking strategies and positive word-ofmouth towards the old place brand. No support is found for hypothesis $6 c(\beta=-0.02$, $\mathrm{SE}=0.17$ ) and it can be concluded that attribution does not moderate the relationship between expressive support seeking and positive word-of-mouth. 
In figure 4.2 and table 4.2 below, the results of the study are summarized. Bold lines in the figure indicate support for the hypothesis, interrupted lines indicate no support for the hypothesis.

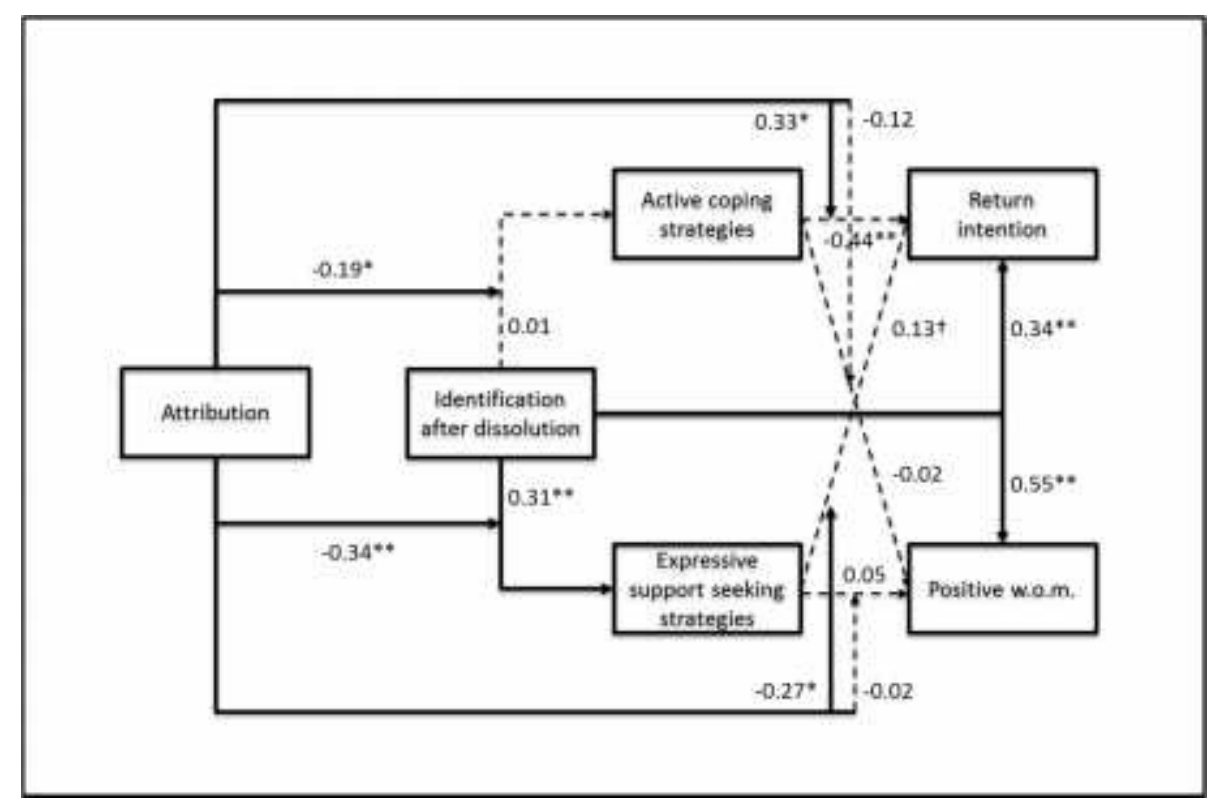

Figure 4.2 Results overview study $2^{9}$

9 Bold lines indicate support for the hypothesis, interrupted lines indicate no support for the hypothesis. $0.1>p>0.05=+, 0.05>p>0.001=* p<0.001=* *$ 
Table $4.2^{10}$ Results overview study 2

\begin{tabular}{|c|c|c|c|c|}
\hline & Hypotheses & Coefficient & SE & Finding \\
\hline H1a & Identification after $\rightarrow$ Return intention & $0.34 * *$ & 0.09 & Supported \\
\hline H1b & Identification after $\rightarrow$ Positive w.o.m. & $0.55^{* *}$ & 0.08 & Supported \\
\hline $\mathrm{H} 2 \mathrm{a}$ & $\begin{array}{l}\text { Identification after } \rightarrow \text { Active coping } \\
\text { strategies }\end{array}$ & 0.01 & 0.12 & Not supported \\
\hline $\mathrm{H} 2 \mathrm{~b}$ & Identification after $\rightarrow$ Expressive support seeking & $0.31^{* *}$ & 0.10 & Supported \\
\hline H3a & $\begin{array}{l}\text { Active coping strategies } \rightarrow \text { Return } \\
\text { Intention }\end{array}$ & $-0.44 * *$ & 0.11 & Not supported \\
\hline H3b & Active coping strategies $\rightarrow$ Positive w.o.m. & -0.02 & 0.11 & Not supported \\
\hline $\mathrm{H} 4 \mathrm{a}$ & $\begin{array}{l}\text { Expressive support seeking } \rightarrow \text { Return } \\
\text { intention }\end{array}$ & $0.13+$ & 0.09 & Not supported \\
\hline $\mathrm{H} 4 \mathrm{~b}$ & Expressive support seeking $\rightarrow$ Positive w.o.m. & 0.05 & 0.13 & Not supported \\
\hline H5a & $\begin{array}{l}\text { Identification after * Attribution } \rightarrow \text { Active coping } \\
\text { strategies }\end{array}$ & $-0.19 *$ & 0.10 & Supported \\
\hline $\mathrm{H} 5 \mathrm{~b}$ & $\begin{array}{l}\text { Active coping strategies * Attribution } \rightarrow \text { Return } \\
\text { intention }\end{array}$ & $0.33^{*}$ & 0.18 & Supported \\
\hline H5c & $\begin{array}{l}\text { Active coping strategies * Attribution } \rightarrow \text { Positive } \\
\text { w.o.m. }\end{array}$ & -0.12 & 0.12 & Not supported \\
\hline $\mathrm{H6a}$ & $\begin{array}{l}\text { Identification after } * \text { Attribution } \rightarrow \\
\text { Expressive support seeking }\end{array}$ & $-0.34 * *$ & 0.08 & Supported \\
\hline $\mathrm{H} 6 \mathrm{~b}$ & $\begin{array}{l}\text { Expressive support seeking strategies * } \\
\text { Attribution } \rightarrow \text { Return intention }\end{array}$ & $-0.27 *$ & 0.16 & Supported \\
\hline H6c & $\begin{array}{l}\text { Expressive support seeking strategies * } \\
\text { Attribution } \rightarrow \text { Positive w.o.m. }\end{array}$ & -0.02 & 0.17 & Not supported \\
\hline
\end{tabular}

\subsubsection{Mediation Test}

As the results did not show a relationship between identification and active coping, the mediating effect of active coping could not be tested for. Next to this, the lack of signif-

$100.1>p>0.05=+, 0.05>p>0.001=* p<0.001=* *$ 
icant results for the relationships between coping and word-of-mouth ensures the mediating effect cannot be tested here either. However, the mediating influence of expressive support seeking in the relationship of identification with the old place brand after dissolution and return intention was tested for by conducting a Sobel (1982) test. The Sobel test shows no significant mediation of expressive support seeking in the relationship between identification with the old brand after dissolution and return intention $\left(\beta_{\mathrm{xm}}=0.31, \beta_{\mathrm{my}}=0.13, z=1.24\right)$. The mediating influences of coping on the relationship between identification and return intention and word-of-mouth that were found in study one could thus not be replicated in the current study.

\subsection{Discussion Study 2}

In the second study of the current dissertation, the hypothesized framework towards as conceptualized in Chapter 3 was extended to the area of place branding. The results show that identification with the old place brand after dissolution remains an important driver of behavior towards the old place brand during the post-dissolution phase. With this, identification proves to be an important asset not only across time, but also across contexts. However, the mediating role of coping could not be replicated in the place branding context.

A possible explanation for the limited role of coping is that coping in a place branding context might partly take place before the actual dissolution. When a customer is relocating, this is a long-term process due to administrative issues, and the customer has abundant time to prepare him or herself for the dissolution that is going to happen or reconsider the decision to move. In the case of place branding, it is possible that the customer already made use of so-called proactive coping (Beehr \& Mc Grath, 1996; Schwarzer \& Tauber, 2002) in which the customer copes with an event before it actually happens. Proactive coping is most used when dealing with situations of personal growth, as a way of goal management instead of risk management (Greenglass \& Fiksenbaum, 2009) and has been shown to positively interact with place attachment (Bogdan, Rioux \& Negovan, 2012). Coping happens as a response to positive or negative stress, which is, in turn, caused by a stressor (Schwarzer \& Tauber, 2002). When a customer moves from one city to another, the stressor (the decision to move and its consequences) and the action (the actual move) are always timely separated, giving a customer time to cope with aspects of the move (e.g. moving away from family, leaving a place behind) before the actual move takes place. This makes the post-dissolution phase in a place branding context more complicated.

Coping still exists in the post-dissolution phase in place branding, as is shown by the findings of our model where the coping responses have an even higher mean value 
than in the context of products and services branding. Coping, however, does not show the expected relationships to the behavioral responses as was predicted in our hypotheses. It was found that active coping has a significant negative instead of positive influence on return intention. Furthermore, active coping is not influenced by positive identification with the old brand. Active coping is, in this context, a form of reactive coping, which is used to align the cognitions with the behavior related to an event in the past that happened with absolute certainty (Schwarzer \& Tauber, 2002) and is hard to reverse. Dissolving the relationship with the place by moving elsewhere is hard to reverse and, therefore, active coping decreases the chances of returning instead of increasing this behavioral intention like it was hypothesized. This method is used reactively to increase consistency in the customer's mind (Winkielman et al., 2012). This finding is strengthened by our moderating effect, which shows that if a person dissolved the relationship with the place because of external factors, the negative relationship between active coping and return intention is stronger. Since the customer feels that the move was due to environmental factors instead of internal factors, the dissolution is perceived as even more definite.

Expressive support seeking, on the other hand, shows a marginal positive effect on intention to return to the previous city while a negative effect was hypothesized. Furthermore, expressive support seeking is infused with positive identification with the old brand, which partly inhibits the customers to adjust to their new environment (Hendrickson, Rosen \& Aune, 2011). In proactive coping, customers have confirmed their decisions in a positive way to construct opportunities for the future (Greenglass \& Fiksenbaum, 2009). However, when these opportunities do not play out well, the customer might experience regret or feelings of homesickness for which customers seek support. Especially when looking for support in their old environment, this leads to increased feelings of wanting to return (Hendrickson et al., 2011) to the old brand. This argument is supported by the findings of our moderating effect, where the positive influence of expressive support seeking on return intention is larger in the case of internal attribution. So, when the decision is more reversible, people seek more help from their environment.

Interestingly, it was found that word-of-mouth in a place branding context is solely influenced by positive identification with the old city brand. This finding has positive implications for place branding institutions. When ex-residents identify with their old habitat, they will talk positively about the brand without this effect being influenced by either coping or attribution. This means that the foundation for positive word-of-mouth after dissolution is built solely during the relationship and is not compromised by the dissolution or its consequences. Place branding managers have been struggling with the transfer of products and services marketing tools to the place branding context and found that the effect of marketing campaigns did not stimulate behavior as much as 
they did in a products and services related context (Anholt, 2008). It is worth investigating if word-of-mouth, which is seen as a more powerful source of information than marketing campaigns (Balakrishnan, 2009), can start to play a more important role in place branding so that inhabitants can be used as a new and powerful tool for place branding.

\subsection{Future Research and Conclusion}

In conclusion, the current chapter shows a partial generalization of the framework as developed in Chapter 3 into the post-dissolution phase of a relationship with a brand in the place branding context. The results show that people can still identify with a place, even if they do not live there anymore, and that this identification has positive consequences for their intention to return to the old city of residence as well as talk positively about it. The identification with the old place of residence also leads to a coping response, but the coping response only partially influences the behavior of the ex-residents in an unexpected way. Most likely this is due to proactive coping efforts.

Extending the framework, as defined in Chapter 3, to the context of place branding results in some interesting avenues for further research. First, following Anholt (2008), the results of the study show that concepts that are grounded in products and services marketing cannot one-to-one be transferred to the field of place branding. Although identification and its relationship with behavioral variables of word-of-mouth and return intention appears to be extremely stable, coping plays a differential role across contexts. Further research into which concepts are transferrable to a place branding context is therefore advisable.

Second, this research shows a need for a deeper investigation into the post-dissolution phase in a place branding context. The results of the current study call for a focus on proactive coping (Beehr \& Mc Grath, 1996; Schwarzer \& Tauber, 2002) in a place branding context as well as the use of word-of mouth as a tool for place branding managers. Finally, as the post-dissolution phase in a place branding context is always paired with an adaptation phase to a new place of residence, an interesting avenue for further research concerns the rebalancing of identities related to the old and new places of residence. In the next chapter of this dissertation, this last recommendation is addressed as the rebalancing of identities and the adaptation process of a resident after a are reviewed. 

Chapter 5

\section{Talking Places - The Development Of Word-Of- Mouth As A Tool For Place Branding.}

Study 3 - Balancing Place Identities 


\subsection{Introduction}

With an employment population decreasing from $64 \%$ in 2010 to an expected $52 \%$ in 2050 (Eurostat, 2012), there is a general realization in the European Union that the way the population is composed, and consequently, the way the economy functions, will undergo a radical change in the coming years. This phenomenon is accompanied with a threat of regional population decrease (Hospers, 2012; Galjaard, Van Wissen \& Van Dam, 2012) and results in a need to attract and maintain investments and inhabitants in diverse cities, regions and countries (Riza et al., 2011; Kotler \& Gertner, 2002; Medway et al., 2010; Hospers, 2006). These developments create the need to cultivate the place as a brand (Konecnik Ruzzier \& De Cheratony, 2013). Place brands however, have an increased level of complexity when compared to products and services brands (Dinnie et al., 2009), which is based on the large number of stakeholder groups involved in the place brand as well as the need for participation in the place brand creation by these stakeholder groups (Kemp et al., 2012b). The use of traditional marketing strategies renders the place branding processes often inefficient (Anholt, 2008) and results in a lack of control of the place brand image and identity (Kavaratzis \& Hatch, 2013).

Inhabitants are one of the stakeholder groups that are important for the identity of the place brand, as they create and live the brand (Konecnik Ruzzier \& De Cheratony, 2013). and consequently influence the place brand equity and image of a place (Merrilees et al., 2009; Choo et al., 2011). In the current research, it is suggested that place brand managers can make more use of this crucial role of inhabitants. Instead of seeing stakeholders in general and inhabitants specifically as a complicating factor in the place branding process, The results of this study show that (ex)inhabitants can be an asset for the place brand as well.

The large influence of residents on a place brand comes from the fact that in general, they are perceived by potential residents to be highly reliable in their information provision as they have no economic gains when talking about a place (Choo et al., 2011) and are believed to be expert sources (Balakrishnan, 2009) by their audience. Research by Nielsen indicated word-of-mouth as the most trustworthy source of consumer information ( $90 \%$ of the customers indicated that they trusted recommendations from people they know) (Nielsen, 2009). Integrating residents into place branding efforts (Choo et al., 2011; Konecnik Ruzzier \& De Cheratony, 2013) therefore leverages the power of word-of-mouth and through this, can make place branding more effective since positive messages from residents can create positive experiences for other people (Choo et al. 2011).

Residents feel connected to their place of residence; they feel like a member of this place and use the place as an important tool to communicate their identity (Cuba \& Hummon, 1993; Dixon \& Durrheim, 2000; Warnaby \& Medway, 2013) through place 
identification. People do not only identify with their place of residence, but with multiple places that they affiliate with at the same time (Cuba \& Hummon, 1993), such as the place of origin where a person was born or grew up. A person develops a meaningful connection with a place brand while living in the place. This connection is based on physical, social and cultural factors (Cuba \& Hummon, 1993). Through this connection, people develop a bond with a place brand that is not easily broken, even when the person moves away from the place (Cuba \& Hummon, 1993). In the current research, self-definitional relationships with the brand are assessed, both during the customer-brand relationship as well as during the post-dissolution phase of such a relationship. In products and services marketing literature, a customer is considered to reach the post-dissolution phase of a relationship after he or she stops buying a product or service (Bogomolova, 2010). Comparably, after a person moves from one place to another, one can say a person is in the post-dissolution phase of the relationship with the old place of residence since the official administrative ties with this place have been broken. At the same time, in line with literature on the relationship life cycle (Dwyer et al., 1987), the individual is in an expansion or commitment phase with regard to the new place of residence.

The multitude of place identities becomes especially apparent after a life transition, such as a move, and studying the multiple identities after such a life transition, therefore, gives most insight into the interplay between different place related identities. After a move, people go through an adaptation process in which they redefine some important social identity aspects in their life (Wheaton, 1990), such as the level of identification with their new residence as well as identification with the place of origin. Furthermore, new residents deal intensely with uncertainty regarding their new role in the new group (Ashforth \& Saks, 1996; Crisp \& Turner, 2011). This redefinition of identities after a life transition has been discussed in different literature streams. In organizational literature, the adaptation process after a life transition is referred to as socialization (Simosi, 2010), while migration literature refers to a process of acculturation (Crisp \& Turner, 2011) for dealing with group differences after a move. The current study draws on concepts of socialization, acculturation, identity management, and identification in order to gain more insight into identity management processes after a move and to shed light on positive behaviors for the place that enhances the place as a brand.

Human kind constantly strives for a positive social identity (Tajfel \& Turner, 1979), by comparing themselves and their identity to other groups. This comparison process intensifies after a life transition (Simosi, 2010) and urges people to find a new balance in the different social identities they have. The creation of this new balance is facilitated by identity management strategies (Mummendey, Kessler, Klink \& Mielke, 1999). Identity management strategies deal with the outcomes of intergroup comparisons in either a collective, or an individual way (Martiny, Kessler \& Vignoles, 2012). With an individual strategy, people choose to improve their own status by trying to become a member of 
another social group. In collective strategies, on the other hand, the individual tries to improve the status of the whole group (Martiny et al., 2012; Niens \& Cairns, 2003; Ellemers \& Van Rijswijk, 1997). The use of a certain identity management strategy partly depends on the environment that the individual is in. Whether or not an individual is accepted by the new social group facilitates or inhibits the use of certain strategies. This facilitation by the social group is referred to as perceived permeability (Kessler \& Mummendey, 2002). The strategy an individual uses is part of the adaptation process and influences the subsequent adjustment to the new situation (Langston \& Cantor, 1989).

Study 3 shows that perceived permeability results in the use of identity management strategies that impact the level of identification with both the place of origin as well as the place of residence, consequently influencing word-of-mouth with respect to these two places. This process then describes the adaptation process that a person goes through after the move. This paper aims to contribute to existent research in three different ways. First, in line with socialization theory and acculturation theory (Ashforth \& Saks, 1996; Crisp \& Turner, 2011) this study shows that (ex)residents effectively redefine their social identity that is related to a place after a move instead of a priori to a change in environment like was done in research up until now (e.g. Ellemers \& Van Rijswijk, 1997; Niens \& Cairns, 2003). Identity management strategies (Mummendey et al., 1999) are used to describe this adaptation process, which results in different levels of identification for the new place of residence as well as the place of origin. Furthermore, the results of this study show that the use of identity management strategies is dependent on the perceived permeability of group boundaries. So, by facilitating the acceptance of newcomers, one can indirectly influence identification with a place.

Second, as people can identify with multiple place brands at the same time (Cuba \& Hummon, 1993) and as people can identify with brands even after the relationship has ended (Oderken-Schröder et al., 2010), this paper focuses on the interplay of different place-based social identities in different phases of the relationship life cycle. In accordance with previous research (Cuba \& Hummon, 1993), it was found that multiple place-based identities in a person can also compromise each other, which, in turn, affects the behavior that a (ex)resident shows with regard to a place. By scrutinizing these (cross) relationships, this research sheds more light on both place branding theory as well as theory on relationship marketing and social identities.

Third, this chapter contributes to place branding in a managerial sense. Importance of residents in the place branding process was stressed (e.g. Konecnik Ruzzier \& De Cheratony, 2013) as well as the effect of word-of-mouth displayed by these residents (Choo et al., 2011). The current research contributes by giving more insight into the role of (ex)residents and to broaden the possibilities in terms of the number and location of place brand ambassadors. Through this, the outcomes of the research aid place brand managers in seeing (ex)inhabitants as an asset instead of a complicating 
factor. Moreover, when place branding practitioners know more about the development of place related word-of-mouth, they also better know who their ambassadors are and why they talk about a place in a certain way, increasing their level of control of the place branding process.

In the current chapter, a study has been conducted among residents of a mid-sized European town. Whereas the focus in study 2 was placed on residents that left a city and thus had their old residence in common, the current study focuses on people that migrated to a certain city and thus have the new place of residence in common. This diversification increases the generalizability of the results. The residents in the sample who moved to the city in the last ten years, but were not originally from this city, participated in an online survey measuring constructs related to perceived permeability, identity management strategies, identification, behavioral intention and word-of-mouth concerning both their current place of residence as well as their place of origin.

Study 3 shows three important findings. (1) Perceived permeability of group boundaries affects the use of identity management strategies during the adaptation process after a move. This relationship is partly moderated by the perceived status of the new social group as well as by the existing ties with the new place of residence. (2) The use of social strategies has an impact on the level of identification with both the new place of residence as well as the place of origin. (3) The level of identification with a place influences behavioral intention and word-of-mouth towards that same place, while cross-relationships between identification and behavioral variables are also found. A comprehensive literature review follows on the topics of place branding, permeability, identity management strategies, identification, behavioral intentions, and word-ofmouth.

\subsection{Place Branding}

A place is recognized as a brand (Kaplan et al., 2010) with a related place brand identity that is embedded in a person's self-identity (Kavaratzis \& Hatch, 2013). This implies that place brands can satisfy people's self-actualization needs (Caldwell \& Freire, 2004) and people identify with places and their brands (Choo et al., 2011; Warnaby \& Medway, 2013) like they identify with products and services and their brands (Bhattacharya et al., 1995). As in products and services brands, a place brand is not static since the identityrelated aspects of a place brand do not stay constant over the life of a resident (Kavaratzis \& Hatch, 2013). The fact that a place brand shares certain characteristics with products and services brands does not mean that products and services marketing techniques can be applied one-to-one to place branding (Anholt, 2008). A place brand cannot simply be designed, but is rather co-created, co-produced and co-consumed (Hankinson, 
2007) by a large and diverse group of stakeholders (Dinnie \& Fola, 2009; Balakrischnan, 2009; Warnaby \& Medway, 2013) as it is based on geographical, historical, cultural (Kotler \& Gertner, 2002) and residential (Konecnik Ruzzier \& De Cheratony 2013) factors. A place always carries a pre-existing image (Skinner, 2008). Therefore, the accomplishment of a change in a place brand perception is a long-term process (Kavaratzis, 2009) and can only be accomplished from the inside out. Consequently, stakeholder management isalso one of the most important points in branding places (Balakrishnan, 2009; Ryan \& Silvanto, 2010; Kemp et al., 2012a; Kemp et al., 2012b) and inhabitants can serve as ambassadors for the place brand and therewith function as a branding agency towards other people. The role of inhabitants as one particular stakeholder group in the process of place branding, is addressed in the next section.

\subsection{Permeability and Identity Management}

Stakeholders in general (Dinnie \& Fola, 2009) and residents in particular are one of the most important influencers and creators of the intellectual property that constitutes the place brand (Kemp et al., 2012b). When people visit a place, they do not merely encounter trained service employees, but also "locals" who contribute to the place brand image in either positive or negative ways (Choo et al., 2011). When moving to a new place instead of merely visiting, "locals" play an even more substantial role as they are a person's new neighbors, colleagues, friends, classmates and sometimes even family. A person only integrates in a place and identifies with this place when this identification is facilitated by the people around him (Cuba \& Hummon, 1993, Kessler \& Mummendey, 2002). This facilitation by "locals" can be referred to as permeability of group boundaries. Therefore, permeability of group boundaries can be defined as the extent to which a person feels able to not only physically, but also mentally, transfer from one group to another (Niens \& Cairns, 2003).

It should be noted that whereas permeability in previous research was often manipulated in an experimental setting (e.g. Ellemers, Spears \& Doosje, 1997), the current research takes place in a real life context and permeability of group boundaries thereby becomes a perceptual construct. The perceived permeability of group boundaries is important as this facilitates the adaptation process of the new inhabitant. To illustrate: when referring to groups of residents as social identity groups, a person leaves one social group of residents behind when moving, in order to physically move to a new social group of residents. This move has consequences for the balance in a person's social identities (Cuba \& Hummon, 1993; Ellemers, 1993) in the sense that identification with the old group goes down and identification with the new group goes up (Ellemers, 1993). A physical move, however, does not automatically imply that a person is accepted by 
the new group of residents, becomes a real member of this group and fully identifies with this group. Whether a person feels that the group boundaries are permeable or not, determines how this person deals with the change in social identities and which strategies this person uses to manage his or her multiple social identities (Al Ramiah, Hewstone \& Schmid, 2011).

A person can have multiple related (place) identities that are meaningful for him or her (Cuba \& Hummon, 1993) and puts effort in keeping these different identities in harmony (Reed, Forehand, Puntoni \& Warlop, 2012). The process of realigning the different social identities after a life transition like a move has been referred to as socialization (Ashforth \& Saks, 1996) or acculturation (Crisp \& Turner, 2011) in different literature streams. Socialization is described as a process in which individuals learn about specific cultural, behavioral and value aspects of the new group, which are necessary in order to effectively fulfill their new roles within this group (Ashforth \& Saks, 1996). Acculturation describes a process in which individuals psychologically react to their new social reality, where they need to resolve conflicting interests between their new and old identities (Berry \& Annis, 1974; Crisp \& Turner, 2011). So, essentially, both theories describe a way to become functional within their new place in society. To benefit from both literature streams in this marketing study, in the current study the term adaptation process is referred to, by which all processes and strategies that new residents use to create a new balance in their social identities and become functional in their new roles after a move are indicated.

In acculturation literature, a taxonomy of different adaptation strategies has been proposed with a focus on stress, coping, cultural learning and social identification (Sam \& Berry, 2010). This taxonomy is dealing with the cultural differences between newcomers and existing residents after migration. In the current research, however, focus is specifically placed on the concept of place identification, thereby concentrating on the cognitive aspect of acculturation (Sam \& Berry, 2010) instead of the adaptation process to cultural differences. Therefore, the use of the identity management strategies taxonomy (Tajfel \& Turner, 1979) is proposed instead of the acculturation strategies (Crisp \& Turner, 2011). Identity management strategies are part of the adaptation process that people use when dealing with social identities (Kessler \& Mummendey, 2002) and are actively used by people to change the current situation they are in (Mummendey et al., 1999) in order to adjust to a new situation (Langston \& Carter, 1989). The identity management strategy taxonomy originates from social identity research, which is based on how people deal with consequences of intergroup comparisons (Niens \& Cairns, 2003) and, therefore, is deemed to fit best to the current research centering around identification and social identity theory.

According to social identity theory, people have several possibilities to manage a new identity. Research classifies identity management strategies in individual and collective 
strategies (Tajfel \& Turner, 1979; Jackson, Sullivan, Harnish \& Hodge, 1996; Finley, 2010). In the individual strategy, which is referred to as social mobility, people choose to change their own status by actively trying to become an accepted member of another social group (Martiny et al., 2012; Niens \& Cairns, 2003; Ellemers \& Van Rijswijk, 1997), meaning that this person decreases identification with his or her old social group and increases identification with the new social group (AI Ramiah et al., 2011). In collective strategies, on the other hand, which can be divided into social creativity and social competition, the person attempts to change the status of the whole group that is related to his or her old identity by means of a comparison to the new identity group (Martiny et al., 2012; Niens \& Cairns, 2003; Ellemers \& Van Rijswijk, 1997). When using social creativity, an individual draws a comparison between the two social identity groups in order to show similarity or even superiority of the old identity group on new and sometimes irrelevant dimensions (Al Ramiah et al., 2011; Finley, 2010). In using social competition, an individual also compares the two identity groups, but then directly challenges the position of the new group on important dimensions (Finley, 2010) instead of the new and irrelevant dimensions that are used in social creativity.

The three strategies differ most in the level of harmony that they each seek. Social competition is a direct approach and might induce conflict between the two identity groups (Tajfel \& Turner, 1986), whereas a person using social creativity tries to avoid conflict between the two groups (Finley, 2010), but also does not accept the new identity completely. By using the individual strategy of social mobility, the individual completely accepts the new identity as his own, which does not imply that the old identity is completely forgotten, and is, therefore, seen as the most harmonic strategy. Collective versus individual strategies require different behavioral and cognitive skills. Thus, pursuing an individual strategydecreases the success of collective strategies and vice versa (Ellemers, 1993). Still, the identity management strategies are complementary as they can be used at the same time (Martiny et al., 2012; Ellemers \& Van Rijswijk, 1997).

As was said before, the use of identity management strategies is in part dependent on the extent to which the environment cooperates (Kessler \& Mummendey, 2002). When groups do not accept other people in their group (and consequently, perceived permeability of group boundaries is low), the use of individual strategies is not well facilitated (Kessler \& Mummendey, 2002) urging residents to resort to collective strategies (Jackson et al. 1996; Kessler \& Mummendey, 2002). High permeability in turn fosters the use of individual strategies (Al Ramiah et al. 2011). People always pursue the strategy that is most likely to succeed given the context of the social situation (Ellemers, 1993), therefore, permeability is seen as an important predictor of the use of identity management strategies (Niens \& Cairns, 2003; Mummendey et al. 1999; Ellemers, 1993; Jackson et al. 1996). Therefore it is hypothesized: 
H1a: Permeability of group boundaries positively influences the use of social mobility as an identity management strategy.

H1b: Permeability of group boundaries negatively influences the use of social creativity as an identity management strategy.

H1c: Permeability of group boundaries negatively influences the use of social competition as an identity management strategy.

The comparisons that are made when using the identity management strategies, create self-esteem for a person after a move and lead a person to categorize him or herself as a member of a certain group (Niens \& Cairns, 2003). According to social identity theory (Tajfel \& Turner, 1986) and self-categorization theory (Turner, Hoggs, Oakes, Reicher \& Wetherell, 1987), a person defines him or herself by making a tradeoff between their own individuality and being a member of different groups or meaningful social categories (Finley, 2010), which are created to construe a simpler version of the environment (Ellemers, 1993). The social categories that are defined in the categorization process constantly influence the psychological state of the individual (Finley, 2010).

When people categorize themselves, they usually define themselves in terms of 'we' and 'us' instead of ' $I$ ' and 'me' (Finley, 2010). This is a signal for the extent to which people cognitively include a place brand as part of their social identity and define themselves as a member of a social group as well as the extent to which they are defined by others as a member of this group (Ellemers, 1993).

\subsection{Identity Management and Identification}

Identification can be defined as the degree to which a person feels a certain group is part of his or her social identity and thus feels psychologically connected with this group (Mael \& Ashforth, 1992) and uses the group as a method for cognitive self-definition (Bhattacharya et al., 1995). Identification can be based on demographic factors (Bhattacharya et al., 1995), but people can also identify with other entities like brands, as long as these entities carry symbolic meaning for this person (Stokburger-Sauer et al., 2012). A place is very symbolic to a person (Cuba \& Hummon, 1993) and therefore also qualifies as a relevant entity for identification. A residence is often tied to certain life events that happened in this dwelling place (Cuba \& Hummon, 1993). Through this, a memorable experience is created with the place brand which serves as a source of identification (Stokburger-Sauer et al., 2012; Warnaby \& Medway, 2013). 
When looking at a place brand from the perspective of the relationship life-cycle, people are in the relationship phase when they live in a certain place, and then during this relationship phase, they develop a degree of identification with this place that is based on physical, social and cultural elements (Cuba \& Hummon, 1993). This development of identification can be paralleled with the development of identification with a product, service, organization or other entity in which case identification is based on for example social and sociocultural factors as well (Stokburger-Sauer et al., 2012). When drawing this parallel, it is to be expected that identification with a place does not end after ending the direct relationship with a place by moving away from the place. In the post-dissolution phase of the relationship life-cycle (Dwyer et al., 1987), a person can still identify with a brand even though the official ties with this brand are no longer present (Odekerken-Schröder et al., 2010; Mael \& Ashforth, 1992), which leads to the assumption that a person still identifies with a place brand even when this person no longer has official ties to the place in terms of working and living. So, after a move, a person is building up identification with the new place brand as well as trying to maintain a certain level of identification with the old place brand.

The state of identification is different from the process of identification (Stokburger-Sauer et al., 2012). As social identities and place identities are not static (Kavaratzis \& Hatch, 2013) the process of identification leads to various states of identification at different points in time. It is posed that identity management strategies are part of the adaptation process and that people have certain states of identification both before and after the use of the different strategies. In previous research on identity management strategies, the focus is on the creation of a desire to belong to a certain group, while manipulating permeability and status of the groups (e.g. Ellemers \& Van Rijswijk, 1997; Jackson et al., 1996), thus focusing on the front end of a social identity change. In these studies, identification is measured a priori leading to the conclusion that identification influences the choice of identity management strategies (Niens \& Cairns, 2003). In the current study however, focus is placed on the latter part of the social identity change as, in line with study 2 , the state of identification is measured after the move and after the use of identity management strategies during the adaptation process, thereby causing a hypothesis on the effects of identity management strategies on the level of identification with both the old place as well as the new place after a move.

After a move, people have increased the physical distance to their former place of residence and spent more time away from the place, causing a shift away from the old social identity (Jackson et al., 1996) towards the social identity related to the new place of residence (Cuba \& Hummon, 1993). The individual strategy of social mobility accommodates this shift. When using social mobility, people attempt to adapt their social identity by switching to another group (Ellemers \& Van Rijswijk, 1997). It is expected that since the resident genuinely wants to become part of the group of residents in the new 
place, he or she berates the position of the old place identity relative to the new place identity and through this, decreases the identification with the old place identity while increasing identification with the new place identity (Al Ramiah et al., 2011).

As a place identity is a social identity, there is always a distinction between insider and outsider groups (Dixon \& Durrheim, 2000). People treat members of their in-group more favorable than members of an out-group (Ellemers \& Van Rijswijk, 1997). Therefore, 'locals' might be inhibited to accept the newcomers as they belong to an out-group, creating a minority group of newcomers. When people form a minority, they are triggered to protect the social identity of this minority by making use of collective strategies (Ellemers \& Van Rijswijk, 1997) and are more focused on their old identity (Ellemers, 1993). People who make use of social creativity also show a desire to belong to new place identity group (Al Ramiah et al., 2011), but instead of decreasing identification with the old place, they make the old place more positive in order to compare it to the new place (Finley, 2010), thereby positively focusing on their old identity (Ellemers, 1993). When using social competition, people directly challenge the qualities of the new group by claiming a more positive view of the old group (Finley, 2010) in order to obtain a positive social identity (Al Ramiah et al., 2011). When using social competition, switching to another group does not seem like an option (Jackson et al., 1996), and, therefore, people are more focused on their old identity (Ellemers, 1993). Thus, it is expected that the use of the collective strategies (social creativity and social competition) has a positive impact on identification with the old place while negatively impacting identification with the new place.

H2a\&b: The use of a social mobility strategy positively (negatively) influences identification with the new (old) place of residence.

H2c\&d: The use of a social creativity strategy negatively (positively) influences identification with the new (old) place of residence.

H2e\&f: The use of a social competition strategy negatively (positively) influences identification with the new (old) place of residence. 
When people identify with an entity, they act positively towards that entity, both in terms of word-of-mouth as well as behavioral intention (Bhattacharya \& Sen, 2003; Tuškej et al., 2011). In the current research, however, two social identities are assessed simultaneously as people can identify with both their old and new places of residence. Furthermore, the identification with these two entities and its impact on word-of-mouth and behavioral intention towards both places is analyzed as well.

\subsection{Identification and Behavioral Outcomes}

In previous research, it has been shown that positive word-of-mouth and behavioral intention are two of the most important behavioral outcomes of identification with a brand (Stokburger-Sauer et al., 2012; Brown et al., 2005; Bhattacharya \& Sen, 2003; Tuškej et al., 2011). In Chapter 3 and Chapter 4, these findings were extended to the post-dissolution phase of a customer-brand relationship in the place branding context. In both chapters behavioral intention was referred to as return intention since only the post-dissolution phase of the customer-brand relationship was discussed. The current chapter reflects on behavior towards the old as well as the new place brand. Therefore, the term behavioral intention is preferred over return intention in this context. When a customer shows behavioral intention to stay in (or move back to) a place, this increases the possibility that this person continues to live in (or move back to) the place (Webb \& Sheeran, 2006), thereby benefitting the place directly through residency as well as indirectly through possible (continued) ambassadorship as a resident. This ambassadorship is conceptualized by word-of-mouth.

Residents can be seen as highly informed sources with respect to place information (Crisp \& Turner, 2011). Through word-of-mouth, these (ex)residents spread consumer information about the place with ease (Tuškej et al. 2011), which is a powerful marketing tool due to the perceived credibility of the delivered message (Sweeney, Soutar \& Mazzarol, 2012). Word-of-mouth is not only the mere activity of passing on a message from one person to another (Sweeney et al., 2012), but consists of different dimensions. One dimension is the valence of word-of-mouth (Lang, 2009). In the current research, focus is placed on word-of-mouth with positive valence. As the absence of positive word-of-mouth does not necessarily point to the presence of negative word-ofmouth (Lang, 2009), and negative word-of-mouth has different delivery characteristics than positive word-of-mouth (Sweeney et al., 2012), it is important to discriminate between these two types of word-of-mouth. When referring to word-of-mouth valence in the current research, we merely talk about positive word-of-mouth messages. Next to this, the intensity of the word-of-mouth also varies (Lang, 2009). An individual can talk 
positively about a place brand, but this does not say anything about how often the person talks about the brand. Word-of-mouth intensity thus describes the frequency of the delivered word-of-mouth messages. Finally, as word-of-mouth can also be used in a social or physical way (Stokburger-Sauer et al., 2012), it is important to point out that there is a focus on social word-of-mouth in this paper. Social word-of-mouth is referring to the recommendation of the brand while physical word-of-mouth refers to actions related to the brand, such as collecting memorabilia.

When people identify with a place brand, this has positive consequences for the brand in terms of behavioral intentions (Ahearne et al., 2005) and positive word-ofmouth (Brown et al., 2005; Tuškej et al., 2011). Therefore, identification with the new place of residence is expected to have positive consequences for behavioral intention, word-of-mouth intensity and word-of-mouth valence related to the new place of residence. These positive consequences of identification with a place brand are expected to not only be present during the relationship (Stokburger-Sauer et al., 2012), but also in the absence of a formal relationship (Bhattacharya \& Sen, 2003; Bhattacharya et al., 1995) or after the relationship has ended (Odekerken-Schröder et al., 2010; Johnson et al., 2011). This leads to hypothesize a positive relationship between identification with the old place of residence and behavioral intention, word-of-mouth intensity and wordof-mouth valence related to the old place of residence as well.

H3a\&b: Identification with the new (old) place of residence has a positive influence on behavioral intention with regard to the new (old) place of residence.

H3c\&d: Identification with the new (old) place of residence has a positive influence on the use of word-of-mouth intensity with regard to the new (old) place of residence.

H3e\&f: Identification with the new (old) place of residence has a positive influence on the use of positive word-of-mouth valence with regard to the new (old) place of resi-

dence.

The adaptation process that people go through after a move has the sole purpose of (re)balancing the newly acquired structure of social place identities (Ashforth \& Saks, 1996; Al Ramiah et al., 2011). After a move, people attempt to identify with the new place of residence while at the same time holding on to their bond of identification with the old place of residence. Although these multiple identities can co-exist, the process of acquiring a social identity related to the new place compromises the identity that was related to the old place (Cuba \& Hummon, 1993) and vice versa. Therefore, it is posed that the shift in the state of identification that results from the adaptation process after a move also has consequences for behavioral intentions towards the other place. 
Stets and Burke (2000) state that each social identity is related, but different from other social identities and role performances (like positive behavior towards a brand) can only be achieved through negotiation. This implies that while identification with a place brand induces positive consequences with regard to the same brand, it simultaneously induces negative consequences towards other place brands. Therefore:

H4a\&b: Identification with the new (old) place of residence has a negative influence on behavioral intention with regard to the old (new) place of residence.

H4c\&d: Identification with the new (old) place of residence has a negative influence on the use of word-of-mouth intensity with regard to the old (new) place of residence.

H4e\&f: Identification with the new (old) place of residence has a negative influence on the use of positive word-of-mouth valence with regard to the old (new) place of residence.

As place branding is a complicated process, which is dependent on many factors (Kaplan et al., 2010; Balakrishnan, 2009), two variables, group status and ties to the new place of residence, have been incorporated as moderating variables in order to control for part of this complexity.

\subsection{Group Status and Ties to New Place of Residence}

Whereas for the current dissertation an empirical study is conducted, with real-life data obtained through survey research, most studies related to identity management conduct research in an experimental context with minimal groups (Mummendey et al., 1999), where the status of the group is manipulated. In the current study, however, status is seen as a perceptual construct. As status (or prestige) is one of the antecedents of identification (Bhattacharya \& Sen, 2003), people who believe the place brand of the new residence has a higher status than their old place brand make more of an effort to belong to the group of new residents (e.g. Finley, 2010; Ellemers, 1993; Jackson et al., 1996) and, therefore, try harder to make use of strategies that facilitate identification with the new social group. As social mobility is seen as a method that is focused on this new identity (Al Ramiah et al., 2011) while social creativity and social competition focus on the old identity (Ellemers, 1993), it is expected that people who believe that the new residence identity has a higher status show a stronger positive relationship between 
permeability and social mobility and a stronger negative relationship between permeability and the collective strategies of social creativity and social competition than people who do not see the new residents as a higher status group.

H5a\&b: The belief that the new resident group is a higher status group than the old resident group induces (a) a stronger positive relationship between permeability and social mobility and a stronger negative relationship between permeability and (b) social creativity and (c) social competition than the belief that the new resident group is not a higher status group.

Next to the status of the group, past and current connections to an area can also be a factor that moderates the relationship between permeability and the use of the social strategies. For example, language is a tool that people use to develop a common identity (Finley, 2010). In the area under research, a strong local dialect is spoken. Speaking this dialect is a binding factor to this place that makes acceptance in the new social identity group easier. Furthermore, friends and family have long known to be factors that tie a person to a place (Berger \& Blomquist, 1992) as well as a job (Bartel, 1979). As experience with a brand induces trust and ultimately identification with a brand (Bhattacharya \& Sen, 2003), it is hypothesized that the more of these ties one has with the new place of residence, the higher the motivation of this person to make use of strategies that facilitate identification with the new place of residence instead of strategies that facilitate identification with the old place.

H6a,b\&c: More ties with the new place of residence lead to (a) a stronger positive relationship between permeability and social mobility and a stronger negative relationship between permeability and (b) social creativity and (c) social competition. 
The hypotheses above together form a conceptual framework that is summarized and visualized in figure 5.1 below.

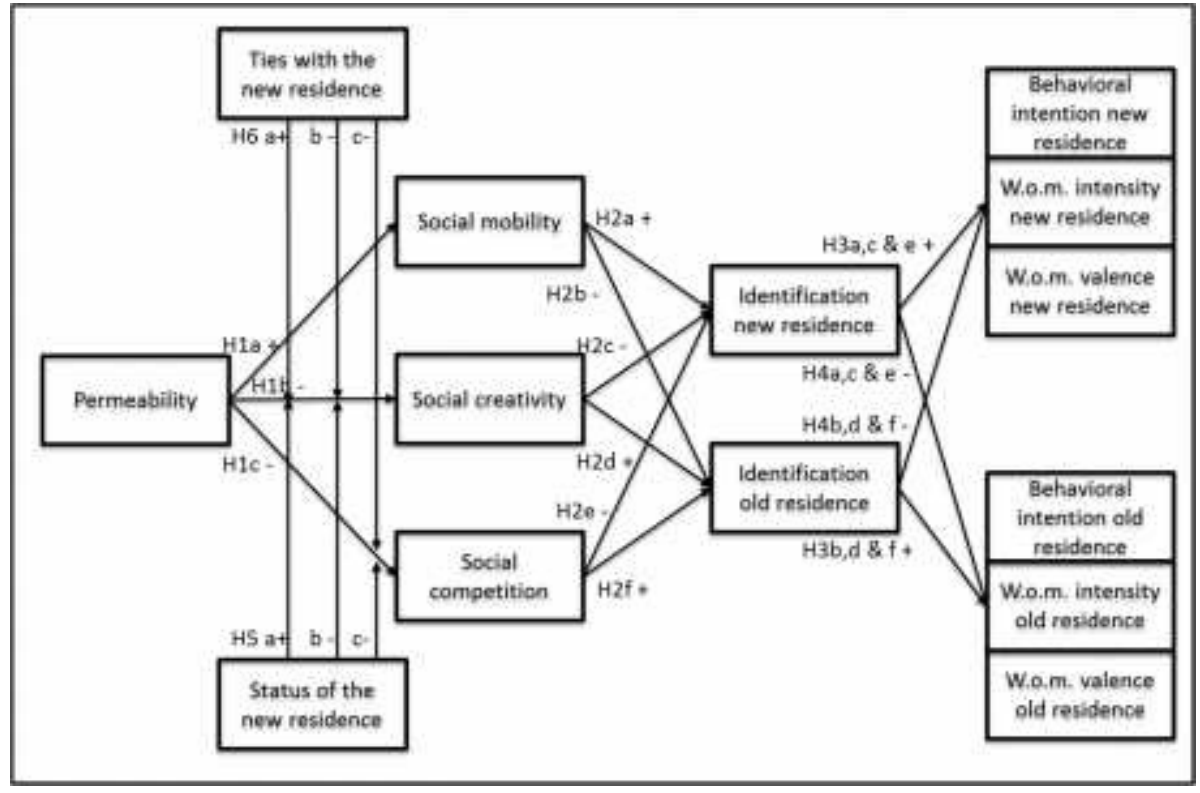

Figure 5.1 Conceptual framework study 3 


\section{Study 3: Balancing Place Identities}

\subsection{Research Method}

\subsubsection{Sample and Procedure}

The data for the current research has been collected in cooperation with a mediumsized European city. Based on the city records, a sample was drawn out of the population of people who migrated to the city in the last years. These participants received a letter at their home address with the request to participate in an online questionnaire about their migration behavior. In total, 525 people completed the questionnaire. These respondents were filtered to see if they could not be categorized as a local. Thus, respondents were asked to categorize themselves as being 'local' or 'non-local'. In order to define local and non-local, a region with a common telephone area code was selected to ensure that the region had clear boundaries and the definition was not biased. The respondents who self-categorized as locals were then deleted from the dataset. Furthermore, the respondents who migrated to the city more than 10 years ago were also removed. As the adaptation process is ongoing, but most intense in the period after the life transition (Simosi, 2010), it was deemed to be important that the move could be remembered well and respondents were not living in the city of interest for most of their lives. Therefore, the boundary of 10 years was adhered to as a way to balance the appropriateness of the sample without losing too many respondents due to exclusion of the sample. As an extra check, tests were conducted to see whether respondents who lived in the city for a short period (shorter than 2 years) responded differently from respondents who lived in the city for a longer period (2-10 years). No significant differences were obtained in any of the items, which justifies the chosen approach.

This selection resulted in a dataset $(\mathrm{N}=285)$ of respondents who answered questions on the constructs related to permeability, identity management strategies, identification with their new as well as their old residence, behavioral intention and word-ofmouth intensity and valence concerning the new and the old residence and status and ties to the new place of residence. Furthermore, the respondents answered questions on their actual migration behavior, their views of the new place of residence, and some social variables. Respondent characteristics show that $48.7 \%$ were male, and the respondents in the sample have an average age of 33 years. Most of the respondents lived in a rented house $(70.48 \%)$ as opposed to a bought house $(29.12 \%)$. 


\subsubsection{Psychometric Properties of the Measurement}

In order to measure the core constructs in the conceptual model, established scales were being used, which are presented and referenced in the Appendix B of this dissertation. In accordance with Brown and Williams (1984), the moderating status variable was measured by asking the respondents which of the groups (locals or non-locals) had the most advantages in the new place. Ties with the new place of residence were measured by asking respondents whether or not they work in the area, were born and/or raised in the area, studied in the area, have friends and family in the area and speak the local dialect. The number of different ties was counted, creating a measure for the different types of ties one can have with a place.

In order to estimate the conceptual model, Smart PLS 2.0 M3 was used for obtaining the model parameters. The psychometric properties of the measurement were assessed by looking at the validity and reliability of the sample. Measures for the convergent validity, reliability and discriminant validity of our sample were obtained. Convergent validity was established by examining the standardized loadings of the scale items on the latent variables (Chin, 1998). As suggested by Hulland (1999), several items were deleted from the constructs in order to improve convergent validity. Usually, one adheres to a cut-off value of 0.5 to 0.7 (Hair et al., 2006). In making a trade-off between the number of items to be deleted and the gain in validity, the decision was made to adhere to a cut-off value of 0.6 for the convergent validity, thereby finding the middle ground of the values suggested by Hair et al. (2006). In a field study with a social identity context, the used measures often lack some reliability and validity (Mummendey et al., 1999), so the deletion of items to establish convergent validity is not uncommon. After deletion of the items to establish convergent validity, the AVE was scrutinized in order to check the reliability of the data. All constructs show an AVE of 0.5 or higher, which adheres to the cut-off as suggested by Fornell \& Larcker (1981), implying that no further items had to be removed. This was confirmed by the measure of composite reliability, which ranged between 0.79 and 0.92 ,exceeding the cut-off value of 0.7 that was suggested by Nunnally \& Bernstein (1994). Finally, discriminant validity was assessed in order to reassure that items do not load high on other constructs than their own (Barclay et al., 1995). As one can see in table 5.1, the square roots of the AVE (in bold) are larger than the correlations between the constructs (Barclay et al., 1995; Chin, 1998) implying that discriminant validity is established for this dataset. 


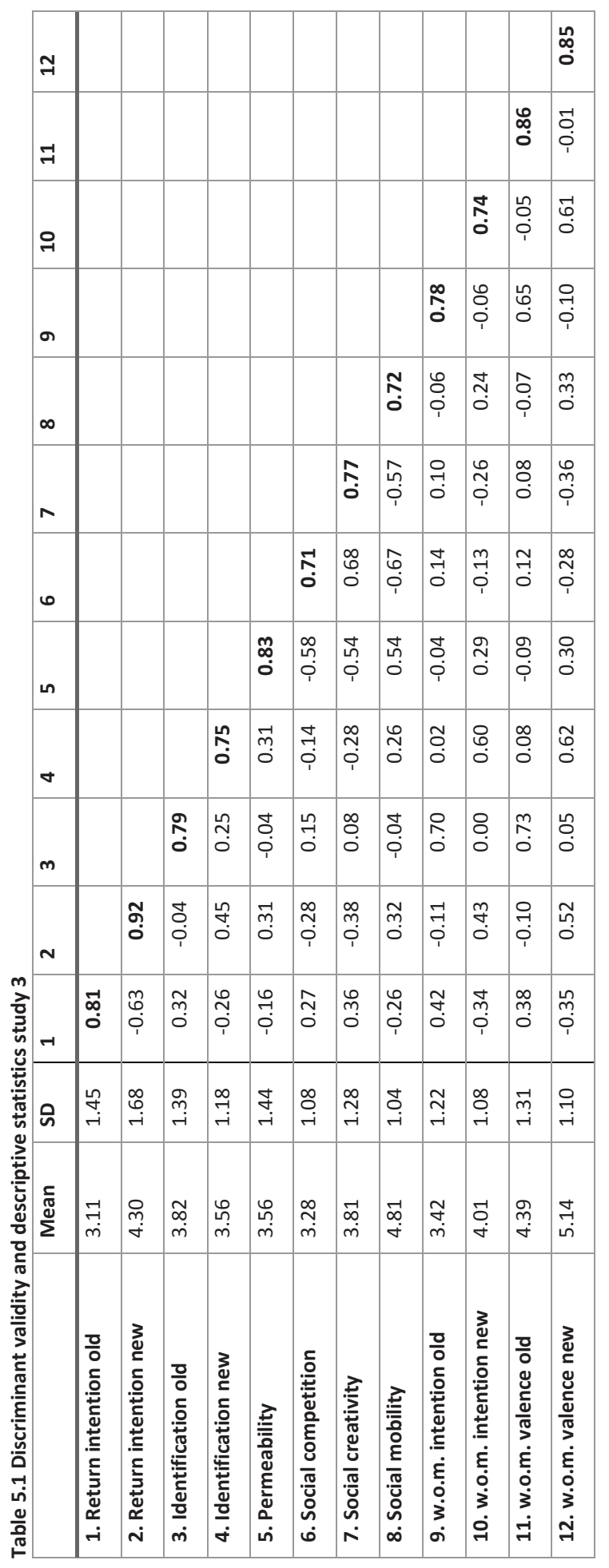




\subsection{Results $^{11}$}

Bootstrapping with 1000 resamples was used in order to obtain standard errors for the parameters in the model. The descriptive statistics of the analyses are included in table 5.1.

\subsubsection{Overall Model Fit}

The R-square ( 0.31 on average for the endogenous constructs) gives a first indication of the strong overall model fit as Cohen (1988) determined cut-off values for a small, medium and large $R^{2}$ to be $0.02,0.13$ and 0.26 , respectively. Furthermore, the GOF measure was used; a global fit measure for PLS path modeling (Tenenhaus et al., 2005). The GOF measure can be defined as the mean of the average communality and average $\mathrm{R}^{2}$ for endogenous constructs (Wetzels, Odekerken-Schröder \& van Oppen, 2009). In line with the proposed cut-off value of 0.5 for communality (Fornell \& Larcker, 1981) and the above mentioned cut-off values for the $\mathrm{R}^{2}$ (Cohen, 1988), benchmark values for the GOF were obtained $\left(\mathrm{GOF}_{\text {small }}=0.1, \mathrm{GOF}_{\text {medium }}=0.25\right.$ and $\mathrm{GOF}_{\text {large }}=0.36$ ) (Wetzels et al., 2009). For the current model, a GOF value of 0.44 was obtained, which exceeds the cut-off value for the largest effect size and leads to the conclusion that the model has a strong fit to the obtained data. Finally, a blindfolding procedure was conducted for the sample to assess the predictive value of the model. The values for the cross-validated redundancy range between 0.01 and 0.38 and thus all exceed the desired value of 0 (Tenenhaus et al., 2005). Based on these results, the estimated model can be used for the analysis without further removal of items or constructs.

For the assessment of the moderating influence of the ties with new place and status, interaction variables were created. As ties to the new place of residence is a metric variable, the interaction variable can be created directly. Status is a non-metric variable with three groups, but since no respondents answered that non-locals had most advantages, two status groups remained: one in which locals were seen as the most advantageous group $(n=115)$ and one in which locals and non-locals were deemed to have equal advantages $(n=170)$. Accordingly, a dummy variable was created, which is included as an interaction variable. The results of the research are discussed in the next section.

11 We report the beta-values and standard errors of the analyses. Significance of the one-sided hypotheses is indicated with an asterisk. For marginally significant results $0.1>p>0.05=t$, for significant results $0.05>p>0.001$ $=*$ and for highly significant results $\mathrm{p}<0.001=* *$. 


\subsubsection{Permeability and Identity Management}

Hypothesis 1 concerns the effect of permeability on the use of the different identity management strategies. More specifically, a positive effect of permeability was expected on social mobility $(\mathrm{H} 1 \mathrm{a})$, while a negative effect of permeability on social creativity $(\mathrm{H} 1 \mathrm{~b})$ and social competition $(\mathrm{H} 1 \mathrm{c})$ was expected. It was found that when people perceive the boundaries of the social group to be more permeable, they are more likely to make use of the individual strategy of social mobility $\left(\beta=0.38^{* *}, \mathrm{SE}=0.05\right)$, while they are less likely to make use of social creativity $\left(\beta=-0.44^{* *}, \mathrm{SE}=0.06\right)$ and social competition $\left(\beta=-0.45^{* *}, S E=0.06\right)$, both collective strategies. These results indicate a support for hypothesis $1 \mathrm{a}, \mathrm{b} \& \mathrm{c}$.

\subsubsection{Identity Management and Identification}

In hypotheses $2 a \& b$, it is expected that the use of a social mobility strategy (a) positively influences identification with the new place of residence, but at the same time (b) negatively influences identification with the old place of residence. The results of the conducted bootstrapping analyses show that the use of a social mobility strategy indeed has a positive effect on identification with the new place of residence $\left(\beta=0.25^{* *}, \mathrm{SE}=0.08\right)$, thereby supporting $\mathrm{H} 2 \mathrm{a}$. On the other hand, it was found that using a social mobility strategy does not have the expected negative effect on identification with the old residence. Instead, a marginal positive effect was found $(\beta=0.12+, \mathrm{SE}=0.08)$. Thus, $\mathrm{H} 2 \mathrm{~b}$ is not supported. It seems that social mobility has a positive impact on place identification with both the new, as well as the old place of residence.

Hypotheses 2c\&d depict a (c) negative effect of the use of social creativity on identification with the new place and (d) a positive effect of social creativity on identification with the old place of residence. A significant effect was found of the use of social creativity on identification with the new place of residence $(\beta=-0.30 * *, S E=0.08)$, supporting hypothesis $2 c$. People identify less with the new place of residence when they make use of a social creativity strategy. The effect of social creativity on identification with the old place of residence is small and not significant $(\beta=-0.01, S E=0.09)$. Thus, hypothesis $2 d$ is not supported.

With hypothesis $2 \mathrm{e} \& \mathrm{f}$, the (e) negative effect of social competition on identification with the new place of residence and the (f) positive effect of social competition on identification with the old place of residence is depicted. Hypothesis $2 \mathrm{e}$ cannot be supported. People who make use of a social competition strategy identify more, and not less, with the new place of residence $(\beta=0.24 * *, S E=0.09)$. People who make use of social competition also identify more with the old place of residence $\left(\beta=0.24^{* *}, S E=0.09\right)$, which supports hypothesis $2 f$. 


\subsubsection{Identification and Behavior}

Hypothesis 3 depicts the direct effects of identification with a place on behavioral intention and word-of-mouth intensity and valence towards that same place. In accordance with hypothesis $3 a$, it was found that when people identify with the new place of residence, they also show more behavioral intention towards the new place of residence $\left(\beta=0.48^{* *}, S E=0.05\right)$. More identification with the old place of residence, in turn, also induces a higher level of word-of-mouth intensity $\left(\beta=0.41^{* *}, \mathrm{SE}=0.06\right)$, supporting hypothesis $3 b$.

In hypothesis 3c, a positive influence of identification with the new place of residence on word-of-mouth intensity towards the new place of residence was expected. Strong support was found for this hypothesis $(\beta=0.64 * *, S E=0.04)$. Furthermore, and in support of hypothesis $3 \mathrm{~d}$, identification with the old place of residence was also found to lead to more word-of-mouth intensity towards the old place of residence $(\beta=0.74 * *$, $\mathrm{SE}=0.03)$.

Hypothesis $3 e$ and $3 f$ depicted a positive relationship between identification with a place and word-of-mouth valence towards the same place. It was found that when a person has a higher level of identification with the new place of residence, this person talks more positively about the new residency $\left(\beta=0.65^{* *}, \mathrm{SE}=0.04\right)$, thus supporting hypothesis $3 e$. At the same time, and in support of hypothesis $3 \mathrm{f}$, identification with the old place of residence also increases the positive valence of word-of-mouth towards the old place of residence $(\beta=0.76 * *, S E=0.03)$.

Hypotheses $4 a-f$ depict the cross relationships between identification and the behavioral variables in the sense that identification with the new place of residence is expected to negatively influence the behavioral intention and the word-of-mouth variables of intensity and valence to the old place of residence and vice versa. In support of hypothesis $4 a$, identification with the new place of residence was found to decrease the behavioral intention related to the old place of residence $\left(\beta=-0.37^{* *}, \mathrm{SE}=0.07\right)$. Hypothesis $4 b$ was also supported, as identification with the old place of residence was found to have a negative effect on behavioral intention related to the new place of residence $\left(\beta=-0.16^{* *}, \mathrm{SE}=0.06\right)$.

In $\mathrm{H} 4 \mathrm{c}$, it was expected that when people identify with the new place of residence, they talk less often about the old place of residence. Hypothesis $4 c\left(\beta=-0.16^{* *}, S E=0.05\right)$ was supported, as well as the opposing relationship of hypothesis $4 d$, which depicted a negative influence of identification with the old place of residence on word-of-mouth intensity related to the new place of residence $\left(\beta=-0.16^{* *}, \mathrm{SE}=0.05\right)$.

Identification with the new place of residence significantly and negatively influences the use of positive word-of-mouth towards the old place of residence $\left(\beta=-0.11^{* *}\right.$, $\mathrm{SE}=0.04)$, which supports hypothesis $4 \mathrm{e}$. Identification with the old place of residence, 
on the other hand, significantly and negatively influences the extent to which people talk positively about the new place of residence $\left(\beta=-0.11^{*}, \mathrm{SE}=0.05\right)$, thereby supporting hypothesis $4 \mathrm{f}$.

\subsubsection{Group Status and Place Connection}

In hypothesis 5, the moderating effect of status on the relationship between permeability and the identity management strategies was depicted. Status is a grouping variable, and, therefore, dummies were created for calculating the interaction. In hypothesis 5a, it was expected that the belief that the new resident group was higher in status than the old resident group positively moderated the relationship between permeability and social mobility. Support was found for hypothesis $5 a\left(\beta=0.14^{*}, \mathrm{SE}=0.05\right)$, meaning that when people believe that the new resident group has a higher status, they are more likely to make use of social mobility than when they believe group boundaries are permeable. The negative moderation of group status on the relationship between permeability and social creativity that was hypothesized in hypothesis $5 \mathrm{~b}$ was not supported $(\beta=-0.04, S E=0.09)$. Also, the predicted negative moderation of hypothesis $5 c$, in which the moderating effect of status on the relationship between permeability and the use of social competition is predicted, is not found significant $(\beta=-0.04, \mathrm{SE}=0.06)$. Thus, the belief that the new resident group has a higher status does induce more use of a social mobility strategy, but does not lower the intention to use social creativity or social competition when group boundaries are permeable.

Hypothesis 6 discusses the moderating effect of ties to the new place with the identity management strategies. In contrast with hypothesis $6 \mathrm{a}$, we find that ties to the new place of residence significantly weaken the effect of permeability on social mobility $(\beta=-0.12 *, S E=0.07)$ implying that the more ties people have with a place, the less likely they are to make use of social mobility when group boundaries are permeable. Furthermore, we find no moderating effect of ties to the new place of residence on the relationship between permeability and social creativity $(\beta=-0.03, \mathrm{SE}=0.09)$ and social competition ( $\beta=-0.04, S E=0.09$ ) respectively. Herewith, we find no support for hypothesis $6 \mathrm{~b}$ and $6 \mathrm{c}$. This implies that when people feel they have more ties with the region, they make less use of social mobility when group boundaries are permeable, but the ties with the region do not influence the tendency of residents to make use of social creativity and social competition when group boundaries are permeable. 
In figure 5.2 and table 5.2 below the results of study 3 are summarized. Bold lines in the figure indicate support for the hypothesis, thin lines indicate marginal support and interrupted lines indicate no support for the hypothesis.

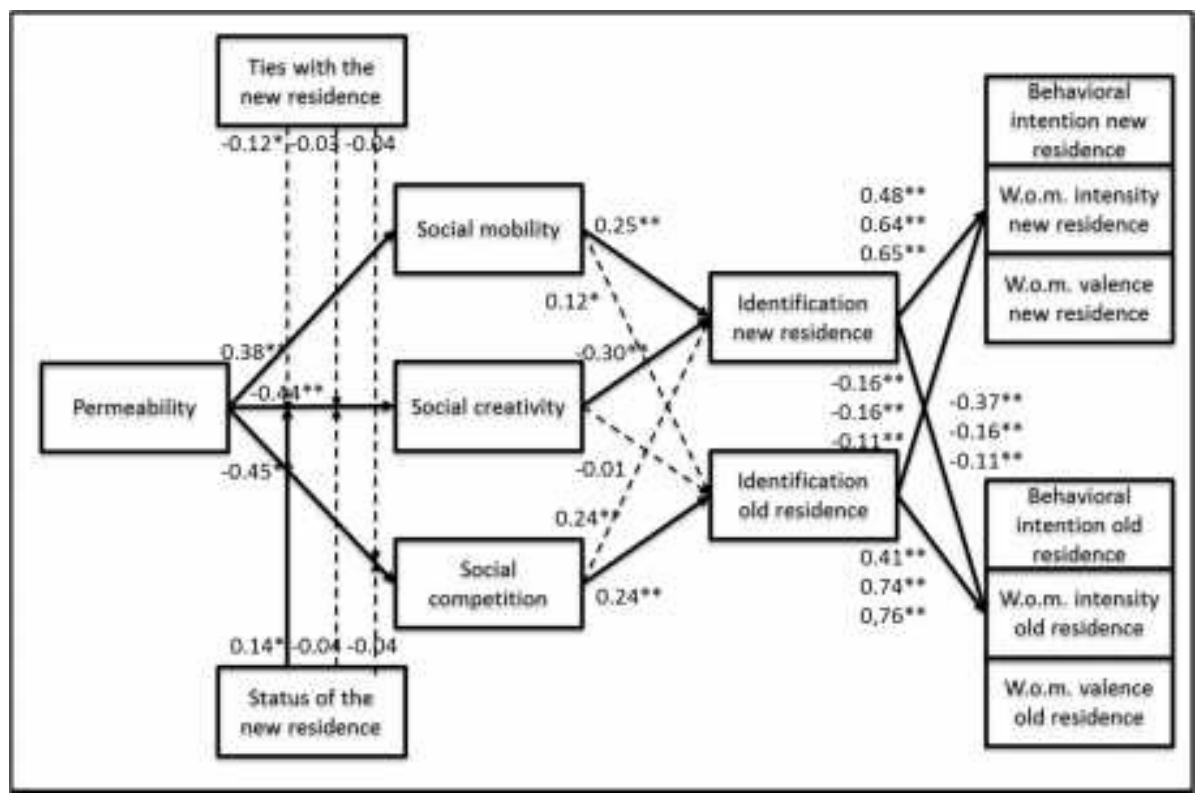

Figure 5.2 Results overview study $3^{12}$

12 Bold lines indicate support for the hypothesis, thin lines indicate marginal support and interrupted lines indicate no support for the hypothesis. $0.1>p>0.05=+, 0.05>p>0.001=* p<0.001=* *$ 
Table 5.2 Results overview study $3^{13}$

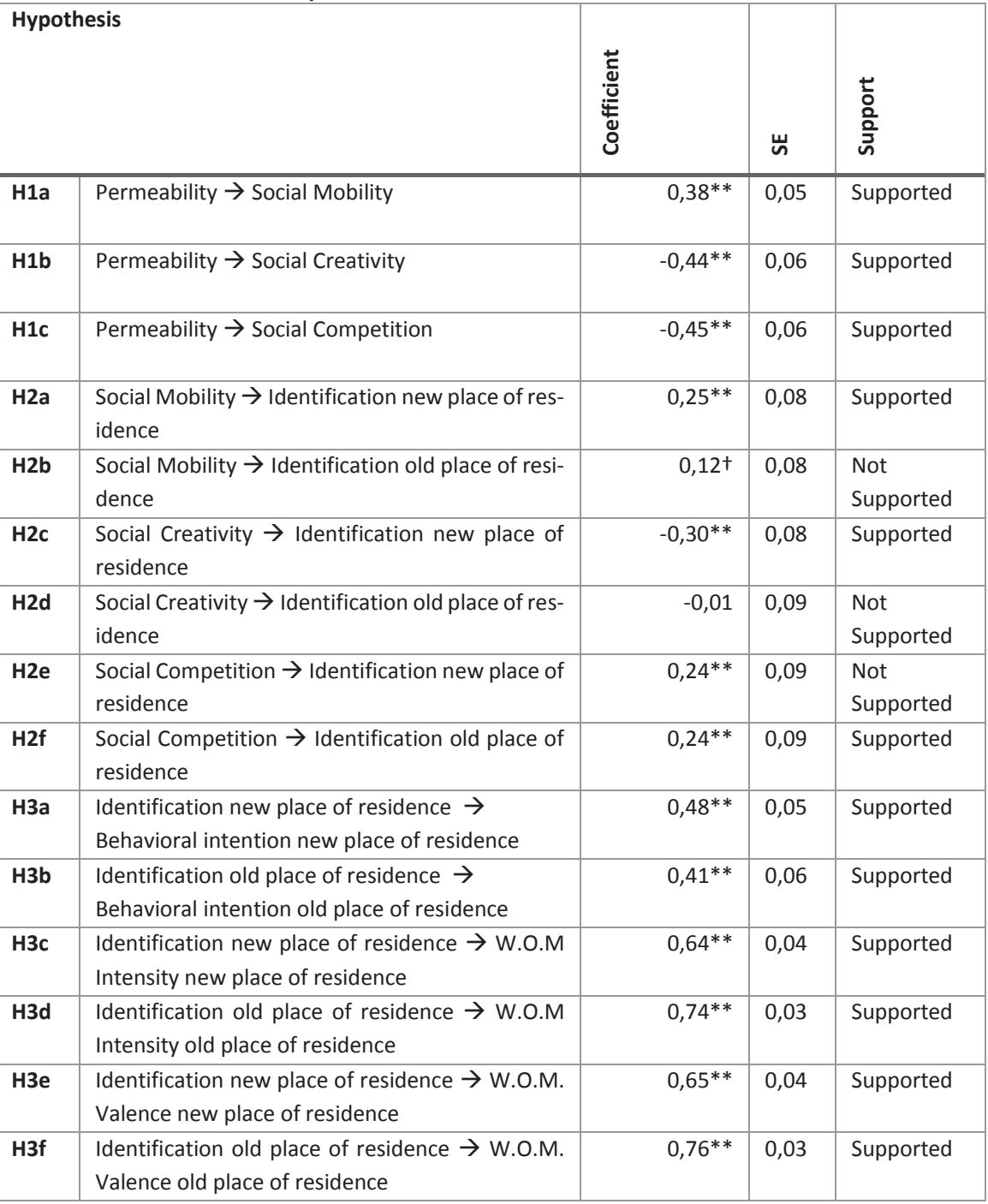




\begin{tabular}{|c|c|c|c|c|}
\hline \multicolumn{2}{|c|}{ Hypothesis } & \multirow{2}{*}{ 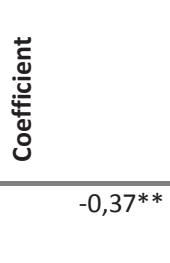 } & \multirow{2}{*}{$\begin{array}{c}\text { 山 } \\
0,07\end{array}$} & \multirow{2}{*}{$\begin{array}{l}\text { tั } \\
\text { 음 } \\
\text { ज }\end{array}$} \\
\hline $\mathrm{H} 4 \mathrm{a}$ & $\begin{array}{l}\text { Identification new place of residence } \rightarrow \\
\text { Behavioral intention old place of residence }\end{array}$ & & & \\
\hline H4b & $\begin{array}{l}\text { Identification old place of residence } \rightarrow \\
\text { Behavioral intention new place of residence }\end{array}$ & $-0,16^{* *}$ & 0,06 & Supported \\
\hline $\mathrm{H} 4 \mathrm{c}$ & $\begin{array}{l}\text { Identification new place of residence } \rightarrow \text { W.O.M } \\
\text { Intensity old place of residence }\end{array}$ & $-0,16 * *$ & 0,05 & Supported \\
\hline H4d & $\begin{array}{l}\text { Identification old place of residence } \rightarrow \text { W.O.M } \\
\text { Intensity new place of residence }\end{array}$ & $-0,16 * *$ & 0,05 & Supported \\
\hline $\mathrm{H} 4 \mathrm{e}$ & $\begin{array}{l}\text { Identification new place of residence } \rightarrow \text { W.O.M. } \\
\text { Valence old place of residence }\end{array}$ & $-0,11^{* *}$ & 0,04 & Supported \\
\hline H4f & $\begin{array}{l}\text { Identification old place of residence } \rightarrow \text { W.O.M. } \\
\text { Valence new place of residence }\end{array}$ & $-0,11^{*}$ & 0,05 & Supported \\
\hline H5a & Permeability * Status $\rightarrow$ Social Mobility & $0,14^{*}$ & 0,05 & Supported \\
\hline H5b & Permeability * Status $\rightarrow$ Social Creativity & $-0,04$ & 0,09 & $\begin{array}{l}\text { Not } \\
\text { Supported }\end{array}$ \\
\hline H5c & Permeability * Status $\rightarrow$ Social Competition & $-0,04$ & 0,06 & $\begin{array}{l}\text { Not } \\
\text { Supported }\end{array}$ \\
\hline H6a & Permeability * Ties $\rightarrow>$ Social Mobility & $-0,12 *$ & 0,07 & $\begin{array}{l}\text { Not } \\
\text { Supported }\end{array}$ \\
\hline H6b & Permeability * Ties $\rightarrow$ Social Creativity & $-0,03$ & 0,09 & $\begin{array}{l}\text { Not } \\
\text { Supported }\end{array}$ \\
\hline H6c & Permeability $*$ Ties $\rightarrow$ Social Competition & $-0,04$ & 0,09 & $\begin{array}{l}\text { Not } \\
\text { Supported }\end{array}$ \\
\hline
\end{tabular}

\subsection{Discussion Study 3}

The results of study 3 first indicate that perceived permeability of group boundaries is an important antecedent for the adaptation process of an (ex)inhabitant. These results are in line with previous work on social identity strategies (e.g. Kessler \& Mummendey, 2002; Jackson et al., 1996; Al Ramiah et al., 2011). Whether or not this individual is accepted by the new social group determines how the adaptation process is going to look in terms of the social strategies that the individual will use after a move. When group boundaries are perceived to be permeable, an individual is more likely to make use of a social mobility strategy in which the new identity is fully accepted. A lower level of permeability, on the other hand, induces the individual to make use of either a social creativity or social competition strategy. Making new inhabitants feel welcome and accepted in a place is, thus, a necessary prerequisite for the use of a social mobility strategy. This 
is especially the case when the new inhabitants believe that the new social group has a higher status than the group that they currently belong to. By making use of social mobility, they then choose to increase their own status by accepting the social identity of the new group (Martiny et al., 2012). Ties to the new place of residence, on the other hand, tend to weaken the positive relationship between permeability and the use of social mobility. This result was unexpected, but can possibly be explained by stating that if a person has more ties with the region, this person feels accepted to a certain extent already, thereby reducing the necessity to make use of the social strategies in general.

When a person already has more ties with a place, it is likely that the cultural distance (difference between the new and the old culture) is small, thereby decreasing the adaptation issues that the individual experiences (Suanet \& Van de Vijver, 2009) and subsequently also decreasing the use of social strategies. Status of the new social group and ties to the new place of residence both do not have an effect on the use of the collective strategies. It is posed that this could be caused by the fact that collective strategies are seen as strategies to resort to when social mobility is less possible because the group boundaries are not permeable (Ellemers \& Van Rijswijk, 1997; Jackson et al., 1996). As the use of the social strategies is not a choice, but rather a consequence of permeability, the ties to the new place of residence and status of the new resident group might not have an impact here. This result contributes to research on identity management as it is shown that the acceptance of newcomers by current residents is a prerequisite for the use of identity management strategies already, thereby reducing the necessity to make use of the social strategies in general. When a person already has more ties with a place, it is likely that the cultural distance (difference between the new and the old culture) is small, thereby decreasing the adaptation issues that the individual experiences (Suanet \& Van de Vijver, 2009) and subsequently also decreasing the use of social strategies. Status of the new social group and ties to the new place of residence both do not have an effect on the use of the collective strategies. It is posed that this could be caused by the fact that collective strategies are seen as strategies to resort to when social mobility is less possible because the group boundaries are not permeable (Ellemers \& van Rijswijk, 1997; Jackson et al., 1996). As the use of the social strategies is not a choice, but rather a consequence of permeability, the ties to the new place of residence and status of the new resident group might not have an impact here. This result contributes to research on identity management as it is shown that the acceptance of newcomers by current residents is a prerequisite for the use of identity management strategies.

Secondly, the outcomes of study 3 show that the use of the different social strategies impact the level of identification with both the new city of residence as well as the city of origin. The use of social mobility increases the level of identification as was expected, but unexpectedly, the use of this individual strategy also increases the level of 
identification with the place of origin. An individual who uses social creativity identifies less with the new place of residence, which is in line with the hypotheses, but does not identify more with the city of origin. Finally, the use of social competition increases the level of identification with the old place of residence in accordance with the hypotheses, but also increases the level of identification with the new place of residence, which is a somewhat counterintuitive result. Research on social strategies has produced mixed and opposing results before (Jackson et al., 1996), yet a convincing explanation for these mixed results is missing to date. Possible explanations include that most previous studies are conducted in a laboratory setting (e.g. Ellemers \& Van Rijswijk, 1997), while the current study is conducted in a real-life context. Another possible explanation is the different focus in the adaptation process. Where most studies focus on the front end of the adaptation process and measure the level of identification a priori (e.g. Ellemers \& Van Rijswijk, 1997; Jackson et al., 1996), the current study focuses on the outcomes of this adaptation process. Another, non-methodological explanation might be that when using social mobility and social competition, there is a strong focus on the important aspects of a place identity (Finley, 2010). This, combined with the fact that people have moved and this move cannot be easily undone, induces that the positive effects of both social mobility as well as social competition can be seen as cognitive dissonance reduction in which the residents are aligning their behavior (of moving) with their cognitions (of identifying with a place) concerning both the new place ("I moved here so I should like the place I live in") as well as the old place ("I do not want to forget about the memories"). In using social creativity, individuals do not focus on these important dimensions, but rather look for irrelevant characteristics of the new place for comparison (Al Ramiah et al., 2011). As the important dimensions of both places do not become salient during the adaptation process, the identification with the old place might not change while the identification with the new place decreases as the comparison with irrelevant dimensions makes the old place look better. These results integrate research on identification and social identity which addresses a gap that was previously defined in literature (Cuba \& Hummon, 1993).

Third, the results of study 3 indicate that when an individual identifies with a place brand, this person will show increased positive behavioral intentions as well as increased word-of-mouth towards this place. Hence, re confirming the strong link between identification and behavioral intentions (Ahearne at al., 2005) on the one hand, and wordof-mouth (Tuškej et al., 2011) on the other hand, regardless of the phase of the relationship that the inhabitant is in. This finding confirms the powerful role of identification in a place branding context and thereby contributes to place branding literature. Next to the direct positive effects of identification with a place on behavioral variables towards the same place, a consistent series of negative cross-effects were also found, implying 
that when a person identifies with a certain place, this identification decreases the behavioral intention as well as word-of-mouth intentions towards other places. It has been suggested before that multiple place identities can compromise each other (Cuba \& Hummon, 1993). In the current study, this suspicion is confirmed.

The outcomes of the conducted research contribute to literature on place branding, social identity and relationship marketing in the context of place branding. The conducted study investigated the role of permeability of group boundaries, social strategies and identification in the development of word-of-mouth and behavioral intention, thereby describing the adaptation process an individual goes through after a life transition such as a move. A large amount of attention has been paid to the topic of place branding and the identity of a place (Kavaratzis \& Hatch, 2013; Cuba \& Hummon, 1993; Konecnik Ruzzier \& De Cheratony, 2013). In these studies, the number of stakeholder groups and the influence these stakeholders had was recently mentioned as a complicating factor in the place branding process (e.g. Kemp et al., 2012b; Konecnik Ruzzier \& De Cheratony, 2013), resulting in a lack of control of the place brand for place branding managers (Kavararatzis \& Hatch, 2009). In the current research, the role of one of these stakeholder groups was reversed. It is posed that (ex)inhabitants can be regarded as an asset to the place branding process instead of the complicating factor that they have been seen as so far. In doing so, the current research has three main contributions. (1) Individuals adapt their social identities after a move; this adaptation process is made more insightful by drawing on acculturation and socialization theory and using identity management strategies as an explanatory mechanism for the adaptation process. (2) This paper shows the interplay between different identities at different points in the relationship life-cycle of an individual with a place brand, thereby contributing to literature on place branding and relationship marketing as well as social identity theory. (3) The results of this research make the social identity processes that (ex)inhabitants go through more insightful, thereby creating opportunities for place brand managers to regain more control over the place branding process and employing (ex)inhabitants as valuable ambassadors for the place and its brand.

\subsection{Future Research and Conclusion}

The outcomes of study 3 suggest several limitations as well as opportunities for further research. First, the current research is a cross sectional study with individuals who have migrated to a city in the last ten years. While the research has extensively attempted to control most of the unexplained variation in the data, it would certainly be an interesting avenue to conduct a study on the adaptation process after a move in a longitudinal fash- 
ion. Whereas this study focuses on the adaptation process itself and its outcomes, following (ex)inhabitants for a longer period of time could broaden insight into the development of the adaptation process over time. As the adaptation process is ongoing, but is especially intense in the period after the life transition (Simosi, 2010), it would be ideal to start with a measure of identification before a move and then following an individual throughout the move and the period thereafter in order to get a grasp of the complete process.

Second, the results that were obtained show unexpected relationships between the use of social strategies and identification with both the new, as well as the old place of residence. This might be related to the use of social strategies as a mechanism, since this approach has rendered mixed results in the past (Jackson et al., 1996). Further research on this relationship is necessary in order to come up with a solid and consistent mechanism that describes the adaptation process after a move in order to still be better able to predict behavioral outcomes.

Finally, from a practical perspective, it is advised to elaborate on this study in the future by focusing on different ways in which place branding managers can influence the adaptation process, thereby creating practical tools that would contribute to the practice of place branding. As residents use the place brand as an important mechanism to communicate about their own identity (Choo et al., 2011), there is a call for direct tools that can facilitate this communication by residents.

In conclusion, the current research provides a comprehensive overview of the process through which individuals rebalance their social identities after a move. Furthermore, the outcomes of this research show that the rebalancing efforts largely result in positive identification with both the new place of residence as well as the place of origin. Identification with a place positively impacts behavioral intention and word-of-mouth towards the same place, whereas it decreases these outcomes with respect to other places. 

Chapter 6

Discussion \& Conclusion 


\subsection{Introduction}

This dissertation centered around the notion of places and brands as sources of identification. Based on the three main concepts of identification, the post-dissolution phase of a customer-brand relationship and place branding, three empirical studies were conducted which integrate these concepts. In recent years, there has been a sharp increase in the practice of place branding (Hanna \& Rowley, 2011; Warnaby \& Medway, 2013). This is driven by an increased competition for (human) resources between places (Riza et al., 2012). Places struggle to brand themselves in the minds of prospective visitors, residents and investors (Dinnie, 2004). In this, managers often make us of traditional product and services marketing techniques as specific tools for place branding are lacking. There is however no consensus on the extent to which product and services marketing tools can be transferred to the place branding context (Anholt, 2008). Therefore, this dissertation used the notion that people use place brands as a tool to communicate about their identity (Kemp et al., 2012a), like they do with product and services brands, to focus on the role of identification in a customer-brand relationship. Next to this, the transfer of products and services marketing techniques to the place branding context was conceptualized.

Ultimately, the main goal of this dissertation was to demonstrate the role of identification in place branding as an integration of these two concepts is considered to be an important contribution to place branding theory (Kavaratzis \& Hatch, 2013). Even though the number of publications on the topic of place branding is growing rapidly (Dinnie, 2009; Lucarelli \& Berg, 2011), there are still a number of gaps between place branding theory and practice (Kavaratzis \& Hatch, 2013). One of these gaps is related to residents being considered as one of the most important stakeholder groups in place branding (Kemp et al., 2012a). As residents identify with a place brand, they positively communicate about it as a means to express their self-identity (Kaplan et al., 2008), making residents important ambassadors for the place brand (Choo et al., 2011). It is, however, not known at the moment which role identification plays in the development of this ambassadorship, neither is it known whether ex-residents can be considered ambassadors even if they no longer live in a place. This leads us to the second main contribution of this dissertation, which is a contribution to literature on relationship marketing in general and the relationship life-cycle specifically. In this dissertation, a conceptual framework was designed to describe the post-dissolution phase of the customer-relationship life-cycle. This phase can be defined as a period of absence from a brand after dissolution of a customer-brand relationship, which can possibly (but not necessarily) be followed by relationship revival (Stauss \& Friege, 1999; Odekerken-Schröder et al., 2010). The development of this framework started in a products and services context and later extended to the place branding context. 
While building on the assumption that the bond of identification that is created during a customer-brand relationship can endure even after the relationship has been dissolved, a framework was developed and tested for the post-dissolution phase of customer brand relationships with place brands. In this, the purpose was to answer the main research question:

What role does identification with a place brand play in the post-dissolution phase of a customer-brand relationship, and what (positive) consequences does identification with a place brand have in the post-dissolution phase of the customer-brand relationship?

In the remainder of this chapter, the main findings of the three empirical studies are summarized. Next, the theoretical and managerial contributions of the research are elaborated upon in a short discussion section. This chapter ends with suggestions for further research related to this dissertation and a conclusion.

\subsection{Synopsis}

\subsubsection{Study 1: Products \& Services and their Ex-Customers}

The first study is mainly aimed at developing a framework for the post-dissolution phase and testing this framework in the context of customer-brand relationships with products and services brands. Central to this framework is the concept of identification, which is defined as the cognitive inclusion of a brand in a person's social identity (Bhattacharya et al., 1995). Previous research has abundantly shown that identification with a brand has positive behavioral consequences during the relationship (e.g. Bhattacharya \& Sen, 2003; He et al., 2012; Ahearne et al., 2005; Stokburger-Sauer et al., 2012; Keh \& Xie, 2009; Brown et al., 2005; Tuškej et al., 2011). As identification has been shown to be rather stagnant across time (Mael \& Ashforth, 1992) and to exist without official membership of a group (Bhattacharya \& Sen, 2003), we pose that positive behavioral consequences of identification can also be found during the post-dissolution phase. Furthermore, the coping mechanisms expressive support seeking and active coping (Duhachek 2005) were included as mediating constructs in the framework. Coping is mentioned in previous research as a cognitive response to relationship dissolution (Bogomolova, 2010) that is used to adapt the identity of the person (Tajfel \& Turner, 1986) and is, therefore, deemed to fit well in the post-dissolution phase of the customer-brand relationship. Finally, attribution of the dissolution is also taken into account as a moderating variable that can shape the coping process (Watson \& Spence, 2007; Sweeny, 2008) and subsequent outcomes (Bogomolova, 2010) either positively or negatively. 
For the purpose of testing this framework in a products and services context, a sample of 225 students participated in a study about their real life experiences with brands that they once had a customer-brand relationship with and which was currently dissolved. The students wrote about a self-selected brand relationship and its dissolution in order to make the relationship salient, and subsequently answered questions on the variables in the framework. The choice of brand was not manipulated, which ensured the description of real experiences and cognitions that were related to the brand.

The findings of this study show the strong and important role of identification in the post-dissolution phase. Similar to studies conducted throughout a customer-brand relationship (e.g. Keh \& Xie, 2009; Brown et al., 2005; Tuškej et al., 2011), identification has a strong, positive and direct impact on positive behavior towards the brand (wordof-mouth intention and return intention). These results show that identification with a brand that is built up during the relationship does not disappear after the relationship has officially been dissolved and even continues to have positive effects on brand related behavior after the end of a relationship. Another finding indicates that coping, in the form of active coping and expressive support seeking, functions as an underlying mechanism when studying the post-dissolution phase in a products and services context. When a customer identifies more with a brand after the dissolution of the relationship, this individual experiences a higher need for coping and thus makes more use of both expressive support seeking as well as active coping. Whereas active coping functions as a facilitator in which the positive input from identification is used to reinforce positive word-of-mouth and return intention (Vélez et al., 2011), expressive support seeking acts as a suppressor. By using expressive support seeking, people vent more and are directed towards the new situation (Tein et al., 2000), thereby suppressing the positive influence of identification and having a negative impact on word-of-mouth and return intention. The attribution of the relationship dissolution plays a moderating role such that internal attribution causes the 'love is blind effect' (Grégoire \& Fisher, 2006), giving more room to the positive cognitions related to the former brand when compared to external attribution.

\subsubsection{Study 2: Places and their Ex-Residents}

The second study extends the previously defined framework into a place branding context. As the applicability of marketing concepts originating from the field of products and services marketing to the place branding field is questioned (Anholt, 2008), a oneto-one duplication of the results of study 1 is not straightforward. Still, as there is a call for further integration of the concepts of place branding and identification (Kavaratzis \& Hatch, 2013), the extension of this framework into the place branding field is deemed necessary. 
For the second study, a sample of 110 respondents who had moved away from a specified mid-sized European city was collected. The respondents were surveyed by means of an online questionnaire and answered questions on their identification with the old place of residence, coping efforts, return intentions, word-of-mouth intentions and attribution. Through this approach, it was ensured that the second study was also conducted in a real-life context and people were referring to a real relationship with a place brand.

The results of the second study show that, like in a products and services context, identification has a strong positive relationship with both return intention as well as positive word-of-mouth during the post-dissolution phase of a customer-brand relationship with a place brand. This confirms the importance of residents in the place branding process (Konecnik Ruzzier \& De Cheratony, 2013; Choo et al., 2011) and even extends the importance of identification to the yet unknown role of ex-residents. Coping, however, does not fulfill a mediating role in the place branding context. Although people make use of coping, the relationships with other variables are often insignificant or counterintuitive. Active coping is not influenced by identification and has a negative instead of the predicted positive impact on return intention. Expressive support seeking shows a marginal positive effect on return intention instead of the predicted negative effect. Both coping styles have no influence on word-of-mouth. This difference in results can possibly be ascribed to a bigger temporal separation of the stressor (the moving decision) and the action (the actual move) in a place branding context than in a products and services context. Due to this temporal separation, a person has time to cope with a move before it actually happens (a method called proactive coping), minimizing the role of coping in the post-dissolution phase (Beehr \& Mc Grath, 1996; Schwarzer \& Tauber, 2002).

Next to the difference in coping, a difference in attribution was also found. In the products and services context, attribution moderates the relationship between coping and return intention, but not between coping and positive word-of-mouth. In the place branding context, on the other hand, only the relationship between coping and positive word-of mouth is moderated by attribution. Thus, in the products and services context, attribution plays a role in the decision to return to the brand, while in a place branding context, attribution plays a role in the decision to talk positively about a brand. Previous studies related attribution to both return intention as well as word-of-mouth (e.g. Choi \& Mattila, 2008), which signals that the opposite effect might be caused by contextual differences. Additionally, in the current research, only the locus of causality was included when determining attribution. Dependent on the context, however, stability of the attribution could also play a role (Weiner, 2000). It is likely that in place branding, the attribution basis is more stable than in the products and services context, related to a higher level of intangibility and a lower level of controllability of a place brand when 
compared to a products and services brand. Since stability determines customers' expectations of future outcomes (Kaltcheva, Winsor \& Parasuraman, 2013), this factor might explain part of the difference in outcomes across the contexts.

\subsubsection{Study 3: Balancing Place Identities}

Study 3 builds on the core notion of the previously defined framework, which is the strong relationship between identification with the old brand and the behavioral outcomes of word-of-mouth and return intention. In study 3, the developed framework is partly redefined. Instead of merely focusing on identification with the old place of residence, the new place of residence is also taken into account in order to test the notion that people can identify with multiple places at the same time (Cuba \& Hummon, 1993). Furthermore, identity management strategies (Mummendey et al., 1999) are incorporated into the framework of the post-dissolution phase in a place branding context. Through this, the adaptation process of a new resident after a life transition (in the current context, a move) is stressed. Identity management strategies concern the outcomes of intergroup comparisons (Martiny et al., 2012) and determine the belongingness and adjustment to different social (resident) groups. Therefore, it is predicted that the use of different identity management strategies influences identification with the new as well as the old place of residence (Langston \& Cantor, 1989).

When using identity management strategies, people can opt for an individual strategy, called social mobility, in which a person actively attempts to become a true member of the new place of residence, thereby transferring his or her identity to this new group of residents (Martiny et al., 2012; Niens \& Cairns, 2003; Ellemers \& Van Rijswijk, 1997; Al Ramiah et al., 2011). Next to this, people can opt for the use of social creativity and social competition, which are collective strategies implying that these strategies are directed at showing superiority of the old resident group on either irrelevant dimensions (social creativity) or core dimensions (social competition) (Finley, 2010). The choice of using the different identity management strategies is dependent on the extent to which the environment accepts the individual. This perceived level of acceptance in the new group is referred to as perceived permeability of group boundaries (Kessler \& Mummendey, 2002). Finally, as people who believe that the new group of residents has a higher status than the old group of residents make a greater effort to belong to this group (Ellemers, 1993), and previously developed ties to a place make it easier to integrate in this place, perceived status and ties to the new place of residence are incorporated as moderating variables in the framework.

In essence, extra attention is paid to identification and the core relationship between this construct and the behavioral constructs of behavioral intention and positive word-of-mouth, which was already determined in studies 1 and 2. As positive word-of- 
mouth was indicated in the previous research as a special variable of interest for place brand managers, this construct is further scrutinized in the current study, in addition to the measurement of behavioral intention. The concept of word-of-mouth in the current study is divided into valence and intensity (Lang, 2009). Valence points to the extent that word-of-mouth is positive and intensity describes the frequency people talk about the place brand. In line with previous research (Ahearne et al., 2005; Brown et al., 2005; Tuškej et al., 2011), a positive relationship is depicted between identification and behavioral intention, word-of-mouth valence and word-of-mouth intensity related to the same place. However, as identification was measured with both the new and old place, cross-relationships between the different variables are also expected. As different identities can compromise each other (Cuba \& Hummon, 1993), negative cross-relationships between identification with one place and behavioral variables related to the other place were predicted.

In study 3, a sample of 285 respondents who had moved to a medium sized European city was analyzed. Whereas in study 2 , the respondents had the old place of residence in common, in the current study, the new place of residence is the common factor among the respondents. The respondents participated in an online survey and answered questions regarding permeability, identity management strategies, status, ties to the region, identification, behavioral intention, word-of-mouth valence and word-of-mouth intensity regarding both the new as well as the old place of residence. Also, in the third study, a real-life context was ensured in order create the highest possible level of validity, reliability and generalizability.

The results indicate that when a customer moves from one place to another, the place-related identities that this individual has need to be rebalanced through an adaptation process. This adaptation process starts with permeability. In line with previous research, results indicate that permeability is an important antecedent for the use of identity management strategies (e.g. Kessler \& Mummendey, 2002; Jackson et al., 1996; Al Ramiah et al., 2011). Raised permeability of group boundaries increases the use of social mobility, while a lower perceived level of permeability indicates more use of social creativity and social competition. Status and ties to the region have a moderating influence on this relationship between perceived permeability and social mobility. High status strengthens this relationship and induces people to improve their own status (Martiny et al., 2012). Ties to the region, on the other hand, makes the relationship between permeability and social mobility weaker. This unexpected result is attributed to the fact that more ties to the region also imply less cultural distance (Suanet \& Van de Vijver, 2009) thereby decreasing the need for identity management in general.

The identity management strategies, in turn, influence identification with the new as well as the old place of residence. Social mobility and social competition positively influence identification with both the new and old place of residence. As the use of both 
strategies results in a focus on the most important aspects of the place identity (Finley, 2010), it is assumed that this focus results in an attempt for cognitive dissonance reduction through which customers align their behavior of moving with their positive identity related cognitions. When using social creativity, there is a focus on less important dimensions (Al Ramiah et al., 2011), which might prevent positive experiences with the important characteristics of the new place and results in a negative relationship between social creativity and identification.

Finally, in line with the two other studies and previous research (Ahearne at al., 2005; Tuškej et al., 2011), a significant positive relationship was reconfirmed between identification and the behavioral variables of behavioral intention, word-of-mouth valence and word-of-mouth intensity regarding the same place. The cross relationships between identification and the behavioral variables are negative indicating that the different place related identities a person has can compromise each other (Cuba \& Hummon, 1993).

These results lead us to conclude that (ex)residents can be seen as ambassadors for their old place of residence as well as for their new place of residence. Identification with a place has a strong, positive and significant effect on behavior towards the same place and positive word-of-mouth intensity and valence towards that place. Additionally, identification with the new place of residence negatively and significantly influences behavioral intention and word-of mouth towards the old place (and vice versa), but this effect is weaker than the positive direct effect. From this, it can be concluded that different place identifications can compromise each other, but that this compromising does not make the strong positive relationship between identification and behavioral variables disappear.

\subsection{Discussion of Implications}

The research that is conducted in the current dissertation advances the literature on the post-dissolution phase of customer-brand relationships as well as place branding literature. Three studies in a products and services context as well as a place branding context were conducted to examine the role of identification with the old brand after dissolution and with the new brand. Second, it was examined how identification relates to behavioral variables like return intention and word-of-mouth. Furthermore, the roles of coping and identity management in the post-dissolution phase were reviewed. In this part of the conclusion, the three most important theoretical contributions are defined, as well as the three primary managerial contributions. 


\subsubsection{The Post-Dissolution Phase}

Despite abundant research on customer-brand relationships (e.g. Ahearne et al., 2005; Dwyer et al., 1987; Fournier, 1998) and customer-brand relationship dissolution and regain management (e.g. Coulter \& Ligas, 2000; Michalski, 2004; Stauss \& Friege, 1999), relatively limited attention has been paid to the period of absence after dissolution and before possible relationship revival, which is referred to as the post-dissolution phase of the customer-brand relationship lifecycle (Odekerken-Schröder et al., 2010). The first theoretical contribution relates to this gap by looking at the identity related processes customers go through in order to handle the separation distress that was caused by the dissolution of the customer-brand relationship. Furthermore, the focus was on how these processes influenced positive behavioral intentions towards the old brand in terms of both return intention as well as positive word-of-mouth.

The findings, first and foremost, indicate that identification with a brand is not only a powerful tool for brand managers during a customer-brand relationship (Bhattacharya et al., 1995), but that identification with an old brand after relationship dissolution has a direct, significant and positive impact on behavioral intentions towards the old brand, in both the products and services context as well as the place branding context. This shows that identification is a psychological construct that cannot just be switched on and off dependent on the situation. Furthermore, investing in a healthy customer-brand relationship before dissolution proves to be important not only during the relationship, but also pays off in the long-term after the relationship has been dissolved.

\subsubsection{Extending Marketing Concepts to the Place Branding Context.}

As identified in previous research, there is a debate on the extent to which marketing concepts applied in products and services marketing can be used in place branding (Anholt, 2008). Furthermore, there is a recent call to further integrate the theory on place branding with the concept of identification (Kavaratzis \& Hatch, 2013). This gap in theory is addressed by this dissertation and leads to the second theoretical contribution, which depicts that the place branding context does require a differential approach in marketing than products and services, but that the concept of identification plays an important role and consistently relates to the tested behavioral concepts.

While the effects of identification on behavioral intentions are consistent, significant and positive across contexts, we do find differential impacts as well. The most important difference is related to the underlying mechanism in the post-dissolution phase. Whereas coping was identified as an underlying mechanism in study 1 , this could not be replicated in study 2 . In a products and services context, identification gives rise to coping responses in the form of both active coping as well as expressive support seeking. 
Active coping is positively related to both return intention as well as word-of-mouth, while expressive support seeking has a negative impact on these behavioral variables. Both coping strategies are infused by identification with the old brand, but have a varying impact on behavioral intention. While active coping is most likely used to align thoughts with behavior and thus translates positive identification thoughts into positive behavior, expressive support seeking is used as a method to adapt to the new situation and thus decreases positive behavior towards the old brand (Tein et al., 2000). When looking at the place branding context, however, the findings indicate different results related to coping. In the place branding context, identification with the old brand only feeds the use of expressive support seeking strategies, and does not influence the use of active coping. Furthermore, active coping has a negative influence on intention to return, while expressive support seeking shows a marginal positive influence on this variable. We pose that this turnaround of effects is caused by the temporal separation of the stressor (the decision to move) and the action (the actual move) in the place branding context, giving the customer time to proactively cope with the situation (Greenglass \& Fiksenbaum, 2009). Thus, it is posed that, dependent on the context of the dissolution, customers cope with different elements of the dissolution, which, in turn, has a differential impact on the customers' behavior towards the old brand. Furthermore, it shows that place branding does seem to be in a different league than products and services marketing and an effort has to be made to shed more light on branding in this context.

From a management perspective, the results indicate that Anholt (2008) is correct in saying that marketing tools that were originally developed for a products and services context cannot simply be copied into a place branding context. On the other hand, the findings also imply that whereas word-of-mouth is positively influenced by active coping and negatively influenced by expressive support seeking in the products and services context, it is remarkably independent of any coping influences during the post-dissolution phase of the customer brand-relationship with a place brand. Thus, this indicates that former inhabitants may function as an important tool for place branding managers, since they base their word-of-mouth intentions solely on positive identification with the old brand and this effect is not altered by any coping after dissolution of the relationship. This supports research that stresses the importance of stakeholders (Van Ham, 2008) and indicates that residents are trustworthy stakeholders who function as expert sources for people with less direct brand experience (Choo et al., 2011). It is, therefore, advised for managers to start place branding efforts with a focus on residents and align branding efforts with the needs of this stakeholder group (Kemp et al., 2012b). Residents, even when they leave the place of residence and turn into ex-residents, are more than just a complicating factor (Konecnik Ruzzier \& De Cheratony, 2013) to a brand, since they can function as valuable ambassadors for the place brand. 


\subsubsection{Balancing Different Place Related Identities}

In previous research, it has been determined that people can identify with multiple places at the same time (Cuba \& Hummon, 1993). Some situations, like a move, are considered to be impactful life transitions that require an adaptation process to accommodate a new balance for a person's social identity (Wheaton 1990) and to deal with uncertainty (Ashforth \& Saks, 1996; Crisp \& Turner, 2011). It has, however, not been researched which impact such a life transition ultimately has on the behavior towards both the new and old place of residence. The current dissertation addresses this gap and shows that the adaptation process after a move, in line with previous research, results in identification with multiple brands simultaneously. Furthermore, identification with a place brand has positive implications for return intention and word-of-mouth regarding the same place brand (Bhattacharya \& Sen, 2003; Bhattacharya et al., 1995), even after the dissolution of the relationship (Odekerken-Schröder et al., 2010; Johnson et al., 2011). The cross-relationships between identification with one brand and behavioral variables related to another brand prove to be negative, but not as strong as the direct relationships. This shows that, as expected by Cuba and Hummon (1993), identification with multiple place brands does indeed have a compromising effect. This effect is, however, not strong enough to cause actual harm. Even after a life transition and the consequent rebalancing of social identity, the positive relationship between identification and return intention as well as word-of-mouth, still holds.

The final managerial contribution relates back to the previous managerial contribution. It was already indicated that residents can be a valuable brand communication source across time. When looking at the rebalancing of identities, it can added that it also holds across place brands. Although the different place related identities compromise each other (Cuba \& Hummon, 1993) in terms of behavioral outcomes, the adaptation process is beneficial for the formation of identification as long as residents focus on the important attributes of a place brand attitude. Nevertheless, based on previous literature (e.g. Ellemers \& Van Rijskwijk 1997; Jackson et al., 1996; Al Ramiah et al., 2011), a differential effect was expected of social mobility, social creativity and social competition on identification with the new and the old place of residence. It is found, however, that as long as residents focus on the important attributes of a place brand, which is the case in both social mobility as well as social competition (Finley, 2010), the effects on identification with both the new and the old place of residence is positive. This implies that place brand managers should attempt to determine which aspects of their place brand are most important for their residents and educate new residents as well as exresidents on these aspects in order to make them salient and ensure an adaptation process in the new place of residence, resulting in positive identification and behavior. 


\subsection{Future Research Intentions}

Research suggestions for each of the studies were discussed at the end of the relevant chapters. These research suggestions and limitations are summarized below.

From a theoretical perspective, the results in this dissertation call for several theoretical extensions. First, an interesting avenue for further research is the combination of the cognitive concept of identification with the emotional concept of brand love (Batra et al., 2012) in the post-dissolution phase. Whereas the focus was specifically on the cognitive perspective in the current dissertation, an extension with an emotional perspective would be valuable. Furthermore, we advise to include other relationship-related variables, such as attribution stability (Weiner, 2000) and brand salience (Romaniuk \& Sharp, 2004). These variables were only included to a limited extent. Attribution was only measured superficially, whereas salience was manipulated by triggering the respondents to think about a brand before participating in the research. A more pronounced role of these variables can, especially when looking at a customer-brand relationship in retrospective, give more insight into customer-brand relationships in the post-dissolution phase. Third, the findings of this research result in a specific call for more research into an underlying mechanism that plays a consistent role in the postdissolution phase of a customer-brand relationship with a place brand. The mediating role of coping that was found in the products and services context could not be duplicated in the place branding context and the identity management strategies continues to show mixed results (Jackson et al., 1996).

From a practical perspective, further research avenues include the role of proactive coping (Beehr \& Mc Grath, 1996; Schwarzer \& Tauber, 2002) and the related temporal separation between the moving decision (stressor) and the actual move (action). Proactive coping implies that a resident copes with the move while still living in the old place of residence and consequently, under direct reach of a place brand manager. More insight into proactive coping processes related to a move might enable a reconsideration of the moving decision in some cases. Second, further research is on advised on which marketing concepts are transferrable from a products and services marketing context to a place branding context and which concepts cannot be transferred. This way, place brand managers can develop specific place branding tools to influence the identification of residents, who, in turn, use the place brand to communicate about their identity (Choo et al., 2011). Finally, from a methodological perspective, it would be of interest to conduct longitudinal research in the place branding context. This taps back into several other research recommendations made above. If a researcher is able to obtain longitudinal data of the entire moving process, this would be a rich source of information on the post-dissolution phase and the adaptation process, which is ongoing, but intensifies at certain moments, like right after a move (Simosi, 2010). 


\subsection{Final Comments}

In conclusion, the research in this dissertation followed a path of analysis starting with the development of a conceptual framework for the post-dissolution phase in a products and services context and continuing with the extension to a place branding context. Furthermore, insight is given into the adaptation process after a move, by looking at both the new as well as the old place brand. With the current research, new insight is presented into the post-dissolution phase of customer-brand relationships with place brands. The central and important role of identification with a place is shown, which has consistent positive consequences for return intention and word-of mouth related to the place brand, not only during the relationship, but also after the relationship has ended. 


\section{References}


Ahearne, M., Bhattacharya, C. B., \& Gruen, T. (2005). Antecedents and consequences of customer-company identification: Expanding the role of relationship marketing. Journal of Applied Psychology, 90(3), 574-585.

Al Ramiah, A., Hewstone, M., \& Schmid, K. (2011). Social identity and intergroup conflict. Psychological Studies, 56(1), 44-52.

Amiot, C. E., Terry, D. J., Jimmieson, N. L., \& Callan, V. J. (2006). A longitudinal investigation of coping processes during a merger: Implications for job satisfaction and organizational identification. Journal of Management, 32(4), 552-574.

Anholt, S. (2005). Some important distinctions in place branding. Place Branding and Public Diplomacy, 1(2), 116-121.

Anholt, S. (2008). Place branding: Is it marketing, or isn't it? Place Branding and Public Diplomacy, 4(1), 1-6.

Anholt, S. (2009). Should place brands be simple? Place Branding and Public Diplomacy, 5(2), 91-96.

Anholt, S. (2010). Definitions of place branding: Working towards a resolution. Place Branding and Public Diplomacy, 6(1), 1-10.

Antioco, M., Moenaert, R. K., Feinberg, R. A., \& Wetzels, M. G. M. (2008). Integrating service and design: The influences of organizational and communication factors on relative product and service characteristics. Journal of the Academy of Marketing Science, 36(4), 501-521.

Arkes, H. \& Blumer, C. (1985). The psychology of sunk cost. Organizational Behavior and Human Decision Processes 35(1), 124-140.

Aronson, E. (1969). The theory of cognitive dissonance: A current perspective. In L. Berkowitz (Ed.), Advances in Experimental Social Psychology, (volume 4. pp. 1-34).

Ashforth, B. K., \& Saks, A. M. (1996). Socialization tactics: Longitudinal effects on newcomer adjustment. Academy of Management Journal, 39(1), 149-178.

\section{B}

Baird, C. M. (2001). Social identity theory and intergroup relations in gender dominated occupations: A thesis presented in partial fulfilment of the requirements for the degree of Doctor of Philosophy in Psychology at Massey University, Albany, New Zealand.

Balakrishnan, M. S. (2009). Strategic branding of destinations: A framework. European Journal of Marketing, 43(5/6), 611-629. 
Barclay, D., Higgins, C., \& Thompson, R. (1995). The partial least squares approach to causal modeling: Personal computer adoption and use as illustration. Technology Studies, 2(2), 285-309.

Bartel, A. P. (1979). The migration decision: What role does job mobility play? The American Economic Review, 69(5), 775-786.

Batra, R., Ahuvia, A., \& Bagozzi, R. P. (2012). Brand love. Journal of Marketing, 76(2), 116.

Beehr, T. A., \& McGrath, J. E. (1996). The methodology of research on coping: Conceptual, strategic, and operational-level issues. In M. Zeidner, \& N.S. Endler, (Eds.), Handbook of coping: Theory, research, applications. (pp. 65-82). Oxford, England: John Wiley \&Sons.

Ben-Zur, H. (2009). Coping styles and affect. International Journal of Stress Management, 16(2), 87-101.

Bergami, M., \& Bagozzi, R. P. (2000). Self-categorization, affective commitment and group self-esteem as distinct aspects of social identity in the organization. British Journal of Social Psychology, 39(4), 555-577.

Berger, M. C., \& Blomquist, G. C. (1992). Mobility and destination in migration decisions: The roles of earnings, quality of life, and housing prices. Journal of Housing Economics, 2(1), 37-59.

Berry, J. W., \& Annis, R. C. (1974). Acculturative stress: The role of ecology, culture and differentiation. Journal of Cross-Cultural Psychology, 5(4), 382-406.

Berry, L., \& Parasuraman, A. (1991). Marketing services: Competing through quality. New York: the Free Press.

Bhattacharya, C., \& Elsbach, K. D. (2002). Us versus them: The roles of organizational identification and disidentification in social marketing initiatives. Journal of Public Policy \& Marketing, 21(1), 26-36.

Bhattacharya, C. B., Rao, H., \& Glynn, M. A. (1995). Understanding the bond of identification: An investigation of its correlates among art museum members. Journal of Marketing, 59(4), 46-57.

Bhattacharya, C. B., \& Sen, S. (2003). Consumer-company identification: A framework for understanding consumers' relationships with companies. Journal of Marketing, 67(2), 76-88.

Bogdan, C., Rioux, L., \& Negovan, V. (2012). Place attachment, proactive coping and wellbeing in university environment. Procedia-Social and Behavioral Sciences, 33, 865-869.

Bogomolova, S. (2010). Life after death? Analyzing post-defection consumer brand equity. Journal of Business Research, 63(11), 1135-1141.

Bonifield, C., \& Cole, C. (2007). Affective responses to service failure: Anger, regret, and retaliatory versus conciliatory responses. Marketing Letters, 18(1), 85-99. 
Breinlinger, S., \& Kelly, C. (1994). Women's responses to status inequality. Psychology of Women Quarterly, 18(1), 1-16.

Brown, T. J., Barry, T. E., Dacin, P. A., \& Gunst, R. F. (2005). Spreading the word: Investigating antecedents of consumers' positive word-of-mouth intentions and behaviors in a retailing context. Journal of the Academy of Marketing Science, 33(2), 123-138.

Brown, R., \& Williams, J. (1984). Group identification: The same thing to all people? $\mathrm{Hu}$ man Relations, 37(7), 547-564.

\section{C}

Caldwell, N., \& Freire, J. R. (2004). The differences between branding a country, a region and a city: Applying the brand box model. Journal of Brand Management, 12(1), 5061.

Carver, C. S., Scheier, M. F., \& Weintraub, J. K. (1989). Assessing coping strategies: A theoretically based approach. Journal of Personality and Social Psychology, 56(2), 267283.

Chin, W. W. (1998). Commentary: Issues and opinion on structural equation modeling. MIS quarterly, 22(1), 7-16.

Chin, W.M., (2002). Multigroup Analysis with PLS. Retrieved March 15, 2011, from http://disc-nt.cba.uh.edu/chin/plsfaq/multigroup.htm.

Chin, W. W., Marcolin, B. L., \& Newsted, P. R. (2003). A partial least squares latent variable modeling approach for measuring interaction effects: Results from a monte carlo simulation study and an electronic-mail emotion/adoption study. Information Systems Research, 14(2), 189-217.

Choi, S., \& Mattila, A. S. (2008). Perceived controllability and service expectations: Influences on customer reactions following service failure. Journal of Business Research, 61(1), 24-30.

Choo, H., Park, S.-Y., \& Petrick, J. F. (2011). The influence of the resident's identification with a tourism destination brand on their behavior. Journal of Hospitality Marketing \& Management, 20(2), 198-216.

Cicognani, E., Menezes, I., \& Nata, G. (2011). University students' sense of belonging to the home town: The role of residential mobility. Social Indicators Research, 104(1), 3345.

Cohen, J. (1988). Statistical power analysis for the behavioral sciences. New York: AcademicPress.

Coulter, R. A., \& Ligas, M. (2000). The long good-bye: The dissolution of customer-service provider relationships, Psychology \& Marketing, 18(6), 482-493.

Crisp, R. J., \& Turner, R. N. (2011). Cognitive adaptation to the experience of social and cultural diversity. Psychological Bulletin, 137(2), 242. 
Cuba, L., \& Hummon, D. M. (1993). A place to call home: Identification with dwelling, community, and region. The Sociological Quarterly, 34(1), 111-131.

Currás-Pérez, R., Bigne-Alcaniz, E., \& Alvarado-Herrera, A. (2009). The role of self-definitional principles in consumer identification with a socially responsible company. Journal of Business Ethics, 89(4), 547-564.

\section{D}

Davis, D. F., \& Golicic, S. L. (2010). Gaining comparative advantage in supply chain relationships: The mediating role of market-oriented IT competence. Journal of the Academy of Marketing Science, 38(1), 56-70.

De Bruyn, A., \& Lilien, G. L. (2008). A multi-stage model of word-of-mouth influence through viral marketing. International Journal of Research in Marketing, 25(3), 151163.

Department of consumer affairs through Sykes E. (2011) Ten Customer Service Secrets To Win Back Customers. Retrieved Nov. 10, 2012, from http://www.thesykesgrp.com/CustomerService10WinBack01.htm

Dinnie, K. (2004). Place branding: overview of an emerging literature. Place Branding, 1(1), 106-110.

Dinnie, K. (2008). Nation branding and Russia: Prospects and pitfalls. Russian Journal of Communication, 1(2), 199-201.

Dinnie, K. (2009). Japan's nation branding: Recent evolution and potential future paths. Journal of Current Japanese Affairs, 16(3), 52-65.

Dinnie, K., \& Fola, M. (2009). Branding cyprus-A stakeholder identification perspective. In 7th International Conference on Marketing, Athens Institute for Education and Research (ATINER), Athens, Greece: July (pp. 6-9).

Dinnie, K., Melewar, T. C., Seidenfuss, K. U., \& Musa, G. (2009, December). Member state perspectives on the ASEAN region brand. In 3rd International Conference on Destination Branding and Marketing, Institute for Tourism Studies, Macau, 2-4 December (pp. 151-8). Butterworth-Heinemann.

Dixon, J., \& Durrheim, K. (2000). Displacing place-identity: A discursive approach to locating self and other. British Journal of Social Psychology, 39(1), 27-44.

Donoghue, S., \& De Klerk, H. M. (2006). Dissatisfied consumers' complaint behaviour concerning product failure of major electrical household appliances: A conceptual framework. Journal of Family Ecology and Consumer Sciences/Tydskrif vir Gesinsekologie en Verbruikerswetenskappe, 34(1), 41-55.

Donoghue, S., \& De Klerk, H. M. (2012). Consumers' anger and coping strategies following appraisals of appliance failure. International Journal of Consumer Studies, 37(2), 1-8 
Duhachek, A. (2005). Coping: A multidimensional, hierarchical framework of responses to stressful consumption episodes. Journal of Consumer Research, 32(1), 41-53.

Dwyer, F. R., Schurr, P. H., \& Oh, S. (1987). Developing buyer-seller relationships. Journal of Marketing, 51(2), 11-27.

Eberly, M. B., Holley, E. C., Johnson, M. D., \& Mitchell, T. R. (2011). Beyond internal and external: A dyadic theory of relational attributions. Academy of Management Review, 36(4), 731-753.

Ellemers, N. (1993). The influence of socio-structural variables on identity management strategies. European Review of Social Psychology, 4(1), 27-57.

Ellemers, N., Spears, R., \& Doosje, B. (1997). Sticking together or falling apart: In-group identification as a psychological determinant of group commitment versus individual mobility. Journal of Personality and Social Psychology, 72(3), 617.

Ellemers, N., \& Van Rijswijk, W. (1997). Identity needs versus social opportunities: The use of group-level and individual-level identity management strategies. Social Psychology Quarterly, 60(1), 52-65.

Elsbach, K. D., \& Bhattacharya, C. (2001). Defining who you are by what you're not: Organizational disidentification and the national rifle association. Organization Science, 12(4), 393-413.

Eurostat (2012). Employment statistics. Retrieved December 12, 2012, from http://epp.eurostat.ec.europa.eu/statistics_explained/index.php/Employment_statistics.

$\mathrm{F}$

Fan, X., Thompson, B., \& Wang, L. (1999). Effects of sample size, estimation methods, and model specification on structural equation modeling fit indexes. Structural Equation Modeling: A Multidisciplinary Journal, 6(1), 56-83.

Faul, F., Erdfelder, E., Lang, A., \& Buchner, A. (2009). G* Power (Version 3.1. 2)(Software).

Finley, S. A. (2010). An identity-based understanding of intergroup conflict. Contemporary Justice Review, 13(4), 425-441.

Florek, M., Insch, A., \& Gnoth, J. (2006). City council websites as a means of place brand identity communication. Place Branding, 2(4), 276.

Fornell, C., \& Larcker, D. F. (1981). Evaluating structural equation models with unobservable variables and measurement error. Journal of Marketing Research, 18(1), 39-50. 
Fournier, S. (1998). Consumers and their brands: Developing relationship theory in consumer research. Journal of Consumer Research, 24(4), 343-373.

Fredrickson, B. L. (2004). The broaden-and-build theory of positive emotions. Philosophical Transactions: Biological Sciences, 359(1449), 1367-1377.

\section{G}

Galjaard, R., Van Wissen, L., \& Van Dam, K. (2012). European regional population decline and policy responses: Three case studies. Built Environment, 38(2), 293-302.

Garnefeld, I., Helm, S., \& Eggert, A. (2011). Walk your talk: An experimental investigation of the relationship between word of mouth and communicators' loyalty. Journal of Service Research, 14(1), 93-107.

Gómez, A., Brooks, M. L., Buhrmester, M. D., Vázquez, A., Jetten, J., \& Swann Jr, W. B. (2011). On the nature of identity fusion: Insights into the construct and a new measure. Journal of Personality and Social Psychology, 100(5), 918-933.

Greenglass, E. R., \& Fiksenbaum, L. (2009). Proactive coping, positive affect, and wellbeing. European Psychologist, 14(1), 29-39.

Greenwald, A. G. (1975). On the inconclusiveness of "crucial" cognitive tests of dissonance versus self-perception theories. Journal of Experimental Social Psychology, 11(5), 490-499.

Grégoire, Y., \& Fisher, R. J. (2006). The effects of relationship quality on customer retaliation. Marketing Letters, 17(1), 31-46.

\section{$\mathrm{H}$}

Hair, J. F., Black, W. C., Babin, B. J., Anderson, R. E. \& Tatham, R. L. (2006). Multivariate Data Analysis. 6th edition. New Jersey: Prentice Hall.

Hair, J. F., Sarstedt, M., Ringle, C. M., \& Mena, J. A. (2012). An assessment of the use of partial least squares structural equation modeling in marketing research. Journal of the Academy of Marketing Science, 40(3), 414-433.

Halinen, A., \& Tahtinen, J. (2002). A process theory of relationship ending. International journal of Service Industry Management, 13(2), 163-180.

Hankinson, G. (2004). Relational network brands: Towards a conceptual model of place brands. Journal of vacation marketing, 10(2), 109-121.

Hankinson, G. (2007). The management of destination brands: Five guiding principles based on recent developments in corporate branding theory. Journal of Brand Management, 14(3), 240-254. 
Hanna, S., \& Rowley, J. (2008). An analysis of terminology use in place branding. Place Branding and Public Diplomacy, 4(1), 61-75.

Hanna, S., \& Rowley, J. (2011). Towards a strategic place brand-management model. Journal of Marketing Management, 27(5-6), 458-476.

Harmon-Jones, E., Amodio, D. M., \& Harmon-Jones, C. (2009). Action-based model of dissonance: A review, integration, and expansion of conceptions of cognitive conflict. Advances in Experimental Social Psychology, 41, 119-166.

He, H., Li, Y., \& Harris, L. (2012). Social identity perspective on brand loyalty. Journal of Business Research, 65(5), 648-657.

Heider, F. (1958) The psychology of interpersonal relations, New York: Wiley.

Hendrickson, B., Rosen, D., \& Aune, R. K. (2011). An analysis of friendship networks, social connectedness, homesickness, and satisfaction levels of international students. International Journal of Intercultural Relations, 35(3), 281-295.

Hogg, M. A., Terry, D. J., \& White, K. M. (1995). A tale of two theories: A critical comparison of identity theory with social identity theory. Social Psychology Quarterly, 58(4), 255-269.

Hogg, M. A. (2003). Social identity. In M. R. Leary, \& J. P. Tangney (Eds.), Handbook of Self and Identity. (pp. 462-479). New York: The Guilford Press.

Homburg, C., Hoyer, W. D., \& Stock, R. M. (2007). How to get lost customers back? Journal of the Academic Marketing Science, 35(4), 461-474.

Homburg, C., Wieseke, J., \& Hoyer, W. D. (2009). Social identity and the service-profit chain. Journal of Marketing, 73(2), 38-54.

Hospers, G.J. (2006). Borders, bridges and branding: The transformation of the $\emptyset$ resund region into an imagined space, European Planning Studies, 14(8), 1023-1041.

Hospers, G.J. (2011). Place marketing in shrinking Europe: Some geographical notes, Tijdschrift voor Economische en Sociale Geografie, 102(3), 369-375.

Hospers, G.J. (2012). Urban shrinkage and the need for civic engagement, in: A. Haase, G.J. Hospers, S. Pekelsma and D. Rink (eds.), Shrinking Areas: Front-Runners in Innovative Citizen Participation. (pp. 7-28). The Hague: European Urban Knowledge Network. Hulland, J. (1999). Use of partial least squares (PLS) in strategic management research: A review of four recent studies. Strategic Management Journal, 20(2), 195-204.

J

Jackson, L. A., Sullivan, L. A., Harnish, R., \& Hodge, C. N. (1996). Achieving positive social identity: Social mobility, social creativity, and permeability of group boundaries. Journal of Personality and Social Psychology, 70(2), 241-254. 
Johnson, A. R., Matear, M., \& Thomson, M. (2011). A coal in the heart: Self-relevance as a post-exit predictor of consumer anti-brand actions. Journal of Consumer Research, 38(1), 108-125.

Jones, T., Dacin, P. A., \& Taylor, S. F. (2011). Relational damage and relationship repair a new look at transgressions in service relationships. Journal of Service Research, 14(3), 318-339.

Jun, S., \& Yeo, J. (2012). Coping with negative emotions from buying mobile phones: A study of Korean consumers. Journal of Family and Economic Issues, 33(2), 167-176.

K

Kaltcheva, V. D., Winsor, R. D., \& Parasuraman, A. (2013). Do customer relationships mitigate or amplify failure responses? Journal of Business Research, 66(4), 525-532.

Kaplan, M. D., Yurt, O., Guneri, B., \& Kurtulus, K. (2010). Branding places: Applying brand personality concept to cities. European Journal of Marketing, 44(9), 1286-1304.

Kavaratzis, M. (2004). From city marketing to city branding: Towards a theoretical framework for developing city brands. Place Branding, 1(1), 58-73.

Kavaratzis, M. (2009). Cities and their brands: Lessons from corporate branding. Place Branding and Public Diplomacy, 5(1), 26-37.

Kavaratzis, M., \& Ashworth, G. J. (2005). City branding: An effective assertion of identity or a transitory marketing trick? Tijdschrift voor Economische en Sociale Geografie, 96(5), 506-514.

Kavaratzis, M., \& Hatch, M. J. (2013). The dynamics of place brands: An identity-based approach to place branding theory. Marketing Theory, 13(1), 69-86.

Kawakami, K., Phills, C. E., Greenwald, A. G., Simard, D., Pontiero, J., Brnjas, A. et al. (2012). In perfect harmony: Synchronizing the self to activated social categories. Journal of Personality and Social Psychology, 102(3), 562.

Keh, H. T., \& Xie, Y. (2009). Corporate reputation and customer behavioral intentions: The roles of trust, identification and commitment. Industrial Marketing Management, 38(7), 732-742.

Kemp, E., Childers, C. Y., \& Williams, K. H. (2012a). Place branding: Creating self-brand connections and brand advocacy. Journal of Product \& Brand Management, 21(7), 508-515.

Kemp, E., Williams, K. H., \& Bordelon, B. M. (2012b). The impact of marketing on internal stakeholders in destination branding: The case of a musical city. Journal of vacation marketing, 18(2), 121-133.

Kessler, T., \& Mummendey, A. (2002). Sequential or parallel processes? A longitudinal field study concerning determinants of identity-management strategies. Journal of Personality and Social Psychology, 82(1), 75. 
Konecnik Ruzzier, M., \& De Chernatony, L. (2013). Developing and applying a place brand identity model: The case of Slovenia. Journal of Business Research, 66(1), 45-52.

Kotler, P., \& Gertner, D. (2002). Country as brand, product, and beyond: A place marketing and brand management perspective. Journal of Brand Management, 9(4), 249261.

Kuenzel, S., \& Halliday, S. (2010). The chain of effects from reputation and brand personality congruence to brand loyalty: The role of brand identification. Journal of Targeting, Measurement and Analysis for Marketing 18(3), 167-176.

$\mathrm{L}$

Lam, S. K., Ahearne, M., Hu, Y., \& Schillewaert, N. (2010). Resistance to brand switching when a radically new brand is introduced: A social identity theory perspective. Journal of Marketing, 74(6), 128-146.

Lang, B. (2009). Toward a better measure of positive and negative word of mouth: a replication and extension and a case for content validity. Paper presented the Proceedings of the Australia New Zealand Marketing Academy Conference, Melbourne, Australia, 2009.

Langston, C. A., \& Cantor, N. (1989). Social anxiety and social constraint: When making friends is hard. Journal of Personality and Social Psychology, 56(4), 649.

Lazarus, R. (1993). Coping theory and research: Past, present and future. Psychosomatic Medicine, 55(3), 234-247.

Leary, M. R., \& Tangney, J. P. (Eds.). (2003). Handbook of Self and Identity. New York: The Guilford Press.

Lucarelli, A., \& Berg, P. O. (2011). City branding: A state-of-the-art review of the research domain. Journal of Place Management and Development, 4(1), 9-27.

M

MacKinnon, D. P., Krull, J. L., \& Lockwood, C. M. (2000). Equivalence of the mediation, confounding and suppression effect. Prevention Science, 1(4), 173-181.

Mael, F., \& Ashforth, B. E. (1992). Alumni and their alma mater: A partial test of the reformulated model of organizational identification. Journal of Organizational Behavior, 13(2), 103-123.

Markus, H., \& Wurf, E. (1987). The dynamic self-concept: A social psychological perspective. Annual review of psychology, 38(1), 299-337. 
Martiny, S. E., Kessler, T., \& Vignoles, V. L. (2012). Shall I leave or shall we fight? Effects of threatened group-based self-esteem on identity management strategies. Group Processes \& Intergroup Relations, 15(1), 39-55.

Maute, M. F. (2011). Restraining the dissolution of faltering exchange relationships: The influence of relationship trust and switching barriers on customer complaining, loyalty, and defection. International Business \& Economics Research Journal (IBER), 1(5), 85-91.

Medway, D., Warnaby, G., \& Dharni, S. (2010). Demarketing places: Rationales and strategies. Journal of Marketing Management, 27(1-2), 124-142.

Merrilees, B., Miller, D., \& Herington, C. (2009). Antecedents of residents' city brand attitudes. Journal of Business Research, 62(3), 362-367.

Michalski, S. (2004). Types of customer relationship ending processes. Journal of Marketing Management, 20(9-10), 977-999.

Morgan, R. M., \& Hunt, S. D. (1994). The commitment-trust theory of relationship marketing. Journal of Marketing, 58(3), 20-38.

Mummendey, A., Kessler, T., Klink, A., \& Mielke, R. (1999). Strategies to cope with negative social identity: Predictions by social identity theory and relative deprivation theory. Journal of Personality and Social Psychology, 76(2), 229.

$\mathrm{N}$

Nielsen (2009). Persbericht Retrieved March 9, 2012 from http://www.nl.nielsen.com/news/Persoonlijkeaanbevelingenenonlinereviews_apr09.pdf.pdf

Niens, U., \& Cairns, E. (2003). Explaining social change and identity management strategies: New directions for future research. Theory \& Psychology, 13(4), 489-509.

Nitzan, I., \& Libai, B. (2011). Social effects on customer retention. Journal of Marketing, 75(6), 24-38.

Nunnally, J. C., \& Bernstein, I. H. (eds.). (1994). Psychometric theory. McGraw, New York.

$\mathrm{O}$

Odekerken-Schröder, G., Hennig-Thurau, T., \& Knaevelsrud, A. B. (2010). Exploring the post-termination stage of consumer-brand relationships: An empirical investigation of the premium car market. Journal of Retailing, 86(4), 372-385.

Oliver, R. L. (1993). Cognitive, affective, and attribute bases of the satisfaction response. Journal of Consumer Research, 20(3), 418-430.

Owens, T. J., Robinson, D. T., \& Smith-Lovin, L. (2010). Three faces of identity. Annual Review of Sociology, 36(1), 477-499. 
Park, C. W., Maclnnes, D. J., Priester, J., Eisingerich, E. B., \& lacobucci, D. (2010). Brand attachment and brand attitude strength: Conceptual and empirical differentiation of two critical brand equity drivers. Journal of Marketing, 74(6), 1-17.

Patrick, V. M., Lancellotti, M. P., \& Demello, G. (2009). Coping with non-purchase: Managing the stress of inaction regret. Journal of Consumer Psychology, 19(3), 463-472.

Price, L. L., \& Arnould, E. J. (1999). Commercial friendships: Service provider-client relationships in context. Journal of Marketing, 63(4), 38-56.

Putrevu, S., \& Lord, K. R. (1994). Comparative and noncomparative advertising: Attitudinal effects under cognitive and affective involvement conditions. Journal of Advertising, 23(2), 77-91.

\section{R}

Reed I, A., Forehand, M. R., Puntoni, S., \& Warlop, L. (2012). Identity-based consumer behavior. International Journal of Research in Marketing, 29(4), 310-321.

Reputation institute (2012) 2012 City RepTrak ${ }^{\mathrm{TM}}$ Topline Report, Retrieved July 18, 2013 from http://www.reputationinstitute.com/thought-leadership/complimentary-re ports-2012

Retail Consumer Report (2011) Retrieved October 30, 2012 from http://media.stellaservice.com/public/pdf/Retail_Consumer_Report_2011.pdf

Riza, M., Doratli, N., \& Fasli, M. (2012). City branding and identity. Procedia-Social and Behavioral Sciences, 35, 293-300.

Romaniuk, J., \& Sharp, B. (2004). Conceptualizing and measuring brand salience. Marketing Theory, 4(4), 327-342.

Roos, I., \& Gustafsson, A. (2007). Understanding frequent switching patterns: A crucial element in managing customer relationships. Journal of Service Research, 10(1), 93108.

Ryan, J., \& Silvanto, S. (2010). World heritage sites: The purposes and politics of destination branding. Journal of Travel \& Tourism Marketing, 27(5), 533-545.

Sam, D. L., \& Berry, J. W. (2010). Acculturation when individuals and groups of different cultural backgrounds meet. Perspectives on Psychological Science, 5(4), 472-481. 
Schwarzer, R., \& Tauber, S. (2002). Tenacious goal pursuits and striving toward personal growth: Proactive coping. In E. Frydenberg (Ed.), Beyond coping : Meeting goals, visions and challenges (pp. 19-35). London : Oxford University Press.

Sillen K. (2013) Vestigingsonderzoek Gemeente Maastricht. Management report on behalf of the city of Maastricht 2012-2013.

Simosi, M. (2010). The role of social socialization tactics in the relationship between socialization content and newcomers' affective commitment. Journal of Managerial Psychology, 25(3), 301-327.

Skinner, H. (2008). The emergence and development of place marketing's confused identity. Journal of Marketing Management, 24(9-10), 915-928.

Sobel, M. E. (1982). Asymptotic confidence intervals for indirect effects in structural equation models. Sociological methodology, 13, 290-312.

Stauss, B., \& Friege, C. (1999). Regaining service customers: Costs and benefits of regain management. Journal of Service Research, 1(4), 347-361.

Stets, J. E., \& Burke, P. J. (2000). Identity theory and social identity theory. Social Psychology Quarterly, 63(3), 224-237.

Strizhakova, Y., Tsarenko, Y., \& Ruth, J. A. (2012). “I'm mad and I can't get that service failure off my mind": Coping and rumination as mediators of anger effects on customer intentions. Journal of Service Research, 15(4), 414-429.

Stokburger-Sauer, N., Ratneshwar, S., \& Sen, S. (2012). Drivers of consumer-brand identification. International Journal of Research in Marketing, 29(4), 406-418.

Suanet, I., \& Van de Vijver, F. J. (2009). Perceived cultural distance and acculturation among exchange students in Russia. Journal of Community \& Applied Social Psychology, 19(3), 182-197.

Sweeney, J. C., Soutar, G. N., \& Mazzarol, T. (2012). Word-of-mouth: measuring the power of individual messages. European Journal of Marketing, 46(1/2), 237-257.

Sweeny, K. (2008). Crisis decision theory: Decisions in the face of negative events. Psychological Bulletin, 134(1), 61-76.

$\mathrm{T}$

Tajfel, H., \& Turner, J. C. (1979). An integrative theory of intergroup conflict. In W. G. Austin \& Worchel (Eds.), The social psychology of intergroup relations (pp.33-47). Monterey, CA: Brooks/Cole.

Tajfel, H., \& Turner, J. C. (1986). The social identity theory of inter-group behavior. In S. Worchel \& L.W.Austin (Eds.), Psychology of intergroup relations. Chicago: Nelson-Hall.

Tein, J.-Y., Sandler, I. N., \& Zautra, A. J. (2000). Stressful life events, psychological distress, coping, and parenting of divorced mothers: A longitudinal study. Journal of Family Psychology, 14(1), 27. 
Tenenhaus, M., Vinzi, V. E., Chatelin, Y. M., \& Lauro, C. (2005). PLS path modeling. Computational Statistics \& Data Analysis, 48(1), 159-205.

Thoits, P. A. (1986). Social support as coping assistance. Journal of Consulting and Clinical Psychology, 54(4), 416-423.

Thomas, J. S., Blattberg, R. C., \& Fox, E. J. (2004). Recapturing lost customers. Journal of Marketing Research, 41(1), 31-45.

Tsarenko, Y., \& Strizhakova, Y. (2012). Coping with service failures: The role of emotional intelligence, self-efficacy and intention to complain. European Journal of Marketing, 47(1/2), 71-92.

Turner, J. C. (1985). Social categorization and the self-concept: A social cognitive theory of group behaviour. In E.J.Lawler (Ed.), Advances in group processes: Theory and research, (Vol. 2. pp. 77-122). Greenwich: CT. JAL Press.

Turner, J., Hogg, M. A., Oakes, P. J., Reicher, S. D., \& Wetherell, M. S. (1987). Rediscovering the social group: A social categorization theory. Cambridge: B. Blackwell.

Tuškej, U., Golob, U., \& Podnar, K. (2011). The role of consumer-brand identification in building brand relationships. Journal of Business Research, 66(1), 53-59.

$\mathrm{V}$

Van Ham, P. (2008). Place branding: The state of the art. The ANNALS of the American Academy of Political and Social Science, 616(1), 126-149.

Vanolo, A. (2008). The image of the creative city: Some reflections on urban branding in Turin. Cities, 25(6), 370-382.

Vélez, C. E., Wolchik, S. A., Tein, J. Y., \& Sandler, I. (2011). Protecting children from the consequences of divorce: A longitudinal study of the effects of parenting on children's coping processes. Child development, 82(1), 244-257.

Verhoef, P. C., \& Lemon, K. N. (2012). Successful customer value management: Key lessons and emerging trends. European Management Journal, 31(1), 1-15.

W

Walker, W. R., Skowronski, J. J., \& Thompson, C. P. (2003). Life is pleasant--and memory helps to keep it that way! Review of General Psychology, 7(2), 203.

Ward, M. K., \& Broniarczyk, S. M. (2011). It's not me, it's you: How gift giving creates giver identity threat as a function of social closeness. Journal of Consumer Research, 38(1), 164-181.

Warnaby, G., \& Medway, D. (2013). What about the 'place' in place marketing?. Marketing Theory, 13(3), 345-363. 
Watson, L., \& Spence, M. T. (2007). Causes and consequences of emotions on consumer behaviour: A review and integrative cognitive appraisal theory. European Journal of Marketing, 41(5/6), 487-511.

Webb, T. L., \& Sheeran, P. (2006). Does changing behavioral intentions engender behavior change? A meta-analysis of the experimental evidence. Psychological Bulletin, 132(2), 249-268.

Webber, S. (2010). Dual organizational identification impacting client satisfaction and word-of-mouth loyalty. Journal of Business Research, 64(2), 119-125.

Weiner, B. (2000). Attributional thoughts about consumer behavior. Journal of Consumer Research, 27(3), 382-387.

Wetzels, M., Odekerken-Schröder, G., \& Van Oppen, C. (2009). Using PLS path modeling for assessing hierarchical construct models: guidelines and empirical illustration. MIS quarterly, 33(1), 177-195.

Wheaton, B. (1990). Life transitions, role histories, and mental health. American Sociological Review, 55(2), 209-223.

Winkielman, P., Huber, D. E., Kavanagh, L., \& Schwarz, N. (2012). Fluency of consistency: When thoughts fit nicely and flow smoothly. In B. Gawronski \& Strack (Eds.), Cognitive consistency: A fundamental principle in social cognition (pp. 89-111). New York: Guilford Press.

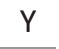

Yi, S., \& Baumgartner, H. (2004). Coping With Negative Emotions in Return-Related Situations. Journal of Consumer Psychology, 14(3), 303-317

\section{Z}

Zenker, S., \& Braun, E. (2010). Branding a city: A conceptual approach for place branding and place brand management. Paper presented at the 39th European Marketing Academy Conference, 1st-4th June.

Zhang, L., \& Zhao, S. X. (2009). City branding and the Olympic effect: A case study of Beijing. Cities, 26(5), 245-254. 


\section{Appendix A}

The following items were used to measure the constructs of interest in the first two studies. Some items were removed to satisfy constraints of validity and reliability. The $\mathrm{X}$-s in the table show which items were used to measure the constructs.

\begin{tabular}{|c|c|c|c|}
\hline & & $\begin{array}{l}\text { Study } \\
1\end{array}$ & $\begin{array}{l}\text { Study } \\
2\end{array}$ \\
\hline $\begin{array}{l}\text { Ider } \\
\text { Ada }\end{array}$ & $\begin{array}{l}\text { tification after } \\
\text { ted from Mael and Ashforth (1992). }\end{array}$ & & \\
\hline (A) & $\begin{array}{l}\text { If someone criticizes the (place)brand, this feels like a personal } \\
\text { insult. }\end{array}$ & $\mathrm{x}$ & $\mathrm{x}$ \\
\hline (B) & $\begin{array}{l}\text { I'm very interested in what others have to say about the } \\
\text { (place)brand. }\end{array}$ & & $\mathrm{x}$ \\
\hline (C) & $\begin{array}{l}\text { If I talk about the (place)brand, I usually refer to "we" instead } \\
\text { of "they". }\end{array}$ & & $\mathrm{x}$ \\
\hline (D) & Successes of the (place)brand are my successes. & $x$ & $\mathrm{x}$ \\
\hline (E) & $\begin{array}{l}\text { If someone speaks positively about the (place)brand, this feels } \\
\text { like a personal compliment. }\end{array}$ & $x$ & $\mathrm{x}$ \\
\hline (F) & $\begin{array}{l}\text { I am ashamed if the media give negative attention to the } \\
\text { (place)brand. }\end{array}$ & $\mathrm{x}$ & \\
\hline $\begin{array}{l}\text { Acti } \\
\text { Ada }\end{array}$ & $\begin{array}{l}\text { e coping strategies } \\
\text { ted from Duhachek (2005). }\end{array}$ & & \\
\hline (A) & Concentrated on ways the problem could be solved & $\mathrm{X}$ & \\
\hline (C) & Generate possible solutions & $\mathrm{x}$ & $\mathrm{x}$ \\
\hline (D) & Think about the best way to handle things & $\mathrm{x}$ & $\mathrm{x}$ \\
\hline (E) & Concentrate my efforts on doing something about it & & $\mathrm{X}$ \\
\hline (H) & Analyze the problem before reacting & $x$ & $x$ \\
\hline (I) & Try to step back from the situation and be objective & & $\mathrm{x}$ \\
\hline (J) & Try to look at the bright side of things & & $\mathrm{x}$ \\
\hline (K) & Focus on the positive aspects of the problem & & $\mathrm{x}$ \\
\hline (L) & Look for the good in what happened & & $\mathrm{x}$ \\
\hline (N) & Try to control my emotions & $x$ & \\
\hline (0) & Try to keep my feelings from controlling my actions & $\mathrm{x}$ & \\
\hline
\end{tabular}




\begin{tabular}{|c|c|c|c|}
\hline & & $\begin{array}{l}\text { Study } \\
1\end{array}$ & $\begin{array}{l}\text { Study } \\
2\end{array}$ \\
\hline $\begin{array}{l}\text { Expr } \\
\text { Ada }\end{array}$ & $\begin{array}{l}\text { essive support seeking } \\
\text { ted from Duhachek (2005). }\end{array}$ & & \\
\hline (A) & Seek others out for comfort & $\mathrm{x}$ & $\mathrm{X}$ \\
\hline (B) & Tell others how I feel & $\mathrm{X}$ & $\mathrm{X}$ \\
\hline (C) & Rely on others to make me feel better & $\mathrm{x}$ & $\mathrm{x}$ \\
\hline (D) & Share my feelings with others I trusted and respected & $\mathrm{x}$ & $\mathrm{X}$ \\
\hline (E) & Ask friends with similar experiences what they did & & $\mathrm{X}$ \\
\hline (F) & Try to get advice from someone about what to do & & $\mathrm{X}$ \\
\hline (G) & Have a friend assist me in fixing the problem & & $x$ \\
\hline (H) & Take time to express my emotions & $\mathrm{x}$ & $x$ \\
\hline (I) & Let my feelings out somehow & $\mathrm{X}$ & $\mathrm{X}$ \\
\hline ( $)$ & Delve into my feelings to understand them & & $\mathrm{X}$ \\
\hline (K) & Would take time to understand what I am feeling & & $x$ \\
\hline (L) & Would realize that my feelings are valid and justified & $\mathrm{X}$ & \\
\hline (M) & Would acknowledge my emotions & $\mathrm{x}$ & $x$ \\
\hline $\begin{array}{l}\text { Retu } \\
\text { Ada }\end{array}$ & $\begin{array}{l}\text { rn Intention } \\
\text { ted from Putrevu and Lord (1994). }\end{array}$ & & \\
\hline $\begin{array}{l}\text { It is } \\
\text { very }\end{array}$ & $\begin{array}{l}\text { ery likely that I will buy something from the brand again/ It is } \\
\text { likely that I will move back to the place }\end{array}$ & $\mathrm{X}$ & $x$ \\
\hline $\begin{array}{l}\text { I wil } \\
\text { the } \\
\text { next }\end{array}$ & $\begin{array}{l}\text { purchase something from the brand as soon as I would need } \\
\text { roduct or service they offer again/ I will move back to the place } \\
\text { time I move }\end{array}$ & $x$ & $x$ \\
\hline I will & definitely retry the product or service from the brand & $\mathrm{x}$ & \\
\hline $\begin{array}{l}\text { Posi } \\
\text { Ada। }\end{array}$ & $\begin{array}{l}\text { ive W.O.M. } \\
\text { ted from Price and Arnould (1999). }\end{array}$ & & \\
\hline $\begin{array}{l}\text { I wo } \\
\text { vice }\end{array}$ & Ild recommend the (place)brand to someone who seeks my ad- & $x$ & $\mathrm{x}$ \\
\hline I say & positive things about the (place)brand & $\mathrm{X}$ & $\mathrm{x}$ \\
\hline I wo & ld recommend the (place)brand in general & $\mathrm{x}$ & $\mathrm{x}$ \\
\hline
\end{tabular}




\section{Appendix B}

The following items were used to measure the constructs of interest. Some items were removed to satisfy constraints of validity and reliability. Only the items that were used to obtain the results of the study are reported. The social mobility, creativity and competition items are based on items for testing gender roles so they are changed drastically to fit in the place branding concept. The word-of-mouth scales from Lang (2009) are combined with adapted items form Price and Arnould (1999).

\section{Identification with old/new residence}

First 6 items adapted from Mael and Ashforth (1992), last item adapted from Bergami and Baggozi (2000)

\begin{tabular}{|l|l|}
\hline (1) & If someone criticizes the place brand, this feels like a personal insult. \\
\hline (2) & I'm very interested in what others have to say about the place brand. \\
\hline (3) & If I talk about the place brand, I usually refer to "we" instead of "they". \\
\hline (4) & Successes of the place brand are my successes. \\
\hline (5) & If someone speaks positively about the place brand, this feels like a personal \\
(6) & I am ashamed if the media give negative attention to the place brand. \\
\hline (7) & My own identity and the brand identity are: \\
\hline
\end{tabular}




\begin{tabular}{|c|c|}
\hline \multicolumn{2}{|c|}{$\begin{array}{l}\text { Social Mobility } \\
\text { Adapted from Breinlinger and Kelly (1994) and Baird (2001). }\end{array}$} \\
\hline$\left(41 \_2\right)$ & $\begin{array}{l}\text { Now that so many people who are not born in this place are accepted, not } \\
\text { speaking the local dialect is no reason not to be accepted in the place. }\end{array}$ \\
\hline$\left(38 \_2\right)$ & $\begin{array}{l}\text { All people have equal opportunities in this place. Whether someone is born } \\
\text { in the place or not does not matter, it's just a matter of having the right } \\
\text { personal characteristics }\end{array}$ \\
\hline (42_1) & $\begin{array}{l}\text { When you adapt to your surroundings, you will be accepted, this has nothing } \\
\text { to do with where you come from. }\end{array}$ \\
\hline$\left(30 \_2\right)$ & $\begin{array}{l}\text { If people who are not born in this place really want to be accepted, there is } \\
\text { little to stop them. }\end{array}$ \\
\hline
\end{tabular}

\section{Social Creativity}

Adapted from Breinlinger and Kelly (1994) and Baird (2001).

\begin{tabular}{|l|l|}
\hline (42_4) & $\begin{array}{l}\text { In general, people who are not born in this place are easier to deal with than } \\
\text { people who are born in this place. }\end{array}$ \\
\hline (39_5) & $\begin{array}{l}\text { People who are not born in this place are more flexible than people who are } \\
\text { born in this place. }\end{array}$ \\
\hline (39_6) & $\begin{array}{l}\text { I prefer comparing myself to people who are not born in this place, rather } \\
\text { than comparing myself to people who are born in this place. }\end{array}$ \\
\hline (38_5) & $\begin{array}{l}\text { People who are not born in this place are more social than people who are } \\
\text { born in this place }\end{array}$ \\
\end{tabular}

\section{Social competition}

Adapted from Breinlinger and Kelly (1994) and Baird (2001).

\begin{tabular}{|c|c|}
\hline (39_9) & $\begin{array}{l}\text { People who are born in this place are counting out people who are not born } \\
\text { in this place so that they can keep being in control of the power and authority } \\
\text { in the place. }\end{array}$ \\
\hline (42_9) & $\begin{array}{l}\text { People who are not born in this place have a lower status than people who } \\
\text { are born in this place, even if they have the same job. }\end{array}$ \\
\hline (40_7) & $\begin{array}{l}\text { There is a lot of prejudice and discrimination to people who are not born in } \\
\text { this place. This prevents them from reaching their full potential }\end{array}$ \\
\hline (38_9) & $\begin{array}{l}\text { When you get right down the basics, people who are not born in this place } \\
\text { are the oppressed group and people who are born in this place are the opres- } \\
\text { sors. }\end{array}$ \\
\hline (42_7) & People who are born in this place have an unequal share of power \\
\hline (41_8) & $\begin{array}{l}\text { It makes me angry that people who speak the local dialect can accomplish } \\
\text { more in daily life }\end{array}$ \\
\hline
\end{tabular}


(38_8) People who are not born in this place must fight to be regarded as equal to the ones that are born here

(42_8) People who are not born in the place should be angry about their low status in society

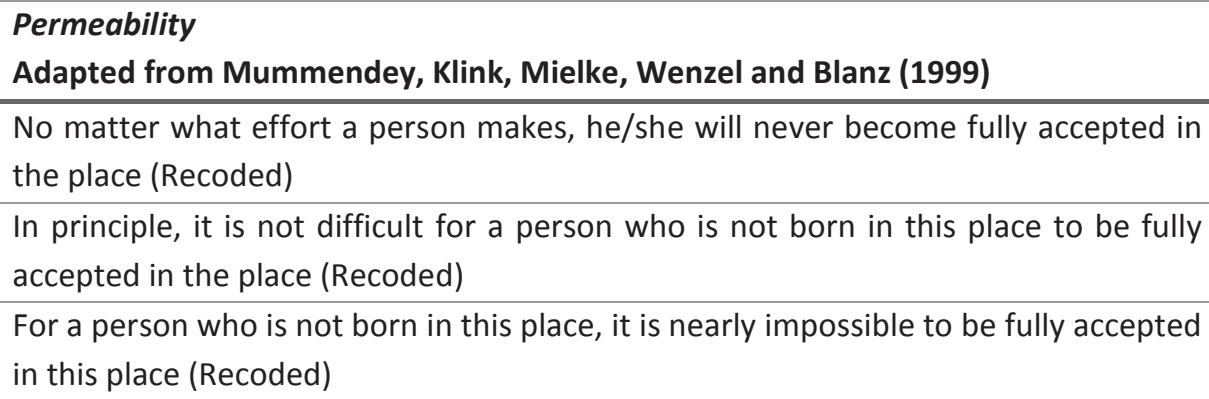

No matter what effort a person makes, he/she will never become fully accepted in the place (Recoded)

In principle, it is not difficult for a person who is not born in this place to be fully accepted in the place (Recoded)

For a person who is not born in this place, it is nearly impossible to be fully accepted in this place (Recoded)

\section{Behavioral Intention old/new residence}

Adapted from Putrevu and Lord (1994).

It is very likely that I will move back to this place/continue to live in this place

I will move back to/within this place next time I move

\section{W.O.M. Intensity old/new residence}

Adapted from Lang (2009).

I talk about my experiences related to this place

I talk to more people about this place than about other places

I seldom miss an opportunity to talk about this place

When I talk about this place, I talk about it in great detail

\section{W.O.M. Valence old/new residence}

Adapted from Lang (2009) and Price and Arnould (1999).

I say positive things about this place

I am proud to tell other people about living in this place

I would recommend the (place)brand in general 


\section{Summary \\ A Place Called Home}

The role of identification in the post-dissolution phase of a customer relationship with a place brand.

More and more places are engaging in branding efforts in order to attract prospective residents but struggle when it comes to the application of product and services marketing tools to the context of place branding. As a consequence, they are looking for other ways to brand places in a more efficient and effective way. In this dissertation, we use three different empirical studies to address this issue, therewith contributing to literature on place branding, relationship marketing and social identity.

People use place brands as well as product and service brands as a tool to communicate something about their social identity. When doing so, they cognitively internalize the brand as part of this social identity, which is further referred to as identification. Identification is created during the relationship with a place brand, but can endure beyond the dissolution of the relationship. This means that although the official customer-brand relationship is no longer existent, a person can still feel cognitively connected to the brand. In this period, which is further referred to as the post-dissolution phase of a customer-brand relationship, a person is absent from a brand, but is still cognitively connected to the brand. As this phase is relatively unknown to both theory and practice, it constitutes the focus of the first study.

For the first study, centered around the concept of brand identification, we developed a framework for the post-dissolution phase in the context of product and services. The findings show that identification has positive behavioral consequences for a brand, in terms of return intention and word-of-mouth, even after the dissolution of a customer-brand relationship. This shows that ex-customers can function as brand ambassadors even after the official dissolution of the relationship.

In the second study, the developed framework was transferred to the context of place branding in order to address the issue of theory application across contexts. Although the results show a strong consistency in the link between identification and its behavioral consequences, the post-dissolution phase in a place branding context proves to be differently structured than in the context of products and services.

As such, the third study builds on the results of the second study and partly redefines the established framework. Instead of merely focusing on identification with the old place brand, this study also includes identification with the new place brand and describes the process of rebalancing one's social identity after a move. The results of the third study indicate that, after a move, people can function as place brand ambassadors for their old and new place of residence simultaneously. 


\section{Samenvatting Een Plek Die 'Thuis' Heet}

De rol van identificatie in de post-dissolution fase van een relatie tussen een persoon en een place brand.

Een groeiend aantal steden, regio's en landen maakt gebruik van branding om toekomstige inwoners aan te trekken. Deze plaatsen worstelen echter met de toepasbaarheid van marketing methodes die oorspronkelijk zijn bedoeld voor producten en diensten en zoeken daarom naar andere manieren om plaatsen op een effectieve en efficiënte manier te vermarkten. Dit proefschrift speelt hierop in door middel van drie empirische studies, waarmee we bijdragen aan literatuur op het gebied van place branding, klant-merk relaties en sociale identiteit.

Mensen gebruiken merken van plaatsen, place brands, maar ook merken van producten en diensten, om te communiceren over hun sociale identiteit. Door zich te identificeren met een merk wordt dit merk cognitief onderdeel van iemands sociale identiteit. Deze identificatie wordt gecreëerd gedurende de relatie tussen een persoon en een merk maar kan stand houden als de relatie verbroken wordt. Dit betekent dat zelfs als de officiële relatie tussen een klant en een merk niet meer bestaat, een persoon zich nog steeds cognitief verbonden kan voelen met dit merk. In deze periode, de postdissolution fase, is een persoon niet meer in directe aanwezigheid van het merk maar heeft nog steeds een cognitieve connectie met het merk. Aangezien de post-dissolution fase nog vrij onbekend is zowel in theorie als in de praktijk is dit concept de focus van de eerste studie in dit proefschrift.

Gebruik makend van identificatie als kernconcept is er in de eerste studie een kader ontwikkeld om de post-dissolution fase te beschrijven. Omdat de post-dissolution fase ook in de product en diensten marketing nog niet goed beschreven is, werd de eerste studie uitgevoerd in deze context. Deze studie laat zien dat identificatie met een merk leidt tot positieve gevolgen voor het merk wat betreft de intentie om terug te keren en wat betreft mond-tot-mond reclame, zelfs nadat de officiële relatie tussen klant en merk verbroken is. Dit geeft aan dat ex-klanten kunnen functioneren als ambassadeurs voor een merk, zelfs als de officiële relatie beëindigd is.

De tweede studie test het ontwikkelde kader in de context van place brands om de toepasbaarheid van de theorie binnen verschillende contexten te toetsen. Hoewel de resultaten de sterke link tussen identificatie en gedrag bevestigen, blijkt de postdissolution fase in relatie tot een place brand anders gestructureerd dan bij producten en diensten.

Vanuit dit inzicht is het ontwikkelde kader geherdefinieerd in de derde studie. In deze studie betrekken we naast het oude place brand ook de identificatie met het nieuwe 
place brand en beschrijven we het vinden van een nieuwe balans tussen de verschillende plaats gerelateerde identiteiten na een verhuizing. De resultaten van deze derde studie laten zien dat mensen na een verhuizing als ambassadeurs kunnen functioneren voor zowel hun oude als hun nieuwe woonplaats tegelijk. 


\section{About the author}

Katja Sillen was born in Geleen, the Netherlands, on September 19th, 1985. Her home from day 1 was however located in Maastricht. She attended secondary school at Stella Maris College in Meerssen, where she obtained her Atheneum degree in 2003. Next, Katja studied International Business at Maastricht University, and spent a semester at Antwerp University before obtaining her Bachelor degree in 2007. She completed her studies with a Master's degree in Strategic Marketing at Maastricht University in 2008. After her studies, Katja worked in Aachen in a company that produces trade fair stands. Soon however, she returned to Maastricht University, where she worked as a Junior Lecturer until the start of het PhD track in 2009. Under supervision of Prof. Dr. Gaby Odekerken-Schröder and Prof. Dr. Martin Wetzels, Katja's PhD research was focused on the topics of place branding, identification and relationship marketing. The PhD position was sponsored by the Maastricht Region Branding Foundation for which Katja conducted market research next to her PhD research. Katja strived for a constant practical focus of her PhD research which featured in several local newspaper articles and television shows. Currently, Katja lives in Bunde and is working on regional statistics in her capacity as a statistical researcher at Statistics Netherlands (CBS), located in Heerlen. 